UNIVERSIDADE DE SÃO PAULO

FACULDADE DE MEDICINA DE RIBEIRÃO PRETO DEPARTAMENTO DE NEUROCIÊNCIAS E CIÊNCIAS DO COMPORTAMENTO PROGRAMA DE PÓS-GRADUAÇÃO EM SAÚDE MENTAL

Helena Pinho de SÁ

\title{
Transtorno Depressivo Maior (TDM) com e sem Sintomas Psicóticos: Investigação Neuroquímica por Espectroscopia de Próton
}


Helena Pinho de SÁ

\section{Transtorno Depressivo Maior (TDM) com e sem Sintomas Psicóticos: Investigação Neuroquímica por Espectroscopia de Próton}

Dissertação apresentada à Faculdade de Medicina de Ribeirão Preto da Universidade de São Paulo para a obtenção do título de Mestre em Ciências Médicas

Programa: Saúde Mental

Orientadora: Prof ${ }^{a}$ Dra. Maristela Schaufelberger Spanghero

Ribeirão Preto - SP 
AUTORIZO A REPRODUÇÃO E DIVULGAÇÃO TOTAL OU PARCIAL DESTE TRABALHO, POR QUALQUER MEIO CONVENCIONAL OU ELETRÔNICO, PARA FINS DE ESTUDO E PESQUISA, DESDE QUE CITADA A FONTE.

\section{Catalogação da Publicação}

SÁ, Helena Pinho de

Transtorno depressivo maior (TDM) com e sem sintomas psicóticos: investigação neuroquímica por espectroscopia de próton. Ribeirão Preto, 2011.

$141 \mathrm{f}$.

Dissertação (Mestrado - Programa de Pós-graduação em Saúde Mental. Área de concentração: Saúde Mental) - Faculdade de Medicina de Ribeirão Preto da Universidade de São Paulo.

Orientadora: Prof ${ }^{a}$ Dra. Maristela Schaufelberger Spanghero

1. Transtorno depressivo maior. 2. Psicose. 3. Giro do cíngulo anterior.

4. Espectroscopia de próton por RM de hidrogênio $\left({ }^{1} \mathrm{H}-\mathrm{ERM}\right)$ 


\section{FOLHA DE APROVAÇÃO}

SÁ, Helena Pinho de

Transtorno depressivo maior (TDM) com e sem sintomas psicóticos: investigação neuroquímica por espectroscopia de próton

Dissertação apresentada à Faculdade de Medicina deRibeirão Preto da Universidade de São Paulo para a obtenção do título de Mestre em Ciências.

Área de concentração: Saúde Mental.

Aprovado em:

Banca Examinadora

Prof. Dr. Julgamento:

Instituição: Assinatura:

Prof. Dr. Julgamento:

Instituição: Assinatura:

Prof. Dr. Julgamento:

Instituição: Assinatura: 
Dedicatória

À todas as mães que eu tive, especialmente à minha mãe Lêda que me ensinou a aprender a crescer 


\section{AGRADECIMENTOS}

À professora Maristela pela orientação prestada e pelo exemplo de perseverança e ética na pesquisa e no lidar com os pacientes.

Ao professores Antônio Carlos, Carlos Ernesto Garrido pela ajuda na elaboração do presente trabalho e pelas orientações e sugestões concedidas. Esse agradecimento se estende a toda equipe de biomédicos, atendentes e enfermeiros da Ressonância pela amizade e generosidade prestadas.

À professora Cristina, aos contratados e enfermeiros e auxiliares de enfermagem da UE/ EPIB pela solidariedade e amizade durante a execução desse trabalho.

Ao professor Alexandre Crippa pela bondade com minhas dificuldades de tempo.

A todos da pós-graduação da Saúde Mental, Ivana, colegas e professores (Sônia, Francisco, Beatriz, Jaime, Juruena) pela ajudas, ensinamentos e trocas realizadas.

Aos pacientes pela generosidade ainda que em seu sofrimento.

Ao voluntários saudáveis que acreditaram em ajudar com o crescimento do conhecimento em depressão ao participarem do estudo.

Ao professor Carlos Teixeira Brandt pelos inesquecíveis conhecimentos adquiridos durante a iniciação científica na UFPE.

A minha linda família, Paula, Germana, Pedro e Luzinete pelo aprendizado com a convivência.

Ao meu pai Gilberto pelas sábias palavras de um professor experiente.

Ao meu querido marido Fernando pela tolerância com as faltas em casa, carinho e amor. 


\section{RESUMO}

Sá, H. P. Transtorno depressivo maior (TDM) com e sem sintomas psicóticos: investigação neuroquímica por espectroscopia de próton. 2011. 141 f. Dissertação (Mestrado) - Faculdade de Medicina de Ribeirão Preto, Universidade de São Paulo, Ribeirão Preto, 2011.

Introdução. O Transtorno Depressivo Maior (TDM) é um dos mais prevalentes e incapacitantes entre os transtornos mentais. Apesar disso, sua classificação ainda é baseada em sinais e sintomas, uma vez que suas causas e fisiopatologia ainda não foram totalmente esclarecidas. A presença de sintomas psicóticos é relativamente comum durante um episódio depressivo e está associada a particularidades clínicas e biológicas, mas é subdiagnosticada na prática clínica e os processos fisiopatológicos que caracterizam este tipo de depressão foram insuficientemente estudados, ainda mais ao se considerar a extensa literatura acerca das formas não psicóticas de depressão. $\mathrm{O}$ objetivo principal deste estudo foi o de investigar a neuroquímica do giro do cíngulo anterior (CA), região cerebral constituinte da neurocircuitaria relacionada à fisiopatologia do TDM, na forma psicótica deste transtorno. Para este objetivo, foram comparadas as concentrações absolutas dos metabólitos entre os grupos portadores de TDM com e sem sintomas psicóticos e controles saudáveis por meio de espectroscopia de próton por ressonância magnética de hidrogênio ( ${ }^{1} \mathrm{H}$-ERM). Secundariamente, analisou-se a interferência de variáveis sócio-demográficas e clínicas na medida desses metabólitos. Esperava-se que os pacientes com sintomas psicóticos (TDM-P) apresentassem alterações neuroquímicas tanto em relação ao grupo de controles saudáveis quanto a pacientes com depressão sem sintomas psicóticos (TDM-NP), independentemente da gravidade dos sintomas depressivos. Casuística e métodos. Os pacientes portadores de episódio depressivo maior (com e sem sintomas psicóticos), segundo o DSM-IV, foram recrutados no Hospital das Clínicas da Faculdade de Medicina de Ribeirão Preto da Universidade de São Paulo (HC-FMRP) e avaliados através da Entrevista Clínica Estruturada para o DSM-IV (SCID). A gravidade de sintomas depressivos e psicóticos, bem como o nível de funcionamento global foram avaliados por meio das escalas de Hamilton, BPRS e GAF (respectivamente). Foram coletadas informações a respeito de histórico de tentativas de suicídio, tratamento medicamentoso, comorbidades psiquiátricas e clínicas. Controles saudáveis da comunidade geral foram recrutados por convite da equipe de pesquisa. Utilizouse ${ }^{1} \mathrm{H}$-ERM de voxel único, com tempo de eco (TE) curto $(31 \mathrm{~ms})$, em campo magnético de 3 Tesla para a avaliação do CA de 20 pacientes com TDM-P, 22 com TDM-NP e 20 voluntários saudáveis. Foram analisados valores absolutos do glutamato (Glu), glutamato mais glutamina (Gln+Glu), N-acetilaspartato mais N-acetilaspartato-glutamato (NAA + NAAG), Fosforilcolina mais Glicerol-fosforilcolina (PC + GPC), mio-inositol (myo-Ins) e Creatina (Cr). Dados sócio-demográficos e clínicos foram analisados através de ANOVA e quiquadrado, enquanto os níveis de metabólitos foram comparados através de MANOVA. Correlações bivariadas entre dados clínicos e metabólitos foram analisadas por teste de Pearson ou Spearman. O nível de significância estatística empregado foi o de $p<0,05$. Resultados. Pacientes com TDM-P apresentaram menor escolaridade e pior funcionamento global, tanto em relação aos controles quanto em relação aos pacientes sem psicose. Os grupos de pacientes não diferiram entre si em relação à gravidade dos sintomas depressivos. Em relação aos metabólitos, houve diferença significativamente estatística entre os grupos diagnósticos. O grupo com TDM-P apresentou níveis de Glu inferiores tanto em relação ao grupo TDM-NP quanto ao grupo controle e níveis de PC + GPC e de NAA + NAAG inferiores ao grupo controle (a redução deste último metabólito atingindo significância 
estatística em nível de tendência apenas. Entre os sexos, os níveis de Glu e de NAA+NAAG dos participantes do sexo masculino foram inferiores aos do feminino. Por fim, os níveis de Glu e Gln+Glu foram inferiores no sexo masculino do TDM-P em relação aos demais grupos e os de Cr foram inferiores no sexo masculino no TDM-NP também em relação aos outros grupos. No entanto, as diferenças em relação ao sexo não atingiram significância estatística, possivelmente por limitações do tamanho amostral. Conclusão. Os níveis de metabólitos do CA sofreram interferência do diagnóstico e os resultados apontaram para efeito do sexo e da interação diagnóstico-sexo. As diferenças dos níveis de Glu, NAA+NAAG e PC+GPC entre os diagnósticos sugerem alterações de neurotransmissão glutamatérgica, metabolismo de membrana e integridade neuronal na TDM-P e corroboram os achados de outras áreas de estudo em depressão em psicose, que sugerem que a forma psicótica da depressão estaria mais associada ao estado de hipercortisolemia, e esta, por sua vez, levaria às alterações cerebrais compatíveis com as alterações encontradas no CA neste estudo. Além disso, os resultados corroboram as diferenças da participação do sistema glutamatérgico na fisiopatologia da depressão e dos quadros psicóticos. e a interferência do sexo para os níveis de Glu e $\mathrm{NAA+NAAG}$ sugere um papel protetor dos hormônios femininos para o sistema glutamatérgico e ciclo do NAA. Ainda, este estudo não confirma hipóteses prévias de que as alterações biológicas entre os tipos de depressão seriam secundárias a maior gravidade de sintomas depressivos nos pacientes com TDM-P.

Palavras-chave: Transtorno depressivo maior. Psicose. Giro do cíngulo anterior. Espectroscopia de próton por RM de hidrogênio $\left({ }^{1} \mathrm{H}-\mathrm{ERM}\right)$. 


\begin{abstract}
Sá, H. P. Major depressive disorder with and without psycotic symptoms: neurochemical investigation by proton ressonance spectroscopy. 2011. 141 f. Dissertação (Mestrado) Faculdade de Medicina de Ribeirão Preto, Universidade de São Paulo, Ribeirão Preto, 2011.
\end{abstract}

Introduction: Major depressive disorder (MDD) is one of the most prevalent and disabling of mental disorders. Nevertheless, its classification is still based on signs and symptoms, since its causes and pathophysyology has not been fully clarified. The presence of psychotic symptoms are relatively common during a depressive episode and is associated with clinical and biological peculiarities, but is underdiagnosed and its pathophisiology have been insufficiently studied, especially when considering the extensive literature on non-psychotic forms of depression. The aim of this study is to investigate the neurochemistry of the anterior cingulated gyrus (AC), a brain's neurocircuitry constituent related to the pathophysiology of MDD with psychosis/in the form of psychotic disorder. For this propose, we compared/ were compared the results of the metabolites between groups of patients with MDD with and without psychotic symptoms and controls by proton resonance spectroscopy imaging of hydrogen ( $\left.{ }^{1} \mathrm{H}-\mathrm{MRS}\right)$. Secondly, the interference of socio-demographic and clinical on the cerebral metabolites. It was expected that patients with psychotic symptoms (MDD-P) present neurochemical changes in relation to the group of health controls and patients with depression without psychotic symptoms (MDD-Wo), regardless of the severity of depression symptons. Methods: The groups were diagnosed by the Structured Clinical Interview for DSM-IV (SCID). The severity of depressive and psychotic symptoms, as well as the level of overall functioning were assessed using the Hamilton Rating Scale, BPRS and GAF (respectively). We collected information about the history of suicide attempts, drug treatment, psychiatric and medical comorbidities. ${ }^{1} \mathrm{H}-\mathrm{MRS}$ single voxel, with echo time (TE) short $(31 \mathrm{~ms})$ in a magnetic field of 3.0 Tesla was used for the evaluation of CA in 20 patients with MDD-P, 22 with MDD-Wo and 20 healthy subjects. We analyzed the absolute values of glutamate (Glu), glutamate plus glutamine (Gln+Glu), N-acetylaspartate plus N-acetyl aspartate-glutamate (NAA+NAAG), glycerol phosphorylcholine plus phosphorylcholine plus choline (PC+GPC), myo-inositol (Myo) and creatine ( $\mathrm{Cr}$ ). Data on socio-demographic and clinical information were analyzed using ANOVA and chi-square, while the levels of metabolites were compared by MANOVA. The statistical significance level used was $p<0.05$. Results: Patients with MDD-P had less schooling and poorer overall functioning, both in relation to the controls as compared to patients without psychosis. Patient groups did not differ in the severity of depressive symptoms. Glu levels of MDD-P were lower than the MDD-Wo and the control group; NAA+NAAG levels of MDD-P were lower than in control and GPC+PC levels of MDD$\mathrm{P}$ were lower than the MDD-Wo. Between the sexes, Glu and NAA + NAAG levels of males were lower than females. Finally, Glu, Glu+Gln and Cr levels were different between the sexes within the groups. Conclusion:The group levels of metabolites of CA have been interfered with diagnosis and the effect of gender and gender-diagnosis interaction were close to be meaningful. The differences in the levels of Glu, NAA + NAAG and GPC + PC between diagnoses are possibly related to higher hypercortisolemia found in the MDD-P and the brain concentration of kynurenine metabolites imballance more similar with schizophrenia than MDD. The interference of sex for the levels of Glu and NAA + NAAG suggests a protective role of female hormones to glutamatergic system and cycle of the NAA. Still, probably the severity of the depressive episode is not implicated in the neurochemical differences between MDD-P and MDD-Wo.

Key-words: Major depression, psychosis, cingulate region, proton resonance spectroscopy imaging of hydrogen $\left({ }^{1} \mathrm{H}-\mathrm{MRS}\right)$. 


\section{LISTA DE ABREVIATURAS}

\begin{tabular}{|c|c|}
\hline $\mathrm{AD}$ & Antidepressivo \\
\hline AP & Antipsicótico \\
\hline BZD & Benzodiazepínico \\
\hline BDNF & Brain derived neuritrofic factor \\
\hline $\mathrm{CA}$ & Cíngulo Anterior \\
\hline $\mathrm{CPF}$ & Córtex Préfrontal \\
\hline CPFDL & Córtex Préfrontal Dorsolateral \\
\hline CPFDM & Córtex Préfrontal Dorsomedial \\
\hline CPFVL & Córtex Préfrontal Ventrolateral \\
\hline $\mathrm{COF}$ & Córtex Órbitofrontal \\
\hline $\mathrm{Cr}$ & Creatina \\
\hline $\mathrm{DM}$ & Diabetes Mellitus \\
\hline DSM-IV-TR & Manual Diagnóstico e Estatístico para Transtornos Mentais, $4^{\mathrm{a}}$ edição \\
\hline ED & Episódio Depressivo \\
\hline E.P. & Erro Padrão \\
\hline FSC & Fluxo sanguíneo cerebral \\
\hline GAF & Escala de Funcionamento Global \\
\hline $\mathrm{Gln}+\mathrm{Glu}$ & Glutamina + glutamato \\
\hline Glu & Glutamato \\
\hline HAS & Hipertensão Arterial Sistêmica \\
\hline${ }^{1} \mathrm{H}-\mathrm{ERM}$ & Espectroscopia de próton por ressonância magnética \\
\hline HPA & Eixo Hipotálamo-pituitária-Adrenal \\
\hline ISRS & Inibidor Seletivo da Recaptura da Serotonina \\
\hline Myo & Mio-inositol \\
\hline
\end{tabular}


$\mathrm{NAA}+\mathrm{NAAG} \mathrm{N}$-acetil aspartato $+\mathrm{N}$-acetil-aspartato- glutamato

NMDA Receptor do tipo N-metil-D-aspartato

PC + GPC $\quad$ Fosforilcolina + glicerol-fosforil colina + colina

PET Tomografia por emissão de pósitrons

PRESS Point Resolved Spectroscopy Sequence

RM Ressonância Magnética

SPECT Single-Photon Emission Computed Tomography

TDM Transtorno Depressivo Maior

TDM-NP Transtorno Depressivo Maior sem sintomas psicóticos

TDM-P Transtorno Depressivo Maior com sintomas psicóticos

TEPT Transtorno de Estresse Pós-traumático

THB Transtorno do Humor Bipolar

TOC Transtorno Obsessivo-Compulsivo

VOI Voxel of interest

$\eta_{\mathrm{pi}}^{2} \quad$ Eta Parcial

5-HT Serotonina 


\section{LISTA DE FIGURAS}

Figura 1: Cíngulo anterior dorsal (áreas 24 b, 24 c e 32 de Brodmann)

Figura 2: Funcionamento dos sistemas de percepção no TDM

Figura 3: Exemplo de espectro obtido com a H-ERM

Figura 4: Posicionamento do voxel em CA, no plano sagital, coronal e axial, correspondente às aéreas 24 b, 24 c, 32 e porção da $24 \mathrm{a}$ de Brodmann.

Figura 5: Espectro do $\mathrm{CA}$ de controle saudável com a localização dos picos e seus respectivos deslocamentos químicos....

Figura 6: Espectro de paciente TDM-P com redução do pico de Glu, $\mathrm{PC}+\mathrm{GPC}$ e $\mathrm{NAA}+\mathrm{NAAG}$

Figura 7: Espectro de paciente do sexo masculino com níveis reduzidos de Glu e $\mathrm{NAA}+\mathrm{NAAG}$

Figura 8: Espectro de paciente TDM-P do sexo masculino com níveis reduzidos de Glu e de Gln+Glu. 


\section{LISTA DE GRÁFICOS}

Gráfico 1: Distribuição das médias e EP dos metabólitos do CA entre os grupos TDM-P, TDM-NP e controle, evidenciando menores níveis de Glu para o TDM-P em relação aos demais grupos

Gráfico 2: Distribuição das médias e EP dos metabólitos do CA entre os grupos TDM-P, TDM-NP e controle, evidenciando menores níveis de PC+GPC para o TDM-P em relação aos demais grupos.

Gráfico 3: Distribuição das médias e EP dos metabólitos do CA entre os grupos TDM-P, TDM-NP e controle, evidenciando menores níveis de NAA+NAAG para o TDM-P em relação aos demais grupos

Gráfico 4: Médias de Glu do CA dos grupos masculino e feminino entre os diagnósticos TDM-P, TDM-NP e controle, em que o sexo masculino é inferior ao feminino para o TDM-P, o qu não é visto para os demais grupos

Gráfico 5: Médias de Gln+Glu do CA dos grupos masculino e feminino entre os diagnósticos TDM-P, TDM-NP e controle, com menores médias no sexo masculino em relação ao feminino dentro do TDM-P

Gráfico 6: Médias de $\mathrm{Cr}$ do $\mathrm{CA}$ dos grupos masculino e feminino entre os diagnósticos TDM-P, TDM-NP e controle em que os níveis desse metabólito encontram-se inferiores ao do sexo feminino para o TDM-NP, o que não é visto para os demais grupos

Gráfico 7: Médias de $\mathrm{PC}+\mathrm{GPC}$ do $\mathrm{CA}$ dos grupos masculino e feminino entre os diagnósticos TDM-P, TDM-NP e controle com níveis reduzidos de $\mathrm{PG}+\mathrm{GPC}$ no sexo masculino e feminino do TDM-P e do sexo masculino do TDM-NP em relação aos demais 


\section{LISTA DE TABELAS}

Tabela 1: Resumo dos achados de ${ }^{1} \mathrm{H}-\mathrm{ERM}$ em TDM, psicose afetiva e Esquizofrenia 41

Tabela 2: Categorias de dimensão do efeito para os valores do $\eta_{\mathrm{pi}}{ }^{2}$ 53

Tabela 3: Categoria de intensidade de correlação para os valores de 'r' 54

Tabela 4: Características sócio-demográficas e clínicas segundo os grupos TDM-P, TDMNP e controle

Tabela 5: Características clínicas dos grupos TDM-P e TDM-NP 60

Tabela 6: Comorbidades psiquiátricas e sintomas psicóticos dos grupos TDM-P e TDMNP

Tabela 7: Tratamento medicamentoso dos grupos TDM-P e TDM-NP

Tabela 8: Correlações bivariadas das variáveis idade e metabólitos e de metabólitos entre si com significância estatística

Tabela 9: Distribuição das médias e E.P. dos metabólitos do CA entre os grupos TDM-P, TDM-NP e controle

Tabela 10: Distribuição das diferenças médias e E.P. dos metabólitos do CA entre os grupos TDM-P, TDM-NP e controle.

Tabela 11: Distribuição das médias e E.P. dos metabólitos do CA entre os sexos

Tabela 12: Distribuição das diferenças médias e E.P. dos metabólitos do CA entre os sexos

Tabela 13: Distribuição das médias e E.P. de Glu do CA entre os sexos dentro dos grupos TDM-P, TDM-NP e controle

Tabela 14: Distribuição das médias e E.P. de Gln + Glu do CA entre os sexos dentro dos grupos TDM-P, TDM-NP e controle.

Tabela 15: Distribuição das médias e E.P. de Cr do CA entre os sexos dentro dos grupos TDM-P, TDM-NP e controle

Tabela 16: Distribuição das médias e E.P. de PC + GPC do CA entre os sexos dentro dos grupos TDM-P, TDM-NP e controle 
Tabela 17: Distribuição das médias e EP dos metabólitos do CA entre os grupos TDM-P, TDM-NP e controle do sexo feminino

Tabela 18: Distribuição das diferenças médias e EP dos metabólitos do CA entre os grupos TDM-P, TDM-NP e controle do sexo feminino

Tabela 19: Distribuição das médias e EP dos metabólitos do CA entre os grupos TDM-P, TDM-NP e controle do sexo masculino

Tabela 20: Distribuição das diferenças médias e EP do NAA+NAAG do CA entre os grupos TDM-NP e controle do sexo masculino

Tabela 21: Distribuição das diferenças médias e EP do Glu do CA entre os diagnósticos TDM-P e controle do sexo masculino

Tabela 22: Correlações bivariadas entre pontuação da HAM 31 e as médias dos níveis dos metabólitos nos grupos TDM-P e TDM-NP

Tabela 23: Correlações bivariadas entre o tempo de uso de AD e as médias dos níveis dos metabólitos nos grupos TDM-P e TDM-NP

Tabela 24: Correlações bivariadas entre o tempo de uso de BZD e as médias dos níveis dos metabólitos nos grupos TDM-P e TDM-NP

Tabela 25: Correlações bivariadas entre o tempo de uso de AP e as médias dos níveis dos metabólitos no grupo TDM-P. 


\section{SUMÁRIO}

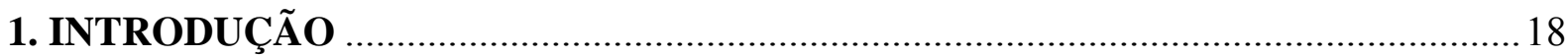

1.1 MODELO NEUROANATÔMICO DA DEPRESSÃO …................................................. 21

1.2 ETIOLOGIA E FISIOPATOLOGIA DA DEPRESSÃO ...............................................24

1.2.1 Interação de fatores genéticos e ambientais em TDM.........................................24

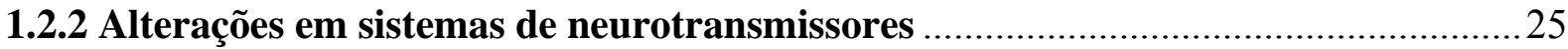

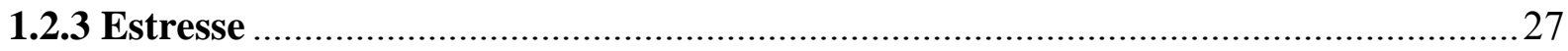

1.3 DIFERENÇAS SÓCIO-DEMOGRÁFICAS, CLÍNICAS E BIOLÓGICAS ENTRE

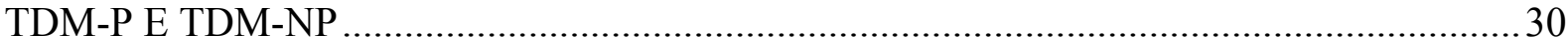

1.4 NEUROIMAGEM E TRANSTORNO DEPRESSIVO MAIOR (TDM) ..........................32

1.4.1. Estudos de volumetria por RM estrutural em TDM........................................... 33

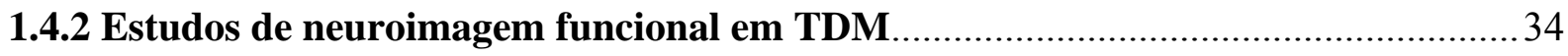

1.4.3 Estudos de espectroscopia por ressonância magnética $\left({ }^{1}\right.$ H-ERM) em TDM ...........36

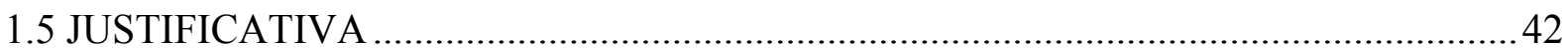

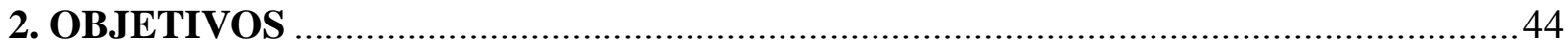

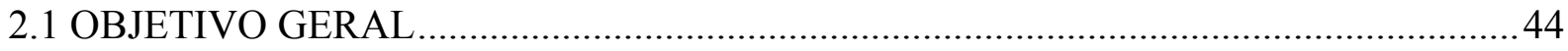

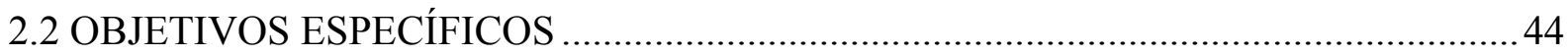

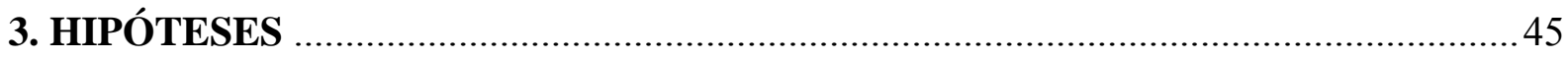

4. MÉTODOS

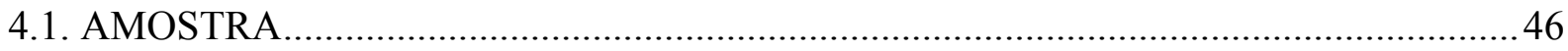

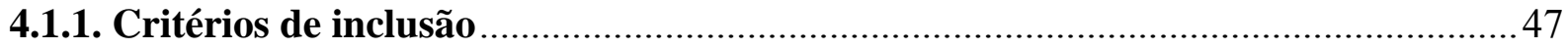

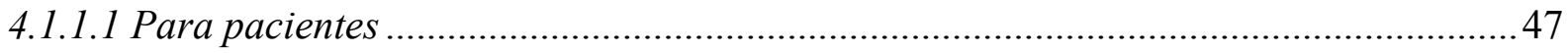

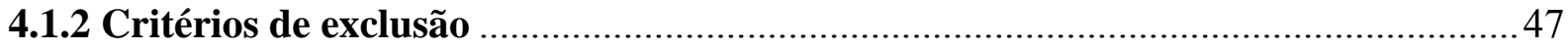

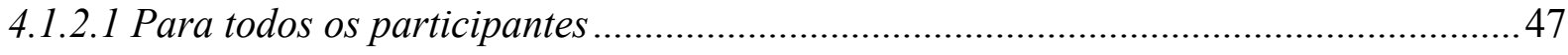

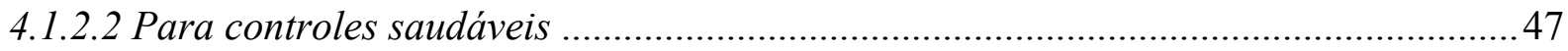




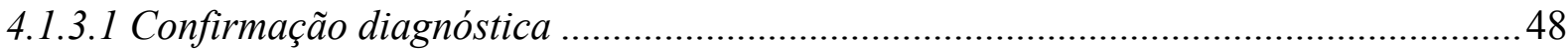

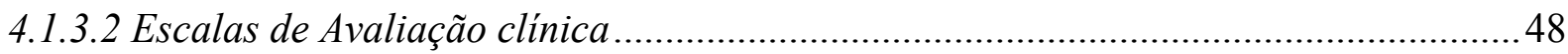

4.1.3.3 Escala de avaliação do nível sócio-econômico (Anexo F) ...........................................49

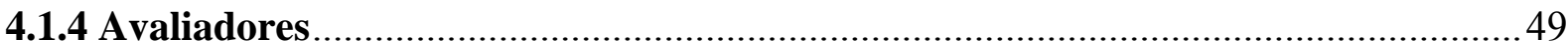

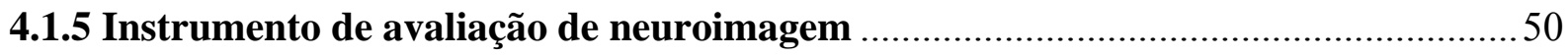

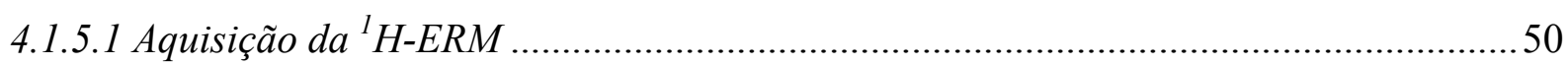

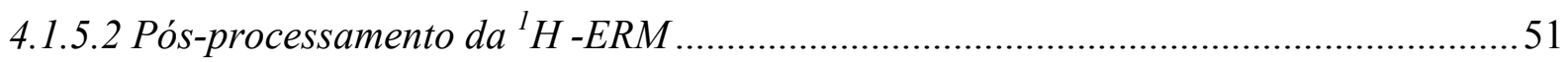

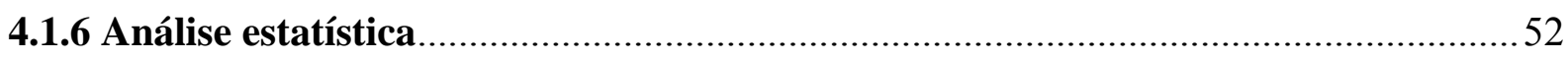

4.1.6.1 Análise de dados sócio-demográficos e clínicos ......................................................52

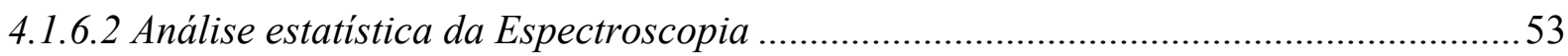

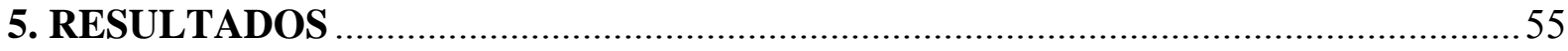

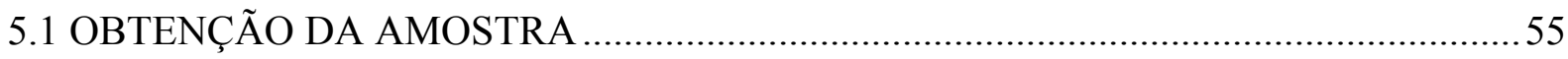

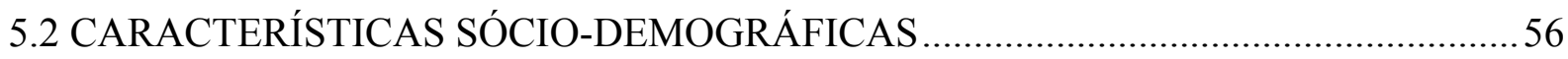

5.3 CARACTERÍSTICAS CLÍNICAS DOS GRUPOS TDM-P E TDM-NP .........................59

5.4 RESULTADOS DAS ANÁLISES DE NÍVEIS DE METABÓLITOS DO CA POR

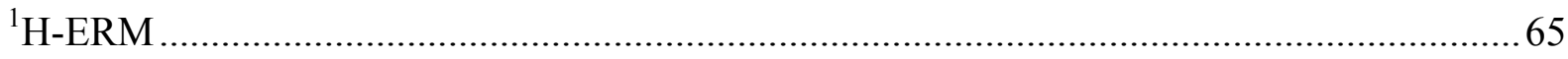

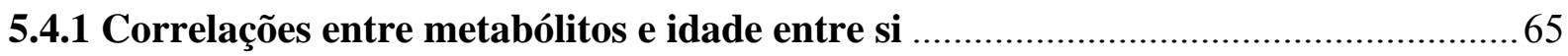

5.4.2 Efeito dos fatores grupo, sexo e interação grupo-sexo sobre os metabólitos............66

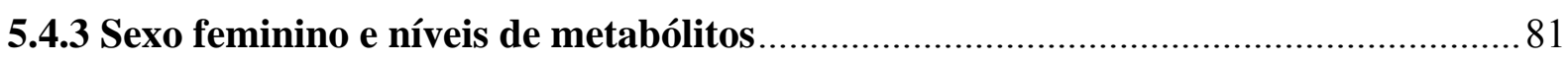

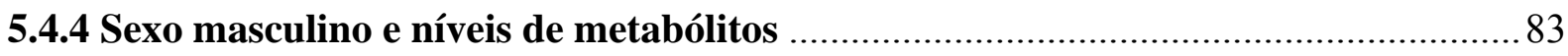

5.4.5 Correlações de níveis metabólitos do CA e pontuação de escala de sintomas

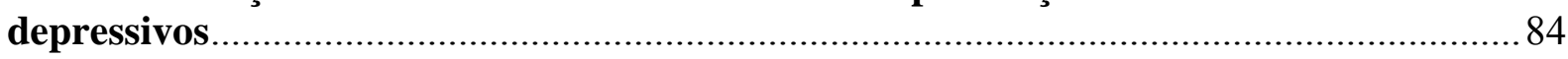

5.4.6 Correlações entre níveis dos metabólitos do CA e dias de uso de medicação ...........85

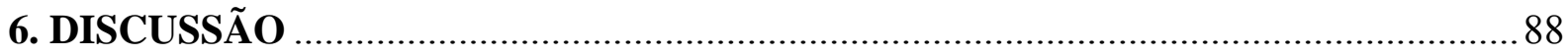

6.1 CARACTERÍSTICAS DEMOGRÁFICAS E CLÍNICAS DA AMOSTRA .....................88

6.2 ASPECTOS DE TRATAMENTO MEDICAMENTOSO …........................................ 92 
6.3.1 Correlações entre as variáveis idade e metabólitos entre si..................................93

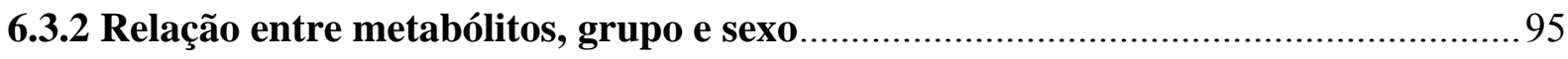

6.3.2.1 Distribuição dos metabólitos entre TDM-P, TDM-NP e controle ...............................95

6.3.2.2 Distribuição dos metabólitos entre os sexos .............................................................98

6.3.2.3 Distribuição dos metabólitos entre os sexos dentro de cada diagnóstico.....................99

6.3.3 Perfil neuroquímico do CA exclusivamente no sexo feminino ............................. 100

6.3.4 Perfil neuroquímico do CA exclusivamente no sexo masculino ........................... 100

6.3.5 Uso de medicação e níveis dos metabólitos CA .................................................... 101

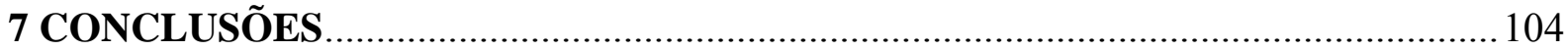

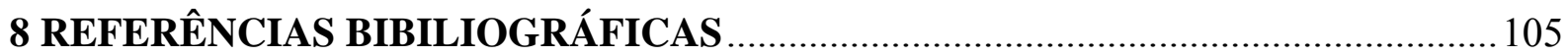

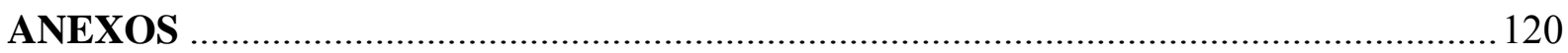

ANEXO A - Termo De Consentimento Livre e Esclarecido ................................................. 120

ANEXO B - Escala de avaliação global do funcionamento .................................................... 123

ANEXO C - Dominância hemisférica cerebral ................................................................ 125

ANEXO D - Escala de Hamilton para Depressão ............................................................... 126

ANEXO E - Escala de Avaliação Psiquiátrica Breve (Brief Psychiatric Rating Scale BPRS)

ANEXO F - Escala de avaliação do nível sócio-econômico 


\section{INTRODUÇÃO}

A depressão unipolar ou Transtorno Depressivo Maior (TDM) é a principal síndrome depressiva dentre os transtornos mentais. A prevalência ao longo da vida é de cerca de $16 \%$ da população geral, segundo o National Comorbity Survey Replication (NCS-R), estudo populacional americano realizado entre 2001 e 2002 (KESSLER et al. 2003). Em relação ao Brasil, um estudo epidemiológico conduzido na região metropolitana da cidade de São Paulo em 2004 encontrou uma prevalência de 18,4\% ao longo da vida (BROMET et al., 2011). O curso é predominantemente crônico, com considerável resistência ao tratamento (FAVA et al., 2006 ) e estima-se que será a principal causa de incapacidade no ano de 2030 (OMS, 2004). Porém, a etiopatogenia deste transtorno mental ainda é desconhecida e seu diagnóstico é baseado em sinais e sintomas (APA, 2000; OMS, 1992).

O relatório da Organização Mundial da Saúde de 2004 (OMS, 2004) a respeito dos efeitos das doenças no mundo identificou cerca de 151 milhões de pessoas com TDM. Segundo o relatório, a prevalência desse transtorno foi maior que os transtornos relacionados ao álcool, encontrando-se como a terceira causa de morbidade entre todos os agravos de saúde e em primeiro lugar nas Américas. Na idade entre 15 e 44 anos, foi o principal responsável por anos perdidos por incapacidade em ambos os sexos (50\% maior entre as mulheres), independente da renda per capita em todo mundo. Dentre as doenças classificadas de alta gravidade, a depressão grave foi incluída pela OMS ao lado de tetraplegia e de câncer em estágio terminal (OMS, 2004).

O NCS-R também caracterizou a significância clínica e os padrões de tratamento dos transtornos mentais e constatou que, além de alta prevalência do TDM, houve aumento da busca de tratamento para esse transtorno mental nessa população em relação ao estudo da década anterior. A média de duração do episódio depressivo foi de 16 semanas e 59,9\% dos episódios identificados eram considerados graves ou muito graves (KESSLER et al., 2003).

O TDM foi associado ainda ao sexo feminino, à escolaridade inferior a doze anos, a indivíduos sem atividade profissional e de classe social baixa ou próxima à faixa da pobreza. Como achado preocupante, encontrou-se que a minoria dos casos recebia tratamento adequado (KESSLER et al., 2003).

Os primeiros registros médicos a respeito dos transtornos do humor datam da Grécia antiga (século IV a.C.). Segundo a teoria dos humores de Hipócrates, as enfermidades eram oriundas das alterações dos humores que circulavam no corpo humano, o "humor vital", e a 
melancolia $($ Melan $=$ negro, Cholis $=$ bile $)$ seria conseqüência do excesso da bile negra no cérebro. Essa teoria é um marco histórico da humanidade em vista de que a partir dela as doenças deixam de ter uma conotação sobrenatural para ter uma base biológica e o termo melancolia ainda é utilizado pelas classificações diagnósticas vigentes para designar certo conjunto de características depressivas (SANTA CLARA, 2009).

As classificações diagnósticas em Psiquiatria têm se modificado ao longo do tempo. Os sistemas de classificação atuais são o "Manual Diagnóstico e Estatístico de Transtornos Mentais - Revisão de Texto" da Associação Psiquiátrica Americana (Diagnostic and Statistical Manual for Mental Disorders, 4th edition, DSM-IV-TR, American Psychiatry Association) (APA, 2000) e a $10^{\mathrm{a}}$ edição da Classificação Internacional das Doenças da Organização Mundial de Saúde, a CID-10 (OMS, 1992).

Em ambos, a entidade central do diagnóstico dos Transtornos de Humor é o episódio depressivo (ED). Segundo o DSM-IV-TR, um episódio depressivo consiste na presença de cinco sintomas por um período mínimo de duas semanas, sendo que pelo menos um deles deve ser humor deprimido ou anedonia. Os outros sintomas listados são: alteração do apetite ou peso; alteração do sono; diminuição de energia; retardo ou agitação psicomotora; sentimentos de menos-valia ou culpa excessivos; ideação suicida ou pensamentos de morte recorrentes e dificuldade de concentração e de tomar decisões. A presente classificação requer que esses sintomas estejam presentes na maioria dos dias e que causem sofrimento significativo ou prejuízo funcional (APA, 2000).

Para o diagnóstico de TDM pelo DSM-IV-TR ainda deve ser excluída tanto a possibilidade de que os sintomas depressivos sejam secundários ao efeito do uso de substância ou de condição médica geral e a possibilidade de Transtorno de Humor Bipolar (THB), devendo ser excluída história prévia ou atual de episódio maníaco, hipomaníaco ou misto. Por fim, um episódio depressivo único ou episódios depressivos recorrentes (na ausência de antecedente de episódio de mania ou hipomania) caracterizam, então, o TDM (APA, 2000), também comumente conhecido como depressão unipolar ou depressão maior.

Além dos critérios acima, o DSM-IV-TR recorre a especificadores para detalhar a caracterização do episódio depressivo. São eles: especificadores clínicos (características catatônicas, melancólicas, atípicas), de período de instalação (depressão com início no pósparto), de curso (episódio único, recorrente, com remissão completa ou incompleta, com padrão sazonal ou curso crônico) e de gravidade (episódio leve, moderado ou grave, sendo que este última subdivide-se de acordo com a presença ou não de sintomas psicóticos). 
Os sintomas psicóticos, delírios e/ou alucinações, podem ainda ser classificados em congruentes (delírios de culpa, de ruína, niilista, hipocondríacos, ou alucinações depreciativas ou acusatórias) ou incongruentes com o humor (delírios persecutórios, de auto-referência, de controle ou alucinações sem conteúdo afetivo) (APA, 2000).

A CID-10 utiliza critérios semelhantes aos do DSM-IV-TR, categorizando a depressão unipolar em Episódio Depressivo Único ou em Transtorno Depressivo Recorrente, quando o paciente exibe história de mais de um episódio. Novamente, o episódio depressivo pode ser subclassificado quanto à intensidade em leve, moderado e grave (este último, novamente, podendo incluir ou não sintomas psicóticos) Nesta classificação são considerados sintomas psicóticos não só os delírios e as alucinações, mas também a presença de estupor depressivo (OMS, 1992).

A prevalência de TDM com sintomas psicóticos (TDM-P) foi investigada em três estudos populacionais. Conforme estudo realizado nos EUA, a prevalência dos sintomas psicóticos foi cerca de 14\% dentre os pacientes com depressão (JOHNSON et al., 1991). Já em estudo multicêntrico conduzido na Europa, a prevalência dos sintomas psicóticos em episódio depressivo foi de $18,5 \%$ e, na população geral, de 0,4\% (OHAYON e SCHATZBERG, 2002).

Outro estudo epidemiológico realizado no Reino Unido encontrou incidência de depressão psicótica similar à de esquizofrenia e levantou a necessidade de aumentar o conhecimento a respeito desse transtorno de humor (CREBBIN et al. 2008).

Um estudo brasileiro, conduzido em São Paulo, identificou que entre 367 pacientes identificados em primeiro episódio psicótico ao longo de dois anos, 50 (13,6\%) preenchiam critérios diagnósticos para TDM-P (MENEZES et al. 2007).

A presença de psicose é maior em episódios depressivos graves, mas também se encontra em quadros leves a moderados. Estudos populacional e prospectivo evidenciaram a presença de delírios e alucinações em cerca de 33\% a 36\% dos episódios depressivos graves e em cerca de 7\% a 15\% dos episódios leves a moderados (MAJ et al, 2007; OHAYON e SCHATZBERG, 2002).

Esses resultados contrariaram o DSM-IV-TR e a CID 10, uma vez que, nestes, a presença dos sintomas psicóticos automaticamente levaria ao diagnóstico de episódio depressivo grave, conforme exposto acima. Os trabalhos atuais de elaboração da quinta edição do DSM prevêem a separação da presença ou ausência de psicose da categorização da 
gravidade da depressão para evitar a falta de investigação destes sintomas no episódio leve a moderado e o consequente subdiagnóstico de TDM-P na prática clínica ${ }^{1}$.

\subsection{MODELO NEUROANATÔMICO DA DEPRESSÃO}

Segundo os conhecimentos neuroanatômicos, neuroquímicos e funcionais atuais, diversas regiões cerebrais que funcionam de forma integrada são implicadas na fisiopatologia do TDM (MAYBERG et al., 1997, PHILLIPS et al., 2003a; PRICE e DREVETS, 2010). Essas áreas são envolvidas com o reconhecimento, a expressão e a regulação das emoções (SOARES e MANN 1997; PHILLIPS et al., 2003a) e quando disfuncionais, seja por uma lesão ou por sobrecarga do sistema diante do aumento de estresse cognitivo ou somático, levam à expressão dos sintomas depressivos (MAYBERG et al., 1997).

Cada estrutura do circuito neural exerce funções específicas, que, quando integradas, são responsáveis por determinados aspectos do comportamento. O córtex pré-frontal é responsável por direcionamento do comportamento e por geração de estratégias de conduta. $\mathrm{O}$ hipocampo está associado à memória declarativa e à conversão da memória de curto prazo em longo prazo (BIRD e BURGESS, 2008). À amígdala cabe a memória de eventos emocionais, em particular, o reconhecimento de faces de medo, raiva e tristeza (CAHILL et al. 1995; MORRIS et al. 1996). A região anterior do giro do cíngulo, através de suas conexões com o córtex orbitofrontal (COF) e áreas límbicas e subcorticais, participa da integração sensorial, da modulação da resposta autonômica e dos comportamentos emocionais e relacionados à recompensa (DREVETS et al. 2010; HAJEK et al. 2008). Circuitos cerebrais envolvendo estas regiões e responsáveis por integração de funções de humor, de comportamento, cognitivas e neurovegetativas encontram-se acometidos no TDM.

O principal circuito cerebral envolvido é constituído por conexões entre o córtex préfrontal medial e orbital (CPFMO), a amígdala, o subiculum hipocampal, o estriado ventral, o núcleo talâmico mediodorsal e mediano e o pálido ventral (ONGÜR et al., 2003).

O CPFMO associa-se a dois outros circuitos cerebrais: primeiramente, a regiões de integração sensorial visual, somática, olfativa e gustativa (ONGÜR e PRICE, 2000), que também estão envolvidas na codificação de características afetivas dos estímulos como a

\footnotetext{
${ }^{1}$ Disponível em: <www.dsm5.org > Acesso em: 12/08/2011
} 
recompensa, a aversão e o valor relativo (DREVETS et al., 2008), e ao circuito compreendido pelas regiões média e posterior do giro do cíngulor, região ântero-superior do giro e sulco temporal e o córtex parahipocampal entorrinal e posterior (SALEEM et al., 2008).

Essas estruturas formam o chamado default system, cujas funções são a percepção de estímulos interoceptivos, como o humor e a emoção, e a reação visceral a estímulos emocionais (GUSNARD et al., 2001) através de conexões com o hipotálamo e a substância periaquedutal (ONGÜR e PRICE, 2000).

Esses circuitos descritos acima constituem os dois principais sistemas neurais responsáveis pela percepção emocional: o ventral e o dorsal. O ventral inclui a amígdala, a ínsula, o estriado ventral e regiões ventrais do cíngulo anterior (CA) (áreas 24 a e 25 de Brodmann) e do córtex préfrontal (CPF), o COF e o CPF ventrolateral (CPFVL). Este sistema ventral é responsável pela identificação do significado emocional do estímulo e a geração do estado afetivo, como também pela resposta autonômica ao estímulo emocional.

O sistema dorsal, por sua vez, engloba o hipocampo e região dorsal do CA (área 32, $24 \mathrm{~b}$ e 24 c de Brodmann), CPF dorsolateral (CPFDL) e CPF mediodorsal (CPFDM). Esse encontra-se envolvido com a integração da cognição e a emoção, em que a última pode influenciar a primeira, com funções executivas, como atenção seletiva, planejamento, e com a regulação dos estados afetivos. Por fim, as porções ventral e dorsal do CA apresentam comunicação recíproca (PHILLIPS et al. 2003b) (v. Figura 1).

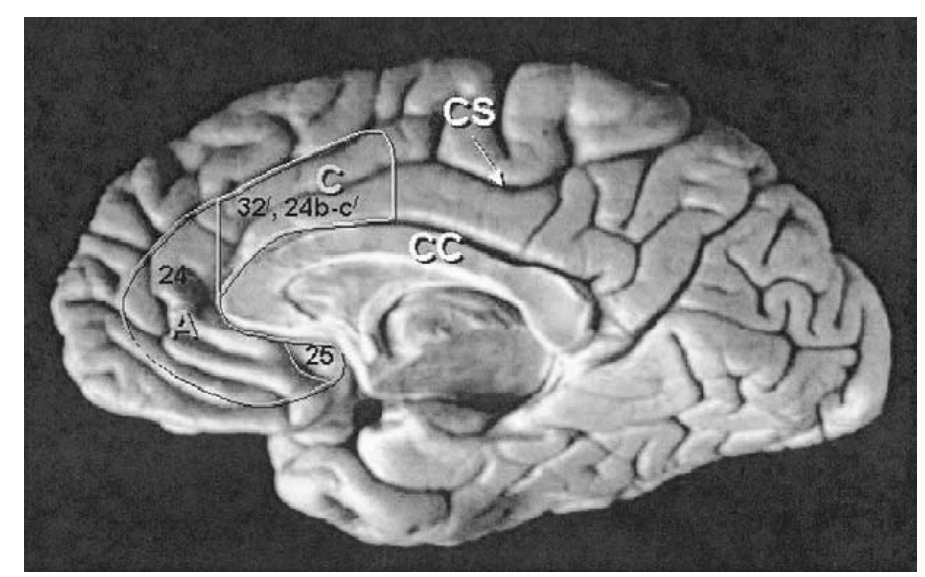

Figura 1: Cíngulo anterior dorsal correspondente ao C (áreas 24 b e c de Brodmann) e cíngulo anterior ventral dividido em pregenual (área 24 a de Brodmann) e subgenual (área 25 de Brodmann) correspondentes ao A.

$\mathrm{Na}$ fisiopatologia do TDM, sugere-se que o sistema ventral encontra-se hiperativo e o dorsal, hipoativo (PHILLIPS et al., 2003a), o que gera os diversos sintomas depressivos. Entre os primeiros, destacam-se o aumento da auto-observação, aumento da identificação de 
estímulos como emocionalmente significativos, principalmente dos negativos, exacerbação das reações emocionais e hiperativação do sistema nervoso autônomo.

A hipoativação dos circuitos dorsais, por sua vez, está relacionada à anedonia, ao déficit de concentração, de memória e de controle de afetos e de comportamentos relacionados (PHILLIPS et al., 2003a).

Como ilustrado na figura 2, o sistema ventral hiperativo predomina sobre o dorsal hipoativo e com isso há predomínio do pensamento e humor negativos (v. FIGURA 2).

\section{Dorsal}
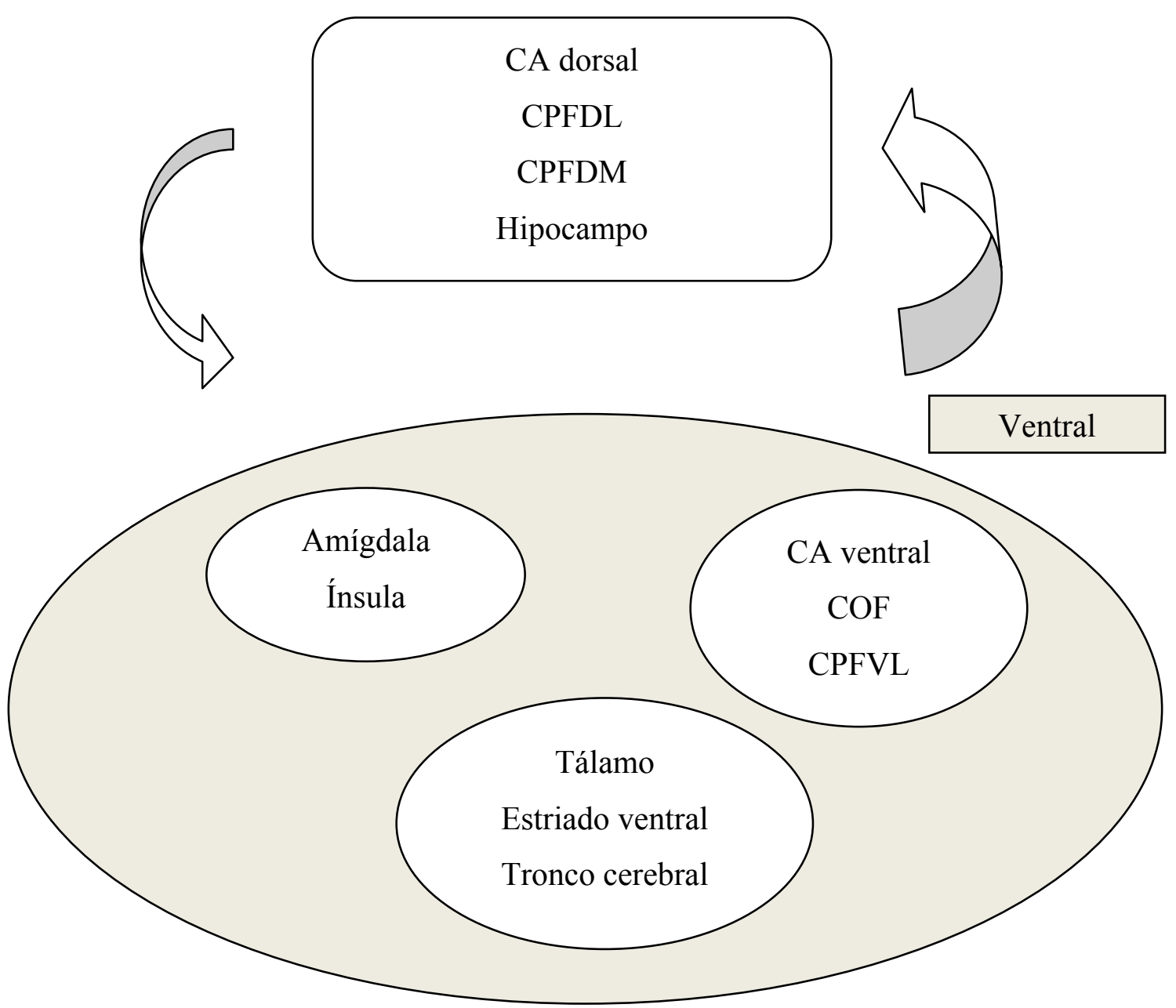

Figura 2: Funcionamento dos sistemas de percepção no TDM, onde o ventral encontra-se hiperativo e o dorsal hipoativo, o que leva ao aumento da percepção de eventos negativos e redução da regulação da percepção do afeto pelo dorsal e o predomínio do humor e pensamentos negativos. CA, cíngulo anterior; CPFDL, córtex prefrontal dorsolateral; CPFDM córtex prefrontal dorsomedial; COF, córtex orbitofrontal; CPFVL, córtex prefrontal ventrolateral (adaptado de PHILLIPS et al., 2003a) 


\subsection{ETIOLOGIA E FISIOPATOLOGIA DA DEPRESSÃO}

Atualmente, a etiopatogenia da síndrome depressiva é atribuída à interação de fatores genéticos e ambientais (NESTLER et al., 2002). Segundo estudos epidemiológicos, a contribuição dos fatores genéticos é cerca de $40 \%$ a $50 \%$ para o desenvolvimento desse transtorno mental, porém não foi confirmado nenhum gene responsável diretamente implicado na sua etiologia. Com isso, os mecanismos de interação entre fatores genéticos e ambientais são foco atual de investigação em depressão unipolar (NESTLER et al., 2002).

\subsubsection{Interação de fatores genéticos e ambientais em TDM}

Vários fatores herdados geneticamente estão associados ao TDM, como aspectos da personalidade e da neurotransmissão cerebral e são descritos na revisão de BELMAKER et al. (2008) e, assim, vários genes estariam envolvidos na fisiopatogenia desse transtorno mental complexo, o que aumenta a dificuldade na identificação dos genes envolvidos (NESTLER et al., 2002). Acredita-se que a hereditariedade do TDM possa ser explicada por um modelo complexo, assim como a hipertensão arterial sistêmica (HAS) e a diabetes mellitus (DM), em que fatores genéticos e ambientais interagem para o surgimento síndrome (NESTKER et al., 2002).

Um exemplo de interação entre fatores genéticos e ambientais na etiologia do TDM relaciona-se ao polimorfismo da região promotora do gene transportador da serotonina (5HT). Verificou-se que essa região promotora (5-HTTLPR) pode apresentar um alelo "curto" e um "longo" e que a variante curta dessa região está associada à redução da expressão desse gene e à diminuição na recaptura da 5-HT de forma significativa em relação à variante longa. Essa interação foi evidenciada em estudo prospectivo em que indivíduos homozigóticos para o alelo curto ou heterozigóticos apresentavam mais sintomas depressivos e diagnóstico de ED que os homozigóticos para o alelo longo da 5-HTTLPR em associação a eventos estressantes (CASPI et al., 2003). 


\subsubsection{Alterações em sistemas de neurotransmissores}

Dentre as muitas hipóteses biológicas subjacentes ao TDM, destaca-se a hipótese de deficiência do sistema de neurotransmissão monoaminérgica. Vários achados pertinentes à esta hipótese já foram descritos ou ainda estão sob investigação e são revistos por BELMAKER et al (2008) e resumidos a seguir.

Medicamentos que aumentaram a disponibilidade de monoaminas na sinapse neuronal apresentaram efeito antidepressivo (AD) e com isso inauguraram a teoria de que haveria deficiência de monoaminas na depressão. Inicialmente, esse mecanismo foi descrito para os inibidores da monoaminooxidade (IMAOs) e, posteriormente para os tricíclicos. A partir de então, tanto os inibidores seletivos da recaptura da serotonina, quanto os $\mathrm{AD}$ desenvolvidos a seguir, apresentam esse efeito de aumento de neurotransmissão monoaminérgica (direta ou indiretamente) como conseqüência do seu mecanismo de ação.

Os estudos em modelos animais de depressão, cuja maioria utiliza a exposição a estressores, apontaram para o envolvimento da neurotransmissão serotoninérgica (BELMAKER et al., 2008).

Deakin e Graeff (1991) propuseram uma teoria em que a 5-HT atuaria como moduladora diante de eventos aversivos. A idéia seria a de que projeções serotoninérgicas do núcleo mediano da rafe (NMR) para o hipocampo, onde há receptores $5-\mathrm{HT}_{1 \mathrm{~A}}$, permitiriam a adaptação ao evento aversivo por meio do aumento da neurotransmissão mediada por 5-HT. Diante de eventos estressantes em excesso, associado à elevação de cortisol e ansiedade, haveria falha desse sistema e com isso ocorreria a instalação da depressão (DEAKIN e GRAEFF, 1991). Essa teoria é corroborada por diversas evidências tanto em animais - quando há modificação genética e ausência do receptor 5- $\mathrm{HT}_{1 \mathrm{~A}}$ há maior sensibilidade aos estressores (GROSS et al., 2000) -, quanto em humanos, em vista da redução do receptor $5-\mathrm{HT}_{1 \mathrm{~A}}$ no hipocampo de pacientes deprimidos que cometeram suicídio (LOPEZ et al., 1999).

Inúmeras outras evidências corroboram a hipótese monoaminérgica do TDM, em pontos diferentes da neurotransmissão. Verificou-se, por exemplo, que a depleção de triptofano, substrato da síntese da serotonina, leva à recaída de pacientes deprimidos que se encontravam tratados e assintomáticos. Estudos de receptores serotoninérgicos em humanos evidenciaram deficiência de proteína (p11), que aumenta a eficiência do receptor $5-\mathrm{HT}_{1 \mathrm{~B}}$, e sensibilidade insuficiente do $5-\mathrm{HT}_{1 \mathrm{~A}}$. Segundos mensageiros e fatores transcritores do sistema 
monoaminérgico também estariam implicados no TDM, em vista de que há evidências de alterações de AMPc, inositol e CREB em estudos post mortem (BELMAKER et al., 2008).

Além do sistema serotoninérgico, outro sistema de neurotransmissão em estudo atualmente relacionado ao TDM é o glutamatérgico. Antagonistas de receptores glutamatérgicos do tipo N-metil-D-aspartato (NMDA), como a ketamina, mostraram efeito antidepressivo em vários modelos animais de depressão (PAPP et al., 1994; LAYER et al., 1995). O uso da ketamina em humanos com TDM também foi verificado, inclusive seu início de ação foi bem mais rápido que o de drogas monoaminérgicas o que se levou a crer que o sistema glutamatérgico seja mediador do efeito dos AD monoaminérgicos (ZARATE et al., 2006).

Já o efeito da ketamina na esquizofrenia causa piora dos sintomas psicóticos (STEINER et al., 2011). A modulação do receptor NMDA por metabólitos inflamatórios endógenos oriundos do triptofano poderia explicar esses efeitos diversos. Quando o triptofano é metabolizado na glia pela via da kinurenina, produz metabólitos com ações opostas no receptor tipo NMDA; na esquizofrenia foi observado aumento, principalmente do ácido kinurênico nos astrócitos, que antagoniza o receptor tipo NMDA (ERHARDT et al., 2001; NILSSON et al., 2005), Esse produto metabólico também foi associado à redução dos níveis de glutamato (Glu) em cérebro de animais (WU et al., 2009).

No TDM a essa modulação dos receptores glutamatérgicos pela via da kiurenina é diferente da encontrada em Esquizofrenia (STEINER et al., 2011). Encontrou-se em modelos animais de depressão predomínio da produção do ácido quinolínico ao invés do kinurênico a partir da metabolização do triptofano (MYINT e KIM, 2003). Este último ácido tem efeito agonista no receptor NMDA (MYINT e KIM et al., 2003) e foi associado a aumento dos níveis de Glu em cérebro de ratos (TAVARES et. al., 2005).

Por outro lado, diversas evidências apontam para diferenças regionais do sistema glutamatérgico. O aumento do ácido quinolínico, por exemplo, é encontrado na amígdala, mas no CA está reduzido em modelos animais de depressão (LAUGERAY et al., 2010). Como descrito anteriormente, o modelo neuroanatômico de depressão contempla diferenças regionais de atividade cerebral do TDM baseado em achados histopatológicos e de neuroimagem em animais e em humanos (PHLLIPS et al., 2003a e Phillips et al., 2003b) e o sistema glutamatérgico, por meio do glutamato, é o principal sistema excitatório do sistema nervoso central (ROTHEMAN et al., 2003). Os resultados de espectroscopia por ressonância de próton $\left({ }^{1} \mathrm{H}-\mathrm{ERM}\right)$ descritos adiante reforçam esse padrão de diferenças quanto aos níveis de glutamato e glutamina entre as regiões cerebrais. 


\subsubsection{Estresse}

Estresse crônico constitui importante componente da depressão, mesmo que não seja um fator necessário ou suficiente para seu desenvolvimento (LEE et al., 2010). O estudo do eixo hipotálamo-pituitária-adrenal (HPA), por sua vez, tem trazido evidências biológicas quanto à resposta do organismo ao estresse na depressão (GAUDIANO et al., 2009; GOMES et al., 2006).

A partir de estudos epidemiológicos, mostrou-se correlação temporal entre períodos de estresse e episódios afetivos (POST, 1992). O estresse costumava preceder o episódio de humor em indivíduos com THB e, além disso, observou-se uma sensibilização do indivíduo para depressão quando se necessitava de menos estresse para o desencadeamento de novas crises depressivas (POST, 1992).

O estresse envolve uma cascata hormonal bastante estudada que envolve o córtex, o hipotálamo, a pituitária (ou hipófise) e as adrenais, sendo que estes últimos três constituem o eixo hormonal HPA (SAPOLSKY et al., 2000). O córtex cerebral, ao perceber um evento aversivo, emite um estímulo ao hipotálamo, levando à liberação do hormônio liberador da corticotrofina $(\mathrm{CRH})$ a partir dos núcleos paraventriculares. O CRH, então, estimula a hipófise para a secreção do hormônio adrenocorticotrófico (ACTH) que, por sua vez, atua nas adrenais para a liberação de cortisol. Essa cascata hormonal desencadeia alterações comportamentais ao agir em várias regiões cerebrais. O cortisol elevado no plasma atua em receptores glicocorticóides (GR) do hipocampo e amígdala e outras regiões cerebrais, o que leva à inibição destes eventos, exercendo assim, efeito de feedback negativo sobre o próprio eixo HPA (LEE et al., 2010).

A elevação excessiva do cortisol conseqüente ao estresse leva a danos cerebrais e hiperativação do eixo HPA uma vez que o feedback negativo deixa de funcionar corretamente (LEE et al., 2010). Verificou-se que a hipercortisolemia aumenta a excitotoxidade em neurônios piramidais do hipocampo, resultando em atrofia dendrítica, redução da formação de espinhas dendríticas, apoptose de neurônios e, possivelmente, inibição da neurogênese em adultos (SAPOLSKY, 2000).

Essas alterações dos neurônios hipocampais reduzem também a ativação de seus receptores GR, o que provoca a redução do tônus inibitório sobre o eixo HPA e assim leva à hiperativação do mesmo (LEE et al., 2010). Além disso, receptores GR não estão presentes somente no hipocampo: quando há redução do volume do CA no TDM há também a redução 
do feedback negativo que ocorreria a partir da estimulação de receptores GR que também estão presentes nesta região cerebral (DREVETS et al., 2010).

Cerca de 50\% dos pacientes com TDM apresenta hiperativação do eixo HPA e a inibição da neurogênese hipocampal relacionada à hipercortisolemia é um dos possíveis mecanismos implicados na fisiopatogenia deste transtorno mental. Esta associação foi evidenciada por ressonância magnético $(\mathrm{RM})$ por meio da qual se encontrou atrofia hipocampal em indivíduos com TDM e hiperativação do eixo HPA (MCQUEEN et al., 203; SHELINE et al, 2003).

Por outro lado, evidências de tratamento com $\mathrm{AD}$ em animais e humanos mostraram reversão da hiperativação do eixo HPA, como também das alterações hipocampais associadas a ela, com o aumento da neurogênese hipocampal (LEE et al., 2010; WEDEKIND et al., 2007).

Estudos postmortem em TDM verificaram outras alterações cerebrais que se assemelharam àquelas presentes na Doença de Cushing, na qual há elevação de glicocorticóide sistêmico (BELMAKER et al., 2008): redução do número de células gliais do giro do cíngulo subgenual, a atrofia de neurônios do CPFDL e COF e o aumento de células em hipotálamo e no núcleo dorsal da rafe (BELMAKER et al., 2008).

Porém, há evidências que enfraquecem a relação causal entre estresse e TDM. Como citado anteriormente, há os outros 50\% dos portadores de TDM que não apresentam alteração do eixo HPA, como também aqueles que não possuem fator de risco psicossocial para tal. Além disso, o uso de antagonista do CRH no tratamento da depressão foi desapontador e o bloqueio do receptor de cortisol só foi eficaz em TDM grave ou com sintomas psicóticos (BELMAKER et al., 2008). Por fim, a redução da neurogênese encontrada no TDM poderia ser resposta apenas ao estresse e à ansiedade e não levar à alteração do comportamento (BELMAKER et al., 2008).

Outros caminhos têm sido trilhados na busca do ponto de encontro entre TDM e estresse, entre eles as alterações do peptídeo fator neurotrófico derivado do cérebro (brain derived neurotrofic factor, BDNF). Tanto eventos estressantes quanto o cortisol mostraram alterar os níveis de BDNF e estudos foram desenvolvidos para conhecer o papel desse peptídeo no TDM (BELMAKER et al., 2008).

A ação do BDNF foi relacionada à plasticidade sináptica, sobrevivência neuronal e crescimento axonal; pacientes deprimidos que cometeram suicídio apresentaram redução dos níveis desse fator neurotrófico em hipocampo e, por outro lado, os níveis de BDNF encontravam-se elevados em pacientes submetidos a tratamento com AD e eletroconvulsoterapia (ECT). Porém, é possível que a redução do BDNF não seja encontrada de forma exclusiva nesse transtorno mental. Além disso, a dosagem sérica desse peptídeo é $80 \%$ de origem plaquetária (BELMAKER et al., 2008). 
Além disso, o estresse, por meio do cortisol, ativa a metabolização do triptofano pela via da kiurenina o que desencadeia as conseqüentes modulações dos receptores do NMDA descritas acima. Como os produtos dessa via diferem entre o TDM e esquizofrenia, o estresse desencadearia ações diferentes nó sistema glutamatérgico entre esses dois transtornos mentais (STEINER et al., 2011).

Outro ponto de associação entre estresse e TDM é a morbidade cardiovascular associada à depressão, sendo que o estresse encontra-se relacionado a ambas as enfermidades (BELMAKER et al., 2008).

É freqüente o TDM preceder doenças cardiovasculares e vice-versa, ambas apresentam redução de ácido graxo e aumento de homocisteína, como também apresentam sinais de atividade inflamatória presente. O endotélio sabidamente está acometido nas doenças cardiovasculares, já no TDM com hiperativação do eixo HPA poderia haver comprometimento desse tecido vascular como conseqüência do aumento da gordura visceral relacionada à hipercortisolemia. Então, em ambas o endotélio poderia estar com suas funções alteradas, e entre elas, a participação na neurogênese cerebral e a secreção do BDNF, levando ao desenvolvimento ou perpetuação do TDM (BELMAKER et al., 2008).

Vários outros mecanismos estão sob investigação como fatores etiopatogênicos do TDM. Estudos identificaram alterações do ritmo circadiano, redução da neurotransmissão GABAérgica, deficiência da síntese de neuroesteróides, distúrbio da função opioide endógena, desbalanço entre os sistemas monoaminérgicos e colinérgico, aumento de citocinas pró-inflamatórias, alterações de tiroxina e modificações de histona. (BELMAKER et al., 2008; LEE et al., 2010).

Percebe-se, assim, que vários fatores estão envolvidos na etiopatogenia e fisiopatologia do TDM e que, além disso, deve haver mais de uma causa para este transtorno. Idosos com TDM apresentariam mais provavelmente doença cardiovascular e, assim, alterações do endotélio, caracterizando a chamada depressão vascular, diferente de pacientes com depressão de início precoce, nos quais seria mais provável o envolvimento de fatores genéticos (BELMAKER et al., 2008).

Ou seja, o TDM parece ser uma entidade nosológica heterogênea, e da mesma forma que pode haver diferentes mecanismos subjacentes ao TDM de início precoce e ao TDM de início tardio, pode haver diferentes substratos para as diferentes formas clínicas do TDM. Uma das formas clínicas que pode apresentar características clínicas e biológicas específicas dentro da grande síndrome do TDM é a depressão com sintomas psicóticos (o TDM-P). 


\subsection{DIFERENÇAS SÓCIO-DEMOGRÁFICAS, CLÍNICAS E BIOLÓGICAS ENTRE TDM- P E TDM-NP}

O TDM com sintomas psicóticos está associado, em maior ou menor grau, à diferenças quanto a variáveis sócio-demográficas, clínicas e biológicas quando comparado ao TDM-NP. Esse fato implica em questões de diagnóstico, prognóstico e tratamento dos diferentes subtipos de TDM que são ainda pouco exploradas.

Quanto às características sócio-demográficas, poucas evidências da literatura diferenciaram o TDM-P do TDM-NP. Em vários estudos os grupos não diferiram em relação à idade e ao sexo (GAUDIANO et al., 2009 ; FORTY et al., 2009 ; LEE et al., 2003; BELANOFF et al., 2001). Apenas em um destes houve diferença em relação a este item, com o TDM-NP apresentando maior frequência de pacientes com o sexo feminnino do que o TDM-P (CONTRERAS et al. 1996). E em outro estudo idetificou-se diferença quanto à etnia e à escolaridade, no qual os integrantes do grupo TDM-P foram mais frequentemente identificados como não-caucasianos e com escolariade menor do que a equivalente ao nosso ensino médio que os com TDM-NP (GAUDIANO et al., 2009).

Em relação às características clínicas da depressão, a noção geral é a de que a forma psicótica seria um tipo mais grave de depressão, o que está inclusive implícito na descrição de TDM no DSM-IV-TR e CID-10 conforme já apresentado. Alguns estudos confirmam esta idéia, mostrando que a gravidade do episódio depressivo, por exemplo, apresentou-se pior em vários aspectos em pacientes com TDM-P (FORTY et al. 2009; GAUDIANO et al, 2009).

Verificou-se nos casos psicóticos piores índices na escala de funcionamento global (Global Assessment Function Scale, GAF) e na escala de impressão global (Clinical Global Impression scale, CGI), além de maior prevalência de ideação e tentativas de suicídio, número de internações e prejuízo funcional e laboral (JAGER et al., 2005 ; FORTY et al., 2009; GAUDIANO et al., 2009).

No entanto, alguns estudos avaliaram particularmente escalas de gravidade de sintomas depressivos para verificar a possível associação dessa variável com o subtipo da TDM-P e TDM-NP. Os resultados de estudos mais recentes a respeito dessa análise não foram congruentes (CONTRERAS et al., 2007; KELLER et al., 2006a; SKAF et al., 2002; GAUDIANO et al., 2009), o que foi compatível com o que foi encontrado na revisão realizada por SCHATZBERG e ROTHSCHILD, em 1992 que também não mostrou consenso 
a respeito da relação entre presença de sintomas psicóticos e gravidade dos sintomas depressivos (SCHATZBERG e ROTHSCHILD, 1992).

Outras características clínicas foram relacionadas ao TDM-P. Neste subtipo de depressão houve maior estabilidade diagnóstica ao longo de episódios subsequentes (CORYELL et al. 1994), a idade de início dos episódios foi menor nos psicóticos e estes evoluíram mais frequentemente com cronicidade do quadro (FORTY et al, 2009; GAUDIANO et al., 2009). Ainda, foram encontradas diferenças entre os grupos quanto à psicomotricidade, observando-se haver maior retardo nos psicóticos (FORTY, 2009; LEE et al., 2003), como também pior resposta ao tratamento (BROWN et al, 1982; SIMPSON, 1999) e sentimento de culpa e inutilidade mais frequentes (LEE et al., 2003) e maior comorbidade com Transtorno de Estresse Pós-Traumático (TEPT), Transtorno Obsessivo Compulsivo (TOC) e transtorno somatoforme (GAUDIANO et al., 2009).

A história familiar em vários estudos não apresenta diferença significativa entre os subtipos psicóticos e não psicóticos (GAUDIANO et al., 2009, SIMPSOM et al., 1999; GAUDIANO et al., 2008; LEE et al., 2003). Apenas um estudo evidenciou que pacientes com depressão psicótica apresentavam história de THB do tipo I mais frequentemente do que os sem psicose (MAJ et al., 2007).

Aspectos neuropsicológicos também demonstraram diferenças entre a forma psicótica e a não-psicótica da depressão unipolar. Segundo metanálise de SCHATZBERG (2000), apesar de poucos estudos, a memória verbal, a velocidade e a habilidade psicomotoras e a função executiva mostraram-se significativamente diferentes entre os deprimidos psicóticos e os não-psicóticos, com maiores prejuízos nos primeiros (SCHATZBERG et al., 2000).

Além disso, em um estudo (JESTE et al., 1996) o padrão de várias funções cognitivas de deprimidos psicóticos se assemelhou ao de pacientes com esquizofrenia e, em dois estudos (JESTE et al.,1996; NELSON et al., 1998), verificou-se que a atenção encontrava-se prejudicada de forma semelhante nestes dois grupos diagnósticos.

Por fim, há evidências de características biológicas próprias da depressão unipolar com psicose. $\mathrm{O}$ aspecto mais estudado é a evidência de não supressão do eixo HPA após o uso de dexametasona (teste de supressão da dexametasona, com falha na redução de liberação de cortisol, que seria esperada caso o feedback negativo do eixo estivesse funcionando apropriadamente) nos pacientes com depressão psicótica (GAUDIANO et al., 2009; CONTRERAS et al., 2007), além de se encontrar a elevação do cortisol basal e da curva do cortisol (GOMES et al., 2006; KELLER et al., 2006; BELANOFF et al., 2001). Ainda há evidências de que o eixo HPA difere entre os subtipos clínicos de TDM, visto que o subtipo 
com características atípicas apresenta hipoativação, enquanto o melancólico a hiperativação do eixo HPA (GOLD e CROUSOS, 2002) e este último está mais frequentemente associado a sintomas psicóticos (PARKER et al., 1996). O conjunto dos dados, então, sinaliza a maior hiperativação do eixo do TDM-P em relação ao TDM-NP.

Outras variáveis biológicas que podem mostrar-se diferentes entre os grupos foram investigadas em pequeno número de estudos e por isso não permitem, ainda, resultados conclusivos. São elas: anomalias físicas menores (CULAV-SUMIC, 2010); dosagem de creatinocinase (SEGAL, 2007), fator neurotrófico BDNF (LEE et al., 2007), dopaminabetahidroxilase (MEYERS, 1999) e prolactina (LYKOURAS, 2007); dados de eletroencefalografia após eletroconvulsoterapia (WAZIRI, 1996; WAHLUND, 2009) e dados de eletroculografia (HARRIS, 2009), potencial evocado (KARAASLAN; 2003) e neuroimagem estrutural (KELLER et al., 2008) e funcional (SKAF et al., 2002).

Apesar das evidências apontarem para significativa prevalência e pior prognóstico da forma psicótica do TDM, esses casos são subdiagnosticados na prática clínica. Esse fato foi evidenciado em estudo que encontrou fatores de subdiagnóstico em ambos os lados da relação médico-paciente. As evidências apontaram para dois fatos relevantes: a falta de investigação de sintomas psicóticos pelos médicos e o estado paranoide do paciente possivelmente interferindo no relato de seus sintomas ao médico. (SCHATZBERG, 2003; KELLER et al. 2007).

Diante das diversas evidências acima, alguns autores da atualidade sugerem que o TDM-P seja considerado uma categoria de depressão unipolar com características clínicas, biológicas e prognósticas próprias (CORYELL e TSUANG 1985; PARKER et al., 1991; PARKER et al. 1995; SCHATZBERG e ROTHSCHILD, 1992 ; ROTHSCHILD, 2003; KELLER et al., 2007) .

Deve-se notar, também, que a forma psicótica do TDM vem sendo relativamente pouco estudada, e pela presente revisão da literatura observa-se que a maioria dos estudos clínicos e biológicos sobre o tema vem sendo conduzida de forma concentrada pelos mesmos (poucos) grupos de pesquisa.

\subsection{NEUROIMAGEM E TRANSTORNO DEPRESSIVO MAIOR (TDM)}

O surgimento da neuroimagem permitiu a avaliação de aspectos anatômicos, bioquímicos e funcionais do sistema nervoso central (SNC) in vivo. Os avanços nessa área têm permitido a 
investigação dos mecanismos fisiopatológicos de vários transtornos neuropsiquiátricos através da comparação de pacientes portadores com grupos de controles saudáveis.

Diversas técnicas de neuroimagem têm sido empregadas no estudo dos Transtornos do Humor. Por meio da RM pode-se estudar a anatomia e a volumetria do sistema nervoso central, com o emprego da RM estrutural, e aspectos da neuroquímica cerebral, com o uso da espectroscopia de próton por ressonância magnética de hidrogênio $\left({ }^{1} \mathrm{H}-\mathrm{ERM}\right)$.

Além da RM, técnicas de Medicina Nuclear, como a Tomografia por emissão de fóton único (Single-Photon Emission Computed Tomography, SPECT) ou a Tomografia por emissão de pósitrons (Positron Emission Tomography, PET) permitem avaliação funcional do cérebro, com medidas, por exemplo, de fluxo sanguíneo ou metabolismo de glicose, respectivamente.

O uso destas diversas técnicas de neuroimagem nas últimas décadas permitiu avanços na investigação da fisiopatologia dos Transtornos de Humor. Os resultados principais destes estudos em TDM são descritos a seguir, com ênfase no estudos de espectroscopia, objeto deste trabalho.

\subsubsection{Estudos de volumetria por RM estrutural em TDM}

Vários estudos têm evidenciado alterações volumétricas por RM em TDM, porém a investigação em TDM-P e sua comparação ao TDM-NP ainda é escassa. Achados consistentes de RM estrutural são encontrados em adultos com TDM não psicótico relacionado à redução de volume em relação a controles saudáveis em: hipocampo (CAMPBELL et al., 2004; MCKINNON et al., 2009; VIDEBECH e RAVNKILDE, 2004), amígdala (HAMILTON et al., 2008), em CA (DREVETS et al., 1997) e CPFDL e COF (KONARSKI et al., 2008).

Apesar de seu número reduzido, estudos de RM estrutural evidenciaram diferença de volume entre TDM-P e TDM-NP. Um estudo comparativo entre estes grupos, realizado em idosos, verificou redução volumétrica em lobo frontal e lobo temporal no TDM-P, regiões envolvidas na cognição e no processamento emocional, respectivamente (SIMPSON et al., 1999). Em outro estudo avaliando depressão geriátrica, os pacientes com TDM-P apresentaram redução de córtex pré-frontal, em relação aos pacientes com TDM-NP, enquanto não foi encontrada diferença entre os grupos nas seguintes regiões: núcleos da base, lobos temporais, giro temporal superior, complexo amígdala-hipocampo, ventrículos laterais e cérebro total (KIM et al. 1999).

Diferenças de volume de amígdala e hipocampo entre pacientes adultos com TDM-P e TDM-NP e controles saudáveis foram investigadas por Keller et al., em 2008. Embora não 
tenha havido diferença no volume do hipocampo entre os grupos, pacientes com sintomas psicóticos apresentaram menor volume de amígdala em relação aos TDM-NP e aos controles (KELLER et al., 2008).

Um estudo epidemiológico recente conduzido no Brasil avaliou por RM estrutural pacientes com depressão psicótica. Neste estudo, foi utilizada a técnica de morfometria voxel a voxel e foi constatada redução volumétrica de substância cinzenta em CPFDL bilateral em deprimidos psicóticos em primeiro surto em relação a controles saudáveis e aos pacientes bipolares em primeiro episódio de mania psicótica. No entanto, neste estudo, não foram avaliados deprimidos não psicóticos, não permitindo, portanto, a comparação dos dados de depressão com e sem psicose (AZEVEDO-MARQUES PÉRICO et al., 2011).

Estudos volumétricos por RM em adultos demonstraram alterações específicas em pacientes com TDM-P em relação a outros transtornos mentais psicóticos e a controles saudáveis. Um deles observou que, além de especificidade da redução de córtex frontal no grupo com esquizofrenia, o grupo com TDM-P apresentou aumento do volume ventricular em relação aos controles, enquanto o grupo com TDM-NP apresentou maior volume de substância branca em relação aos outros grupos de pacientes (SALOKANGAS et al., 2002). Redução de volume de córtex pré-frontal subgenual posterior esquerdo foi avaliado em outro estudo em pacientes com TDM-P em comparação a pacientes com esquizofrenia e redução de espessura cortical em relação a controles saudáveis (CORYELL et al., 2005).

Outro estudo avaliou diferenças volumétricas por RM entre psicose afetiva, esquizofrenia e controles saudáveis. Alterações mais extensas foram verificadas nos pacientes com esquizofrenia. No entanto, nesta amostra, o grupo com psicose afetiva era pequeno, majoritariamente constituído por pacientes em mania e os pacientes com depressão não foram avaliados separadamente (KUBICKI et al., 2002).

\subsubsection{Estudos de neuroimagem funcional em TDM}

Técnicas de neuroimagem funcional como o SPECT e o PET também têm contribuído para investigar o papel de determinadas estruturas cerebrais na fisiopatologia do TDM, por meio da avaliação do fluxo sanguíneo cerebral e da taxa de metabolismo de glicose. A comparação entre TDM-P e TDM-NP por meio destas técnicas, até o momento, é rara. 
A maioria dos estudos foi realizada em TDM sem diferenciação quanto à presença de psicose. O principal resultado destes estudos refere-se às alterações de fluxo sanguíneo cerebral (FSC) e taxa de metabolismo de glicose CA em pacientes com TDM-NP em relação a controles saudáveis (ITO et al., 1996; MAYBERG et al., 1994, BREMNER et al., 2004; DREVETS et al., 1997; GEORGE et al., 1997). Relatou-se ainda que a recuperação completa após tratamento farmacológico (MAYBERG et al., 2000; HOLTHOFF et al., 2004) e cognitivo-comportamental (KUMAR et al., 2003) está associada à normalização do metabolismo no CA em pacientes com TDM.

Estudos de neuroimagem funcional avaliando diferenças entre TDM-P e TDM-NP, apesar de escassos, mostram resultados significativos. Um estudo do fluxo sanguíneo cerebral regional por meio de SPECT demonstrou redução de fluxo na porção subgenual do CA esquerdo e de ínsula bilateral em pacientes com TDM-P em relação tanto a pacientes com TDM-NP quanto a controles saudáveis. A redução de fluxo sanguíneo em ínsula esquerda não se manteve após correção para comparações múltiplas. Os achados deste estudo não foram explicados pela gravidade da doença em si, mas sim pela presença ou não de sintomas psicóticos (SKAF et al., 2002).

Um segundo estudo encontrou diferença de FSC entre os pacientes deprimidos em relação à presença de psicose. Encontrou-se redução do FSC em córtex parietal esquerdo e cerebelo esquerdo e aumento do FSC em córtex pré-frontal ventro-orbital esquerdo e núcleo caudado esquerdo em pacientes com TDM-P em relação aos TDM-NP. Verificou-se ainda que o FSC do CPFDL esquerdo se correlacionou negativamente com a gravidade da depressão em ambos os grupos (GONUL et al., 2004).

A taxa de metabolismo da glicose foi utilizada em um estudo com PET para avaliar a resposta ao tratamento de pacientes com TDM-P. Dez pacientes com TDM-P foram submetidos ao PET após eletroconvulsoterapia (ECT) e identificou-se aumento do metabolismo de glicose no CA subgenual esquerdo e no hipocampo. A melhora dos sintomas depressivos correlacionou-se com o aumento de metabolismo em ambas as regiões cerebrais; já o efeito antipsicótico da ECT correlacionou-se apenas com o aumento do metabolismo no hipocampo (MCCORMICK et al., 2007).

A atividade cerebral por RM funcional (RMf) em TDM refletem também as regiões cerebrais acometidas do circuito cerebral desse transtorno mental. Aumento de atividade cerebral em córtex órbitofrontal e CA pregenual (CApg) durante estímulos negativos foi encontrado em TDM (ELLIOT et al., 2002) e condizentes com aumento da percepção de fatos negativos por estas regiões do sistema ventral nesse transtorno mental. Em TDM-P, no entanto, não há estudos com essa técnica de neuroimagem até o momento. 


\subsubsection{Estudos de espectroscopia por ressonância magnética $\left({ }^{1}\right.$ H-ERM) em TDM}

Com o emprego da ERM, é possível medir a concentração de substâncias químicas do SNC in vivo (STANLEY, 2002). Dentre os diversos tipos de núcleos que podem ser utilizadas para a aquisição da espectroscopia, o mais utilizado para investigação dos transtornos psiquiátricos tem sido o hidrogênio (isótopo ${ }^{1} \mathrm{H}$ ) (YILDIZ-YESILOGLU e ANKERST, 2006) e por isso a denominação "espectroscopia de próton" ou ${ }^{1} \mathrm{H}-\mathrm{ERM}$.

O hidrogênio é encontrado de forma abundante na natureza e, em 99,9\% das vezes, na sua forma de próton, ou seja, contendo apenas um próton e nenhum nêutron, o que lhe atribui a propriedade de rotação nuclear. Essa propriedade, por sua vez, gera um campo eletromagnético e o aparelho de RM, ao emitir um pulso de frequência, é capaz de alterar a orientação do eixo desse campo. Essa alteração de eixo do próton gera uma oscilação de radiofrequência que pode então ser captada e ampliada pelo conversor e traduzida pelo computador em forma de um gráfico (SALIBI e BROWN, 1998).

Os sinais de RM gerados por estes núcleos produzem então um pico espectral, ao invés de uma imagem. A posição do pico no eixo ' $x$ ' é específica, determinada pelo entorno eletrônico dos núcleos de hidrogênio de cada molécula. Essa posição é denominada de chemical shift ou deslocamento químico cuja freqüência é representada em parte por milhão (ppm). A amplitude do pico, por sua vez, está representada no eixo 'y'. A área sob determinado pico permite o cálculo da concentração de determinado metabólito na região cerebral estudada (v. FIGURA 3).

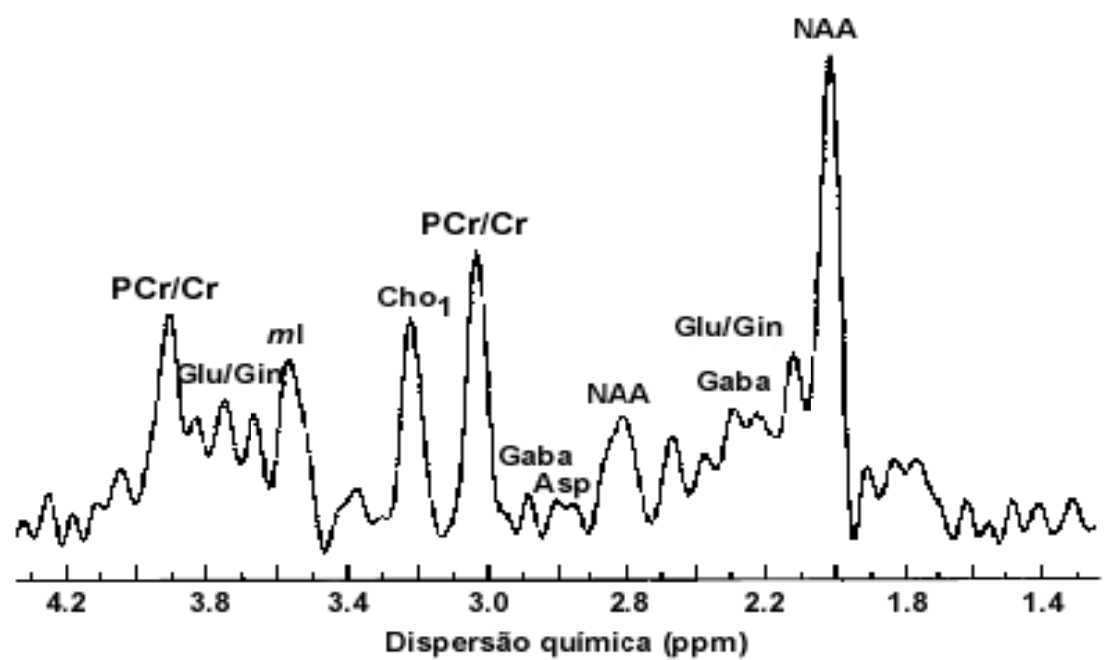

Figura 3: Exemplo de espectro obtido com a H-ERM - disposição dos picos de diversos metabólitos ao longo do eixo $\mathrm{x}$. 
O campo magnético é fundamental para a acurácia da espectroscopia (STANLEY, 2002). Quanto maior a intensidade do campo magnético, maior é a sensibilidade da técnica e melhor é a captação de sinal do volume do tecido (voxel) que se deseja estudar (STANLEY, 2002). Atualmente as maiores intensidades de campo estão entre 3 e 7 T, porém, conforme revisão de Capizzano et al. (2007), a maioria dos estudos em depressão foram realizados com aparelhos de 1,5 T.

$\mathrm{O}$ valor dos metabólitos obtidos pela ${ }^{1} \mathrm{H}-\mathrm{ERM}$ pode ser expresso de forma relativa ou absoluta em mmol $/ \mathrm{kg}$. A creatina, por ser considerada o metabólito cerebral mais estável, é o mais comumente utilizado no denominador para o cálculo da medida relativa dos metabólitos (TOFTS et al., 2003). Porém, evidências recentes (ONGUR et al., 2009) mostraram que a medida da creatina pode diferir entre os grupos de sujeitos com Esquizofrenia e controles saudáveis, o que reduz a confiabilidade dessa forma de quantificação.

Os elementos mais estudados pela ${ }^{1} \mathrm{H}$-ERM na TDM são o $\mathrm{N}$-acetil-aspartato (NAA), os componentes da colina (Cho), o mio-inositol (Myo), o glutamato (Glu), a glutamina (Gln) e o ácido gama-aminobutírico (GABA), a creatina $(\mathrm{Cr})$ e a fosfocreatina (PCr) (YILDZYESILOGLU e ANKERST, 2006).

O pico de NAA é o mais proeminente do espectro cerebral normal. Esse elemento é sintetizado nas mitocôndrias neuronais pela $\mathrm{N}$-acetil-L-aspartato transferase e está presente nos neurônios e nos oligodendrócitos quando o cérebro está em desenvolvimento e apenas nos neurônios nos adultos. Está relacionado à morte neuronal e, mais recentemente, tem-se apontado o NAA como marcador da produção de energia mitocondrial (BASLOW et al., 2003). Sua posição no eixo 'x' da frequência (chemical shift ou deslocamento químico) é 2.01 ppm e sua concentração está em torno de 8 a $10 \mathrm{mmol} / \mathrm{Kg}$, a segunda maior de aminoácido do cérebro (BASLOW, 2003).

O pico da colina é considerado um marcador do metabolismo da membrana fosfolípide e seu sinal encontra-se em 3.23 ppm (STANLEY, 2002). Entre seus componentes, encontra-se a colina livre (Cho) que é precursora dos lipídeos de membrana e assim encontra-se em maior concentração na substância branca. Ainda há a glicerolfosfocolina (GPC) e fosforilcolina (PC) respectivamente precursor e metabólito da fosfatidilcolina, componente da membrana celular e fonte de diacilglicerol, um segundo mensageiro e correspondem a $50 \%$ do pico da colina e por isso a representação desse pico é (PC + GPC) (YILDIZ-YESILOGLU e ANKERST, 2006).

Assim, o pico de colina tem sido estudado como medida da transdução de sinal neuronal, que estaria diminuído no TDM (STANLEY, 2002). E, por fim, a sua elevação indica aumento do renovação celular que pode ser tanto pela proliferação como pela 
degradação das estruturas de membrana (por exemplo, tumor cerebral, esclerose múltilpla) (STANLEY, 2002; YILDIZ-YESILOGLU e ANKERST, 2006).

O sinal do Myo, localizado no eixo ' $\mathrm{x}$ ' a $3.56 \mathrm{ppm}$, representa predominantemente esse elemento e apenas cerca de 5\% do mesmo é composto por glicina e inositol-1-fosfato (YILDIZ-YESILOGLU e ANKERST, 2006). O Myo é constituinte do sistema de segundo mensageiro do fosfatidil-inositol (KIM et al., 2005) e, dessa forma, participa da transdução de sinais entre os neurônios. Também é um marcador glial, já que é encontrado predominante nessas células onde é estocado até quando é requisitado como precursor do sistema de segundo mensageiro neuronal (YILDIZ-YESILOGLU e ANKERST, 2006).

$\mathrm{A} \mathrm{Cr}$ e a $\mathrm{PCr}$ são representadas no espectro cerebral no mesmo pico como $\mathrm{Cr}+\mathrm{PCr}$ com a ressonância em $3.02 \mathrm{ppm}$. A PCr funciona como estoque e transporte de energia e manutenção dos níveis de ATP e quando seu pico está baixo infere-se que a produção de $\mathrm{PCr}$ está reduzida ou que há hipometabolismo cerebral. Diante de relativa estabilidade desse pico, tem-se utilizado a creatina como referência para mensuração dos demais elementos, mas, conforme já citado anteriormente, os achados recentes apontam para alteração do mesmo em condições clínicas como transtornos psiquiátricos, regiões cerebrais, idade e uso de lítio e valproato. Dessa forma, recomenda-se sua utilização como referência entre grupos clínicos que não apresentem diferença da Cr em relação ao controle saudável (STANLEY, 2002).

$\mathrm{Na}$ freqüência de $2.3 \mathrm{ppm}$ encontra-se a sobreposição de vários metabólitos, principalmente o Glu, o GABA e a Gln, sendo que o pico que engloba estes três elementos denomina-se Glx (STANLEY, 2002; YILDZ-YESILOGLU e ANKERST, 2006). O Glu encontra-se em maior concentração, representando cerca de $70 \%$ do pico e é o principal neurotransmissor excitatório cerebral, por meio da liberação do influxo de cálcio (ROTHEMAN et al., 2003). A Gln está diretamente relacionada ao Glu, pois serve de substrato para o Glu nos neurônios. O Glu, por sua vez é catabolizado nos astrócitos e de seus metabólitos é produzida a Gln. O GABA é o principal neurotransmissor inibitório e encontra-se em proporção inferior aos dois anteriores neste pico, em cerca de 1/9 em relação ao Glu e 1/6 em relação à Gln (STANLEY, 2002). Com o aumento da intensidade de campo da ${ }^{1} \mathrm{H}$-ERM, tornou-se possível a análise dos elementos desse pico separadamente (CAPIZZANO et al., 2007)

Os estudos acerca desses elementos nos Transtornos do Humor têm se intensificado, principalmente em relação ao Glu após a utilização de drogas antiglutamatérgicas e gabaérgicas com eficácia significativa no TDM e no THB (ZARATE et al., 2006; YÜKSEL e ÖNGÜR, 2010). 
A utilização da ${ }^{1} \mathrm{H}-\mathrm{ERM}$ em estudos que avaliam pacientes com TDM-NP tem fornecido resultados variáveis (CAPIZZANO et al., 2007). O resultado mais consistente até o momento, já descrito em três metanálises, foi a redução de níveis de Gln + Glu em lobo frontal nos pacientes com TDM-NP comparados a controles saudáveis (YILDIZYESILOGLU e ANKERST 2006; CAPIZZANO et al. 2007; YÜKSEL e ÖNGÜR, 2010).

Segundo a metanálise realizada por Yüksel \& Öngür (2010), a maioria dos estudos a respeito das alterações de Gln + Glu nos transtornos do humor foi publicada nos últimos quatro anos (YÜKSEL e ÖNGÜR, 2010). A maioria dos estudos encontrou o Gln + Glu reduzido em TDM, como no córtex do CA (AUER et al. 2000) e no CPFDL e no CPF dorsomedial (HASLER et al., 2007).

Além disso, aqueles que estudaram pacientes com TDM remitido ou após tratamento com resposta, o nível de Gln + Glu encontrou-se elevado ou dentro dos níveis normais (PFLEIREDER et al., 2003) . Porém, aqueles portadores de THB mantiveram a elevação dos níveis de Gln + Glu independentemente do estado de humor (YÜKSEL e ÖNGÜR, 2010).

Ainda de acordo com a metanálise citada acima, poucos estudos avaliaram o valor do Glu e Gln separadamente. (YÜKSEL e ÖNGÜR, 2010). Dentre quatro estudos que fizeram essa análise, um estudo evidenciou redução de Glu em CA de pacientes graves segundo CID10 em relação aos demais pacientes deprimidos e aos controles (AUER et al., 2000), um com redução de $\mathrm{Gln} / \mathrm{Cr}$ e níveis de $\mathrm{Glu} / \mathrm{Cr}$ sem alteração em $\mathrm{CA}$ de pacientes com escores elevados de anedonia (WALTER et al., 2009), um com redução de $\mathrm{Gln} / \mathrm{Cr}$ em hipocampo (BLOCH et al., 2008) e um com Gln normal, mas elevação do Glu em lobo occipital (SANACORA et al., 2004). O estudo dos níveis de Glu isolado do Gln então evidencia diferenças dependendo da região cerebral estudada, compatível com o modelo neuroanatômico descrito anteriormente de diferença regional da atividade cerebral no TDM (PHILLIPS et al., 2003a; PHILLIPS et al., 2003b) e do tipo de TDM estudada (AUER et al., 2000).

Já entre os estudos em THB, apenas um fez essa diferenciação e obteve Glu elevado e Gln normal. Após a administração da lamotrigina (modulador glutamatérgico) (CALABRESE et al., 1999), houve elevação da Gln. Esses achados apontaram para a possibilidade de que a relação entre os valores desses elementos e não os valores isolados sejam determinantes para os estados de humor desses transtornos (YÜKSEL e ÖNGÜR, 2010).

Em uma das metanálises também foi identificado, de forma consistente, aumento da razão Cho/Cr em pacientes com TDM nos núcleos da base e ausência de alterações de NAA, 
o que sugere um aumento da renovação da membrana sem a ocorrência de neurodegeneração (YILDIZ-YESILOGLU e ANKERST, 2006).

Conforme metanálise de Capizzano et al. (2007), os estudos que dizem respeito a alterações de NAA e Myo são isolados, pouco consistentes e por vezes discordantes. Ainda, de acordo com esta metanálise, o aumento de $\mathrm{PC}+\mathrm{GPC}$ nos núcleos da base não seria um achado consistente.

Embora o TDM-NP tenha sido objeto de várias investigações por ${ }^{1} \mathrm{H}-\mathrm{ERM}$, a forma psicótica do TDM só foi estudada em apenas um estudo. BLASI et al. (2004) encontraram redução da razão de NAA/Cr no hipocampo de pacientes em primeiro episódio de psicose afetiva, em relação a controles saudáveis, embora não tenham encontrado alterações em outras 10 regiões anatômicas avaliadas. Deve-se notar que o achado refere-se a uma amostra que engloba tanto pacientes unipolares quanto bipolares (BLASI et al., 2004).

Outras formas de psicose também têm sido investigadas através da ${ }^{1} \mathrm{H}-\mathrm{ERM}$. Na esquizofrenia foram encontradas principalmente alterações nos níveis de Glu/Gln e de NAA principalmente em lobo frontal e temporal. O Glu encontrou-se aumentado em familiares de primeiro grau de pacientes com esquizofrenia (TIBBO et al., 2004), como também em início desse transtorno mental (THEREBERGE et al., 2002), porém, os níveis de Glu apresentaramse reduzidos na esquizofrenia com15 anos de história (THEREBERGE et al., 2004).

Esses dados são compatíveis com a teoria de hipofunção do receptor NMDA em que haveria aumento de Glu compensatório em fase inicial e consequente neurotoxicidade pelo excesso desse metabólito com lesão glial (OLNEY et al., 1999).Como os níveis do Glu são predominantemante intra-celulares, a perda de células gliais corresponderia aos baixos níveis desse metabólito detectado pela ${ }^{1} \mathrm{H}$-ERM. Esse achado também é corroborado por dados de RM de redução do volume frontal desses pacientes (HO et al., 2003).

Os achados quanto ao NAA na esquizofrenia também evidenciaram alterações na fase crônica (ABBOTT e BUSTILLO, 2006). Tanto o giro do cíngulo posterior (SHIMIZU et al., 2005), quanto o CPFDL (MOLINA et al., 2005) de pacientes com tais características apresentaram redução dos níveis de NAA e tais resultados também poderiam traduzir a neurotoxidade relacionada à hipofunção do receptor do tipo NMDA descrita acima. Outros estudos de ${ }^{1} \mathrm{H}-\mathrm{ERM}$ ainda evidenciaram que o uso de antipsicóticos (APs) não justificou as alterações de Glu, Gln, nem de NAA encontradas nesse transtorno mental (BUSTILLO et al, 2006).

Por fim, vale-se frisar que não há estudos de ${ }^{1} \mathrm{H}-\mathrm{ERM}$ de pacientes com TDM-P.

A seguir, encontra-se uma tabela com o resumo dos principais achados em 1H-ERM de interesse para a compreensão do presente trabalho 
Tabela 1: Resumo dos achados de ${ }^{1} \mathrm{H}-\mathrm{ERM}$ em TDM, psicose afetiva e Esquizofrenia

\begin{tabular}{|c|c|c|c|}
\hline Estudos de ${ }^{1}$ H-ERM & Amostra & Região estudada & $\begin{array}{l}\text { Alteração do } \\
\text { metabólito }\end{array}$ \\
\hline $\begin{array}{l}\text { Yildiz-Yesiloglu e } \\
\text { Ankerst, } 2006\end{array}$ & Metanálise em TDM & Várias regiões & $\begin{array}{c}\downarrow \text { Glx em lobo frontal, } \\
\downarrow \text { Glx em gânglios da } \\
\text { base e NAA sem } \\
\text { diferença }\end{array}$ \\
\hline Capizzano et al., 2007 & Revisão em TDM & Várias regiões & $\downarrow$ Glx em lobo frontal \\
\hline Hasler et al., 2007 & TDM & CPFDM e CPFDL & $\downarrow$ Glu \\
\hline Pflerider et al., 2003 & TDM Pós-tto & $\mathrm{CA}$ & $\uparrow \mathrm{Glu}$ \\
\hline Auer et al., 2000 & $\begin{array}{l}\text { Grupos: TDM, TDM grave } \\
\text { (CID-10) e controles }\end{array}$ & $\mathrm{CA}$ & $\begin{array}{c}\downarrow \text { Gln+Glu em TDM } \\
\downarrow \text { Gln+Glu e Glu em } \\
\text { TDM grave }\end{array}$ \\
\hline Walter et al., 2009 & TDM & $\mathrm{CA}$ & $\begin{array}{c}\downarrow \text { Gln/Cr em subgrupo } \\
\text { de TDM ( } \uparrow \text { anedonia); } \\
\text { Glu sem alteração }\end{array}$ \\
\hline Bloch et al., 2008 & $\mathrm{TDM}$ & hipocampo & $\downarrow$ Gln \\
\hline Sanacora et al., 2004 & $\mathrm{TDM}$ & Lobo occipital & $\uparrow \mathrm{Glu}$ \\
\hline Blasi et al., 2004 & $\begin{array}{l}\text { TDM e THB com psicose e } \\
\text { controles saudáveis }\end{array}$ & Hipocampo & $\downarrow \mathrm{NAA} / \mathrm{Cr}$ \\
\hline Tibbo et al., 2004 & $\begin{array}{c}\text { Familiares de } 1^{\circ} . \text { Grau de } \\
\text { EQZ }\end{array}$ & CPF medial & $\begin{array}{c}\uparrow \text { Glu, NAA sem } \\
\text { alteração }\end{array}$ \\
\hline Theberge et al., 2002 & $\begin{array}{l}\text { Esquizofrenia recente }(1,7 \\
\text { anos) vs controles saudáveis }\end{array}$ & $\mathrm{CA}$ & $\begin{array}{c}\uparrow \text { Gln; Glu e NAA sem } \\
\text { diferença }\end{array}$ \\
\hline Theberge et al., 2004 & $\begin{array}{c}\text { EQZ crônica }(15,7 \text { anos }) v s \\
\text { controles saudáveis }\end{array}$ & $\mathrm{CA}$ & $\begin{array}{c}\downarrow \text { Glu e Gln; NAA sem } \\
\text { diferença }\end{array}$ \\
\hline Steen et al., 2005 & $\begin{array}{c}\text { Metanálise em EQZ vs } \\
\text { controle }\end{array}$ & $\begin{array}{l}\text { Lobo temporal } \\
\text { medial e } \mathrm{CPF}\end{array}$ & $\downarrow \mathrm{NAA}$ \\
\hline Molina et al., 2005 & $\begin{array}{l}\text { EQZ crônica, }(9,7 \text { anos }) \text {, } \\
\text { recente (1,8anos) e controle }\end{array}$ & CPFDL & $\begin{array}{c}\downarrow \text { NAA/Cr: crônico em } \\
\text { relação aos demais } \\
\text { grupos }\end{array}$ \\
\hline Shimizu et al., 2005 & $\begin{array}{c}\text { EQZ crônica e controles } \\
\text { saudáveis }\end{array}$ & $\begin{array}{l}\text { GCP, lobo temporal } \\
\text { medial e hipocampo }\end{array}$ & $\downarrow$ NAA em GCP \\
\hline
\end{tabular}

CPF: córtex préfrontal; CPFDL: córtex préfrontal dorsoanterolateal; GC: giro do cíngulo; GCP: giro do cíngulo posterior; EQZ: esquizofrenia. Glx- glutamina + glutamato + GABA. NAA- N-acetil-aspartato. 
Verificam-se, a partir das revisões a respeito de ${ }^{1} \mathrm{H}$-ERM em transtornos mentais, limitações em comum (CAPIZZANO et al., 2007; YÜKSEL e ÖNGÜR, 2010). A principal fonte de limitação dos estudos diz respeito à variabilidade das metodologias empregadas. Entre elas destacam-se os diferentes tipos de amostras, métodos de análise, bem como formas de seleção dos pacientes (YÜKSEL e ÖNGÜR, 2010) e não se encontrou padronização das técnicas de ${ }^{1} \mathrm{H}$-ERM utilizadas e das regiões cerebrais estudadas (CAPIZZANO et al., 2007).

\subsection{JUSTIFICATIVA}

Os estudos descritos anteriormente demonstram que o TDM vem sendo constantemente objeto de investigações de neuroimagem nos últimos anos. No entanto, a maioria desses estudos não incluiu participantes com sintomas psicóticos e tampouco investigaram diferenças entre TDM-P e TDM-NP. O TDM-P é um transtorno frequente, porém subdiagnosticado e seus aspectos neurobiológicos têm sido pouco estudados em relação às formas não psicóticas do TDM. Os estudos de neuroimagem até o momento, apesar de não elucidarem por completo os aspectos neurobiológicos subjacentes aos sintomas psicóticos em TDM, sugerem que existam diferenças biológicas entre pacientes deprimidos psicóticos e não psicóticos, além das diferenças clínicas já observadas entre eles.

$\mathrm{O}$ emprego da ${ }^{1} \mathrm{H}-\mathrm{ERM}$ pode fornecer conhecimento a respeito de alterações bioquímicas cerebrais do TDM-P e TDM-NP. Esta técnica de RM traz dados indicadores de acometimento neuronal, renovação de membrana, metabolismo energético e neurotransmissão excitatória e inibitória em transtornos psicóticos e de humor. Porém, até o momento, não foram conduzidos estudos de ${ }^{1} \mathrm{H}$-ERM que investigassem especificamente o TDM com sintomas psicóticos ou amostras de TDM-P comparadas com TDM-NP.

Considerando a relevância dos achados de neuroimagem em TDM e a escassez dessa técnica de investigação na forma psicótica deste transtorno, este projeto propôs-se a avaliar as diferenças de medidas de marcadores neuroquímicos em regiões cerebrais do circuito cerebral da depressão em pacientes adultos com TDM com e sem sintomas psicóticos e em controles saudáveis por meio da ${ }^{1} \mathrm{H}$-ERM.

Inicialmente, o hipocampo bilateral e CA com predomínio da porção dorsal foram investigados devido a sua participação relevante tanto na depressão quanto nos transtornos psicóticos, porém, estudo piloto evidenciou má qualidade dos dados obtidos dos hipocampos 
devido a sua alta heterogeneidade magnética e, assim, a análise desta região cerebral foi interrompida.

O CA, por sua vez, é uma região acometida tanto no TDM quanto na esquizofrenia. Segundo os achados em TDM descritos acima, essa região cerebral faz parte do sistema dorsal do modelo neuroanatômico desse transtorno mental, a glia dessa região cerebral sofre lesão por hipercortisolemia conforme estudos histopatológicos, e, por fim, poderia apresentar redução do ácido quinolínico como encontrado em modelos animais de depressão. Todos esses achados, então, são compatíveis com diminuição de função do CA dorsal no TDM.

$\mathrm{Na}$ esquizofrenia, o CA também foi relacionado à neurotoxicidade glutamatérgica e por isso haveria redução glial nesta região cerebral e conseqüentes alterações metabólicas.

Finalmente, esta área, ao invés do CA subgenual, é tecnicamente mais favorável ao estudo pela ${ }^{1} \mathrm{H}$-ERM. 


\section{OBJETIVOS}

\subsection{OBJETIVO GERAL}

O objetivo geral desta pesquisa é avaliar em adultos não idosos, com episódio atual de depressão maior, possíveis diferenças neuroquímicas entre pacientes com (TDM-P) e sem sintomas psicóticos (TDM-NP) e entre esses dois grupos de pacientes e controles saudáveis.

\subsection{OBJETIVOS ESPECÍFICOS}

Constitui objetivo específico deste estudo mensurar no CA os níveis de Glu, Gln + Glu, NAA+NAAG, PC+GPC, Myo e Cr obtidos através da ${ }^{1} \mathrm{H}-\mathrm{ERM}$ de pacientes adultos não idosos deprimidos com e sem sintomas psicóticos, comparados entre si e com controles saudáveis.

Além disso, pretende-se investigar as associações entre variáveis demográficas e clínicas (duração da doença, número de episódios, gravidade dos sintomas depressivos e psicóticos, sexo e idade) e as medidas dos metabólitos citados acima, em pacientes com TDM-P e TDM-NP. 


\section{HIPÓTESES}

1) Devido à fragilidade das evidências a respeitos de diferenças entre TDM-P e TDM-NP em termos de variáveis demográficas, espera-se que os dois grupos não serão diferentes em termos de idade e gênero. Diante de evidências recentes que questionam a idéia de que pacientes com TDM-P teriam necessariamente quadros depressivos mais graves do que os não psicóticos, não esperamos encontrar diferenças entre medidas de gravidades de sintomas depressivos entre os grupos.

2) Pacientes com TDM-P e TDM-NP apresentarão diferenças de níveis de metabólitos em relação aos controles. Baseados em estudos espectroscópicos anteriores, espera-se que TDM apresente menores valores de Gln+Glu e que TDM-P apresente menores níveis de Gln+ Glu e $\mathrm{NAA}+\mathrm{NAAG}$.

Apesar das evidências de aumento da atividade do sistema glutamatérgico na fisiopatologia da depressão, a região investigada, o CA dorsal, faz parte do sistema dorsal no modelo neuroanatômico desse transtorno mental, por isso estaria hipoativada e, assim, como já encontrado em literatura em TDM, os níveis de Glu em CA estariam inferiores no TDMNP em relação aos controles.

Já os pacientes com TDM-P apresentarão também redução de Glu nessa região cerebral em relação aos controles, compatível com os achados relativos ao estudo da fisiopatologia da Esquizofrenia (transtorno psicótico), em que o estresse estaria associado à modulação inibitória do sistema glutamatérgico e redução dos níveis de Glu.

Como o a hiperativação do eixo HPA é mais importante no TDM-P que no TDM-NP, espera-se ainda que os níveis de Glu de TDM-P sejam inferiores aos TDM-NP devido à disfunção do CA associado à hipercortisolemia. Diante disso e de dados da literatura, também se espera que pacientes psicóticos apresentarão redução dos níveis de NAA+NAAG em relação aos não psicóticos e aos controles. 


\section{MÉTODOS}

O presente estudo faz parte de um projeto mais amplo, intitulado "TDM com e sem sintomas psicóticos: avaliação de aspectos clínicos, genéticos, neuropsicológicos e de neuroimagem", e foi conduzido pelo Departamento de Neurociências e Ciências do Comportamento da FMRP-USP. Foi aprovado pela Comissão de Normas Éticas Regulamentares do Hospital das Clínicas da Faculdade de Medicina de Ribeirão Preto, da Universidade de São Paulo (Processo HCRP n 7331/2009) em outubro de 2009. A coleta da amostra teve início em seguida e todos os participantes assinaram o Termo de Consentimento Livre e Esclarecido explicado pela autora (Anexo A). Os participantes foram convidados a contribuir para a pesquisa de forma voluntária. Aos pacientes foi assegurado, no momento do convite, que caso não quisessem participar, tal decisão não traria nenhum prejuízo para a continuidade do seu tratamento na instituição.

A autora esteve presente em todas as etapas do estudo. Realizou a seleção de pacientes e controles, aplicou os instrumentos diagnósticos e as escalas de sintomas, acompanhou a realização da RM e da análise de espectroscopia, organizou o banco de dados, conduziu a análise estatística e fez seguimento ambulatorial da maioria dos pacientes.

\subsection{AMOSTRA}

Pretendia-se avaliar 20 pacientes com TDM-P, 20 pacientes com TDM-NP e 40 controles saudáveis. A maioria dos pacientes e controles saudáveis residia em Ribeirão Preto ou em cidades vizinhas. Os pacientes foram selecionados a partir do atendimento na Unidade de Emergência ou da internação na Enfermaria Psiquiátrica de Internação Breve do Hospital das Clínicas da Faculdade de Medicina de Ribeirão Preto - Universidade de São Paulo (FMRP-USP), bem como foram identificados também em outras unidades pela pesquisadora e por colegas e encaminhados para estes serviços.

A busca dos controles foi feita no meio de convívio dos pacientes (não familiares) e no meio de trabalho das pesquisadoras, por convite verbal. 


\subsubsection{Critérios de inclusão}

Participantes entre 18 e 65 anos de ambos os sexos.

\subsubsection{Para pacientes}

i. Diagnóstico de TDM de acordo com o DSM-IV-TR (APA, 2000);

ii. Em episódio depressivo atual, com ou sem presença de delírios ou alucinações.

\subsubsection{Critérios de exclusão}

\subsubsection{Para todos os participantes}

i. Doenças médicas com possibilidade de manifestação depressiva ou psicótica secundária;

ii. Condições clínicas graves ou descompensadas com possibilidade de repercussão no $\mathrm{SNC}$;

iii. Presença de doenças neurológicas do tipo traumatismo crânio-encefálico com perda da consciência, epilepsia, ou história de acidente vascular cerebral (AVC);

iv. Tratamento com esteróides exógenos;

v. Contra-indicação para exame de RM (próteses de metal, clipe de aneurisma cerebral, implante coclear, marcapasso e claustrofobia).

\subsubsection{Para controles saudáveis}

i. Diagnóstico na vida de Transtornos Mentais do Eixo I (DSM-IV-TR), com exceção de transtornos de ansiedade de alta prevalência na população geral, caracterizados por baixa 
gravidade e ausência de necessidade de tratamento psiquiátrico (ex: fobia simples ou fobia específica leves);

ii. Transtorno do Humor ou Transtornos Psicóticos (DSM-IV-TR) em familiares de primeiro grau;

iii Uso atual de psicofármacos.

\subsubsection{Instrumentos de avaliação}

Foram aplicados instrumentos padronizados e já validados em português para confirmação diagnóstica, descrição do perfil clínico e avaliação da gravidade de sintomas, descritos a seguir.

\subsubsection{Confirmação diagnóstica}

Entrevista Clínica Estruturada para o DSM-IV (SCID-IV-CV, FIRST et al., 1995), traduzida e adaptada para o português (DEL-BEN et al., 2001). Foi utilizada para confirmação do diagnóstico de episódio depressivo atual dos pacientes, além do registro de informações clínicas relevantes como tempo de doença, idade de início, tratamentos realizados, uso de psicofármacos e registro de comorbidades psiquiátricas. No caso dos controles, foi aplicada para a identificação de qualquer diagnóstico psiquiátrico, bem como do uso de medicações e da presença de condições médicas gerais.

\subsubsection{Escalas de Avaliação clínica}

i. Escala de funcionamento global (Global Assessment of Functioning, GAF) (anexo B).

Escala utilizada para julgamento clínico do nível de funcionamento global do paciente cuja pontuação é de 0 a 100 , onde o valor 100 corresponde ao melhor funcionamento. Seu resultado é relatado no eixo $\mathrm{V}$ do DSM; 
ii. Escala de Hamilton para Depressão (HAMILTON, 1960), traduzida, adaptada e validada para a língua portuguesa (CARVALHO et al., 1993).

Trata-se de instrumento de hetero-avaliação, destinado ao registro da presença e da gravidade de sintomas depressivos. Foi utilizada a versão composta por 31 itens para possibilitar a avaliação de sintomas atípicos (Anexo C). A aplicação desta escala também foi feita com os controles saudáveis com o objetivo de se certificar que as suas pontuações não seriam significativas para depressão, ou seja, esperava-se que a pontuação dos controles fosse inferior a sete pontos.

iii. Escala de Avaliação Psiquiátrica Breve (Brief Psychiatric Rating Scale - BPRS), desenvolvida por Overall e Gorham (1962), traduzida, adaptada e validada para a língua portuguesa (ZUARDI et al., 1994).

Esta escala é composta por 18 itens graduados em cinco níveis de gravidade que variam de 0 a 4 (Anexo D). Utilizada para registrar e quantificar a gravidade dos sintomas psicóticos. Também foi aplicada nos pacientes com TDM-NP e nos controles, para comprovação de que estes grupos não apresentavam sintomas psicóticos.

iv. Dominância hemisférica cerebral (Anexo E)

A dominância hemisférica cerebral (direita, esquerda ou mista) foi estabelecida por meio da aplicação do inventário de dominância lateral de Edimburgo (OLDFIELD, 1971).

\subsubsection{Escala de avaliação do nível sócio-econômico (Anexo F)}

A classe socioeconômica dos voluntários foi avaliada pelo Critério de Classificação Socioeconômica do Brasil (Associação Brasileira de Empresas de Pesquisa 2003), baseado no Levantamento Socioeconômico de 2000.

\subsubsection{Avaliadores}

A confirmação do diagnóstico de TDM e as avaliações da gravidade dos sintomas foram feitas por duas psiquiatras (a presente autora e sua orientadora) familiarizadas com a 
assistência clínica de pacientes portadores de Transtornos de Humor e de Transtornos Psicóticose, treinadas nos instrumentos de diagnóstico e de avaliação descritos anteriormente.

\subsubsection{Instrumento de avaliação de neuroimagem}

\subsubsection{Aquisição da ${ }^{1} H-E R M$}

Os exames de RM foram realizados no Serviço de Radiologia do Hospital das Clínicas da Faculdade de Medicina de Ribeirão Preto, Universidade de São Paulo (HC-FMRP-USP), utilizando o aparelho de RM Philips Achieva 3.0 T. O protocolo de aquisição das imagens consistiu numa sequência de imagens estruturais ponderadas em T1 para a identificação de possíveis anormalidades cerebrais pelo neurorradiologista.

A próxima etapa foi a realização da espectroscopia por meio da técnica de voxel único (do inglês, single voxel). Sequências estruturais nos três planos ortogonais (coronal, axial e sagital), ponderadas em T1 e T2, foram utilizadas para o posicionamento dos volumes de interesse (volume of interest, VOI). Para localização do CA, uma sequência localizatória PRESS (do inglês Point Resolved Spectroscopy Sequence) foi utilizada com tempo de eco (TE) de $31 \mathrm{~ms}$ e tempo de repetição (TR) de $1500 \mathrm{~ms}$, com resolução espectral de $0.78 \mathrm{~Hz} /$ ponto e largura de banda de $3.200 \mathrm{~Hz}$. A quantificação absoluta dos metabólitos também foi adquirida em cada VOI por um espectro sem a supressão da água.

Optou-se pela avaliação do CA cujo VOI correspondeu à área 24 b, 24 c e 32 e porção da área 24 a de Brodmann, com volume de $3 \times 2 \times 1 \mathrm{~cm}\left(6 \mathrm{~cm}^{3}\right)$, evitando-se a sobreposição com o ramo da artéria cerebral anterior e a interferência do ar do seio ósseo frontal (v. FIGURA 4). Foram utilizadas fotos do posicionamento de cada VOI como modelo para que o técnico, durante esse procedimento, realizasse a conferência cautelosa da anatomia a ser estudada e assim garantisse a reprodutibilidade da amostra. Além disso, a autora deste trabalho acompanhou e conferiu a realização dessas etapas da pesquisa. O tempo total da aquisição da RM variou de 35 a 40 minutos (dependendo da necessidade de repetição de alguma sequência durante alguma aquisição). 


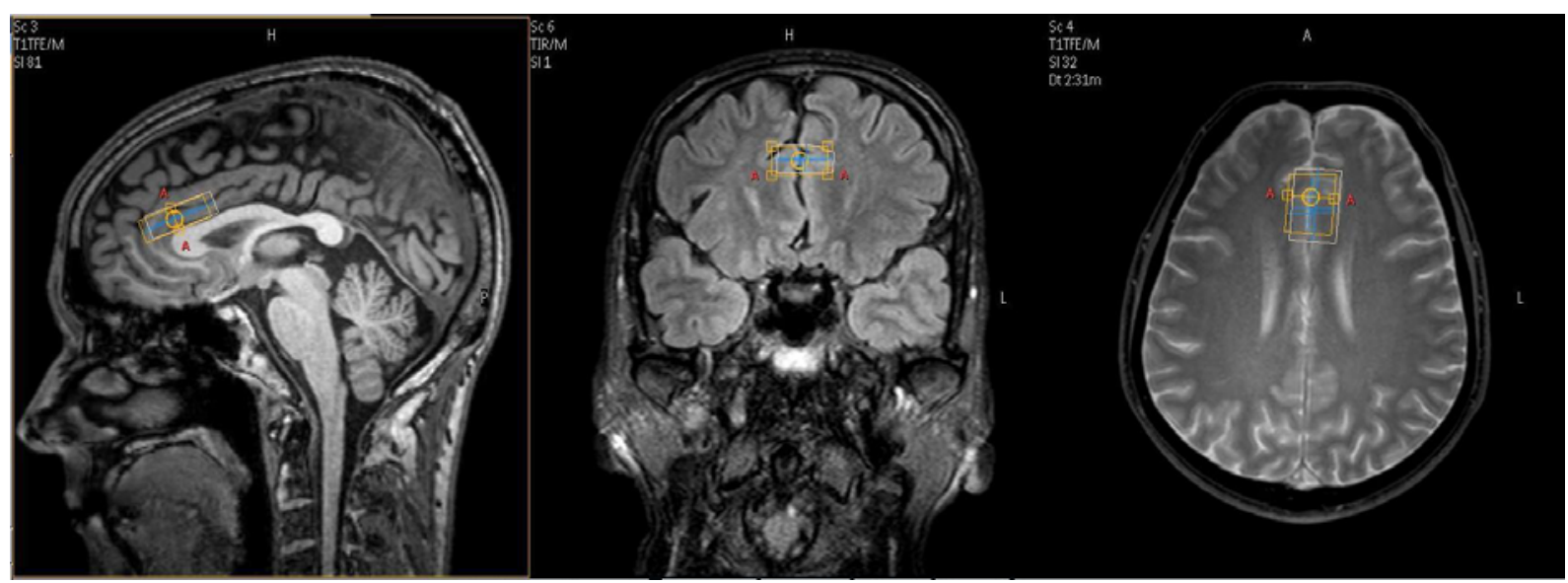

Figura 4: Posicionamento do voxel em CA, no plano sagital, coronal e axial, correspondente às aéreas 24 b, 24 c, 32 e porção da 24 a de Brodmann.

\subsubsection{Pós-processamento da ${ }^{1} H-E R M$}

A quantificação e análise dos dados da espectroscopia foram realizadas pelo programa de computador Linear Combination Model (LCModel) (PROVENCHER, 1993). Esse programa calcula, de forma independente do operador, a área sob os picos do espectro e estima as concentrações dos metabólitos de forma relativa (referida à área do pico da creatina) e/ou absoluta ( $\mathrm{mmol} / \mathrm{kg}$ de peso úmido) e é amplamente usado em estudos de espectroscopia atuais.

Os metabólitos quantificados foram: Glutamina (Gln); Glutamato (Glu); Glutamato + Glutamina (Gln+Glu); N-Acetil-D-aspartato + N-Acetil-D-aspartato-glutamato (NAA+ NAAG); Fosforilcolina + Glicerol-fosforil colina + Colina (PC+GPC); mio-inositol (Myo) e Creatina (Cr). Foram incluídas na análise estatística apenas as concentrações com erros padrões inferiores a $20 \%$ (referido ao próprio valor da concentração) como sugerido pelo manual do programa. Para este estudo, foram utilizados os valores absolutos dos metabólitos (v. FIGURA 5). 


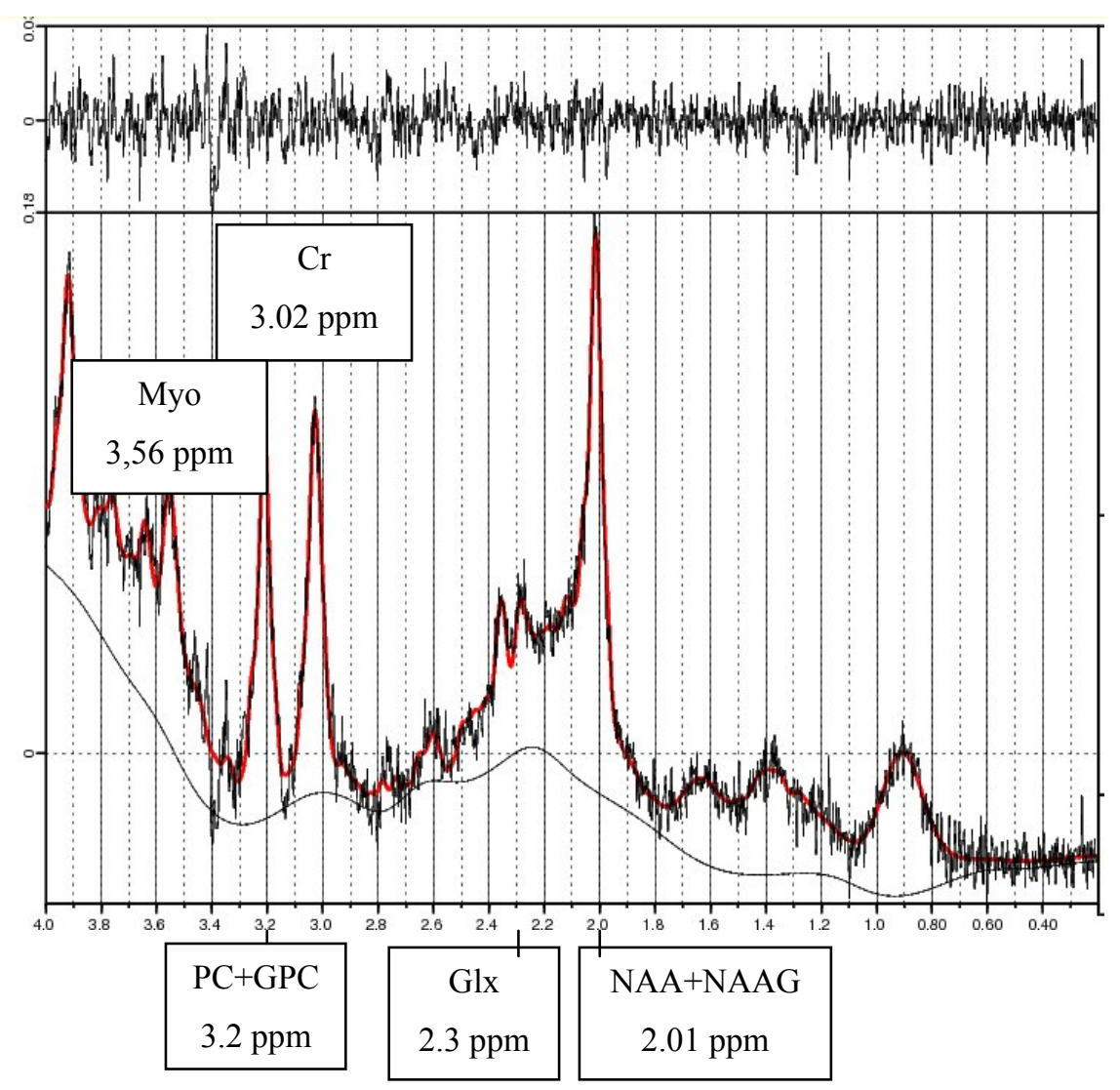

Figura 5: Espectro do CA de controle saudável com a localização dos picos e seus respectivos deslocamentos químicos.

\subsubsection{Análise estatística}

\subsubsection{Análise de dados sócio-demográficos e clínicos}

Os dados foram analisados com o uso do Statistical Package for the Social Sciences (SPSS) versão 19.0. Dados contínuos foram analisados por meio de $t$ de Student e ANOVA com pós-teste de Tukey quando seguissem distribuição normal, e Mann-Whitney ou Kruskal Wallis para dados sem distribuição normal. Para dados nominais, foi empregado o teste do qui-quadrado $\left(\chi^{2}\right)$. Foram consideradas significativas as diferenças com valores de $p<0,05$. 


\subsubsection{Análise estatística da Espectroscopia}

Inicialmente, procedeu-se à análise bivariada entre as variáveis neuroquímicas entre si e entre as variáveis neuroquímicas e idade através da correlação de Pearson.

Posteriormente, a significância dos fatores "grupo" e "sexo" sobre as variáveis metabólicas do CA foi avaliada com uma análise de variância multivariada (MANOVA) depois de validados os pressupostos de normalidade multivariada e de homogeneidade da matriz de variâncias e covariâncias.

A análise estatística foi realizada pelo software SPSS (v. 19, SPSS, Inc Chicago IL). Dado que o SPSS não produz testes para normalidade multivariada, este pressuposto foi validado a partir da normalidade univariada de Shapiro-Wilk $(\mathrm{p}>0,05)$ para todos os grupos, conforme descrito em MAROCO (2007).

O pressuposto da homogeneidade de variâncias-covariâncias em cada grupo foi avaliado como Teste M de Box. Para a avaliação das hipóteses da MANOVA, considerou-se o método de Roy, particularmente potente quando as variáveis estão fortemente correlacionadas.

Quando a MANOVA detectou efeitos estatísticos significativos, procedeu-se a ANOVA para cada uma das variáveis dependentes, seguido de pós-teste de Tukey. Nos casos onde a MANOVA mostrou "significância marginal" (por ex: $\mathrm{p}=0,08 ; 0,07 ; 0,1$ ), procedeu-se a análise conjunta na significância estatística, dimensão do efeito e o poder estatístico. Considerou-se o nível de significância como $\alpha$ igual a 0,05 e poder de 0,8 (1- $\beta$ ). A classificação da dimensão do efeito foi feita de acordo com MAROCO (2007).

Eta parcial: $\eta_{\mathrm{pi}}^{2}$

$\mathrm{O} \eta_{\mathrm{pi}}{ }^{2}$ mede a proporção da variabilidade do fator e do erro que é explicada pelo fator 'e' do erro que é explicado pelo fator 'i'. Não depende do número de outros fatores do modelo, quer eles sejam significativos ou não (v. TABELA 2).

Tabela 2 - Categorias de dimensão do efeito para os valores do $\eta_{\mathrm{pi}}{ }^{2}$

\begin{tabular}{cc}
\hline Dimensão do efeito & $\eta_{p i}{ }^{2}$ \\
\hline Muito elevado & $>0,5$ \\
Elevado & $>0,25, \leq 0,5$ \\
Médio & $>0,05, \leq 0,25$ \\
Pequeno & $<0,05$ \\
\hline
\end{tabular}

$\overline{\eta_{\mathrm{pi}}{ }^{2}: \text { Eta parcial }}$ 
A classificação dos graus de coeficiente de correlação foi feita de acordo com DANCEY e REIDY (2006) (v. TABELA 3).

Tabela 3 - Categoria de intensidade de correlação para os valores de 'r'

\begin{tabular}{cc}
\hline Intensidade da correlação & $r$ \\
\hline Perfeito & 1 \\
Forte & 0,7 a 0,9 \\
Moderado & 0,4 a 0,6 \\
Fraco & 0,1 a 0,3 \\
Zero & 0 \\
\hline
\end{tabular}

r: Coeficiente de correlação de Pearson 


\section{RESULTADOS}

Nesta seção serão apresentados os resultados do trabalho, dispostos na seguinte ordem:

- Obtenção da amostra

- Características sócio-demográficas

- Características clínicas dos grupos TDM-P e TDM-NP

- Resultados das análises de níveis de metabólitos do CA por ${ }^{1} \mathrm{H}-\mathrm{ERM}$

- Correlações entre metabólitos e idade entre si

- Efeito dos fatores grupo, sexo e interação grupo-sexo sobre os metabólitos

- Sexo feminino e níveis de metabólitos

- Sexo masculino e níveis de metabólitos

- Correlações de metabólitos do CA e escalas de sintomas

- Correlações e níveis dos metabólitos do CA e dias de uso de medicação

\subsection{OBTENÇÃO DA AMOSTRA}

Entre novembro de 2009 e fevereiro de 2011, foram entrevistados 55 pacientes com suspeita de TDM e 30 voluntários como possíveis controles saudáveis.

Dentre os pacientes avaliados, cinco foram excluídos por não preencherem os critérios diagnósticos para TDM. Três destes eram portadores de transtorno de personalidade emocionalmente instável e um apresentava episódio depressivo com sintomas psicóticos induzidos por substâncias. Outra paciente foi inicialmente diagnosticada como portadora de episódio depressivo maior, mas durante o seguimento ambulatorial apresentou delírios na ausência de episódio de humor, seguindo-se a hipótese de transtorno esquizofreniforme ou transtorno esquizoafetivo.

Dentre o restante dos pacientes diagnosticados com TDM, seis não finalizaram o protocolo de pesquisa pelas seguintes razões: não comparecimento para realização da RM (2), claustrofobia durante o exame (3), e falha de aquisição do protocolo de imagem (1).

Entre os voluntários avaliados como possíveis controles saudáveis, um deles não compareceu para realização da $\mathrm{RM}$, dois foram excluídos por pontuação na escala de 
Hamilton maior que sete pontos e antecedente de episódio depressivo, um por história familiar de primeiro grau de Transtorno Psicótico, um por história familiar de primeiro grau de Transtorno de Humor, um por preenchimento de critérios diagnósticos TEPT e um por preenchimento de critérios diagnósticos para TDM.

Após análise exploratória, posteriormente ao estudo dos outliers, optou-se por excluir três controles e dois pacientes devido a valores destoantes do restante do grupo, em torno de 2,5 a 3 D.P. Portanto, a amostra final com exame completo de RM foi constituída por 42 pacientes com TDM (22 com TDM-NP e 20 com TDM-P) e 20 controles saudáveis.

Assim, a ${ }^{1}$ H-ERM do CA foi adquirida em todos os participantes (62 sujeitos). Porém, o espectro de alguns pacientes não apresentou os pré-requisitos de qualidade (variação abaixo de $20 \%$ do valor padronizado, índice de Cramer Rao lower bound $<20 \%$ ), entre eles um paciente apresentou qualidade insuficiente de Glu e de Gln + Glu, um não obteve qualidade para todos os metabólitos e um não obteve qualidade para o Gln + Glu.

\subsection{CARACTERÍSTICAS SÓCIO-DEMOGRÁFICAS}

Os grupos TDM-P, TDM-NP e controle diferiram quanto a certos aspectos sóciodemográficos. Os grupos diferiram significativamente em relação à média de anos de escolaridade $\left(\mathrm{F}_{(2,59)}=5,86 ; \mathrm{p}=0,005\right)$. $\mathrm{O}$ grupo TDM-P apresentou uma diferença média de $4,35 \pm 1,27$ com IC $95 \%$ de 1,29 a 7,41 menor que o controle $(p=0,003)$. Não se observou diferença significativa entre TDM-P e TDM-NP, e entre TDM-NP e controle, embora o

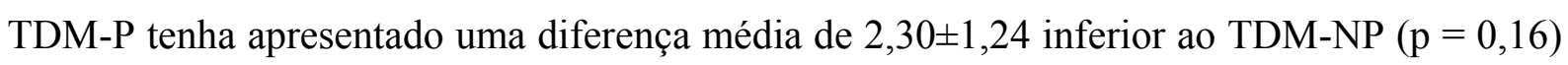
e o TDM-NP apresentou uma diferença média de $2,04 \pm 1,24(\mathrm{p}=0,23)$ em relação ao grupo controle.

Também se encontrou diferença com significância estatística entre os grupos quanto à frequência de indivíduos empregados $\left(\chi^{2}=12,16 ; \mathrm{gl}=2 ; \mathrm{p}=0,002\right)$ e à presença de filhos $\left(\chi^{2}\right.$ $=9,7 ; \mathrm{gl}=2 ; \mathrm{p}=0,008$ ), em que o TDM-P foi o grupo com menor proporção de sujeitos ativos e maior frequência de presença de filhos.

Homogeneidade entre os grupos foi observada quando analisados a idade $\left(\mathrm{F}_{(2,59)}=\right.$ $1,57 ; \mathrm{p}=0,216)$, o gênero $\left(\chi^{2}=0,78, \mathrm{gl}=2, \mathrm{p}=0,68\right)$, o estado civil $\left(\chi^{2}=1,47, \mathrm{gl}=2, \mathrm{p}=\right.$ $0,48)$ e a classe social $\left(\chi^{2}=2,5, \mathrm{gl}=4 ; \mathrm{p}=0,64\right)(\mathrm{v}$. Tabela 4$)$. 
Os três grupos ainda diferiram quanto à pontuação da $\operatorname{GAF}\left(\mathrm{F}_{(2,59)}=187,7 ; \mathrm{p}<0,001\right)$, onde o TDM-P apresentou menor média em relação ao TDM-NP $(p=0,001)$ e ao controle com significância estatística $(\mathrm{p}<0,001)$, como também a média do TDM-NP foi inferior ao controle $(\mathrm{p}<0,001)$. A pontuação da BPRS também se revelou diferente entre os grupos $\left(\mathrm{F}_{(2,59)}=66,42 ; \mathrm{p}<0,001\right)$, e o pós-teste de Tukey evidenciou superioridade da média do controle em relação ao TDM-P ( $<<0,001)$ e ao TDM-NP $(\mathrm{p}<0,001)$ e não revelou diferença entre as médias dos grupos TDM-P e TDM-NP $(\mathrm{p}=0,43)$. Por fim, a pontuação da Hamilton, tanto de $21\left(\mathrm{~F}_{(2,59)}=141,63 ; \mathrm{p}<0,001\right)$ quanto de $31\left(\mathrm{~F}_{(2,59)}=127,86 ; \mathrm{p}<0,001\right)$ itens diferiu entre os grupos. O pós-teste de Tukey não revelou diferença entre TDM-P e TDM-NP para 21 itens $(p=0,43)$ e para 31 itens $(p=0,84)$. Tanto o TDM-P quanto o TDM-NP diferiram do controle para 21 e 31 itens da mesma escala com $\mathrm{p}<0,001$ (v. Tabela 4).

Ambos os grupos TDM-P e TDM-NP apresentaram pontuação inferior a 70 na GAF, enquanto todos os controles pontuaram acima de 70 e, assim, os três grupos foram diferentes significativamente quanto ao funcionamento global $\left(\chi^{2}=62,00 ; p<0,001\right)$. Da mesma forma, quanto à frequência de pontuação da BPRS acima de 4, todos os sujeitos do grupo TDM-P e TDM-NP encontravam-se nesta categoria e diferiram estatisticamente do grupo controle onde todos, exceto um indivíduo cujos pontos foram iguais a 6 devido a sintomas ansiosos, não pontuaram acima de $4\left(\chi^{2}=57,53 ; \mathrm{p}<0,001\right)$, como também todos do grupo controle pontuaram abaixo de 7 na Hamilton (v. Tabela 4). 
Tabela 4 - Características sócio-demográficas e clínicas segundo os grupos TDM-P, TDMNP e controle.

\begin{tabular}{|c|c|c|c|c|}
\hline Características & $T D M-P(n=20)$ & $T D M-N P(n=22)$ & Controles $(n=20)$ & $p$ \\
\hline $\begin{array}{c}\text { Idade em anos } \\
\text { (média } \pm \text { E.P.) } \\
\text { (mínima e máxima) }\end{array}$ & $\begin{array}{c}42,05 \pm 2,35 \\
(22-64)\end{array}$ & $\begin{array}{c}35,50 \pm 2,94 \\
(18-59)\end{array}$ & $\begin{array}{c}37,45 \pm 2,66 \\
(21-58)\end{array}$ & 0,22 \\
\hline $\begin{array}{c}\text { Gênero: homens, } \\
\text { n }(\%)\end{array}$ & $6(30,0)$ & $5(22,73)$ & $7(35,0)$ & 0,73 \\
\hline $\begin{array}{c}\text { Escolaridade, em } \\
\text { anos (média } \pm \text { E.P.) }\end{array}$ & $7,65 \pm 0,84$ & $9,95 \pm 0,95$ & $12,00 \pm 0,84$ & 0,005 \\
\hline $\begin{array}{c}\text { Classe Social A-B, } \\
\mathrm{n}(\%)^{1}\end{array}$ & $7(35,0)$ & $7(31,81)$ & $11(55,00)$ & \\
\hline $\begin{array}{c}\text { Classe social C, } \\
\mathrm{n}(\%)\end{array}$ & $11(55,00)$ & $12(54,54)$ & $8(40,0)$ & 0,64 \\
\hline $\begin{array}{c}\text { Classe social D-E, } \\
\text { n (\%) }\end{array}$ & $1(5,0)$ & $2(9,09)$ & $1(5,0)$ & \\
\hline $\begin{array}{c}\text { Trabalhador ativo, } \\
\text { n (\%) }\end{array}$ & $11(55,0)$ & $13(59,09)$ & $20(100)$ & 0,002 \\
\hline $\begin{array}{c}\text { Estado civil, casado, } \\
\text { n (\%) }\end{array}$ & $11(55,0)$ & $8(36,4)$ & $9(45,0)$ & 0,48 \\
\hline $\begin{array}{l}\text { Participantes com } \\
\text { filhos, } \mathrm{n}(\%)\end{array}$ & $18(90,0)$ & $12(54,54)$ & $9(45,0)$ & 0,01 \\
\hline GAF, (média \pm E.P.) & $29,25 \pm 3,29$ & $48,23 \pm 1,30$ & $86,75 \pm 1,16$ & $<0,0001$ \\
\hline $\mathrm{GAF}<70, \mathrm{n}(\%)$ & $20(100)$ & $22(100)$ & 0 & $<0,0001$ \\
\hline BPRS (média \pm E.P.) & $22,75 \pm 1,88$ & $20,23 \pm 1,54$ & $1,15 \pm 0,38$ & $<0,0001$ \\
\hline $\mathrm{BPRS} \geq 5, \mathrm{n}(\%)$ & $20(100,0)$ & $22(100,0)$ & $1(5,0)^{2}$ & $<0,0001$ \\
\hline Ham 21 (média \pm E.P.) & $29,55 \pm 1,72$ & $27,23 \pm 1,45$ & $0,85 \pm 0,33$ & $<0,0001$ \\
\hline Ham 31 (média \pm E.P.) & $38,90 \pm 2,62$ & $37,41 \pm 1,86$ & $1,15 \pm 0,42$ & $<0,0001$ \\
\hline
\end{tabular}

E.P.- Erro Padrão; ANOVA de uma via seguindo-se de pós-teste de Tukey; $\chi^{2}$ de Pearson; ${ }^{1}$ não foram obtidos dados socioeconômicos de um sujeito do TDM-P e um com TDM-NP ; ${ }^{2}$ controle apresentava $\mathrm{BPRS}=6$, dos quais, 3 foram do subitem ansiedade/depressão por sintomas ansiosos 


\subsection{CARACTERÍSTICAS CLÍNICAS DOS GRUPOS TDM-P E TDM-NP}

Quanto às características clínicas exclusivas dos pacientes, houve diferenças principalmente quanto à história de suicídio e de uso de AD entre TDM-P e TDM-NP. Pacientes com TDM-P apresentaram frequência de tentativa de suicídio no episódio depressivo atual maior que TDM-NP (70\% e 45,45\%, respectivamente), embora essa diferença não tenha alcançado significância estatística $(p=0,11$; poder $=0,36)$. E embora o TDM-P tenha apresentado maior frequência de mais de 2 tentativas de suicídio na vida em relação ao TDM-NP, a diferença também não alcançou significância estatística $(p=0,09$; poder $=0,45)(v$. TABELA 5).

A frequência de uso de AD no dia do exame também foi maior no TDM-P (80\%) em relação ao TDM-NP $(54,54 \%)$, porém o poder do teste foi baixo para demonstrar a diferença com significância estatística $\left(\chi^{2}=3,055 ; \mathrm{p}=0,08\right.$; poder $\left.=0,41\right)$. Por fim, o TDM-P também apresentou maior média de tempo de uso de ADs em relação ao TDM-NP, sendo a diferença média de $318 \pm 188,232$ dias, com IC de -79,076 a 715,998, novamente sem significância estatística $\left(\mathrm{t}_{(1,33)}=1,692 ; \mathrm{p}=0,11\right)(\mathrm{v}$. TABELA 5).

Por outro lado, os grupos de pacientes apresentaram semelhança quanto à frequência de episódios depressivos atuais crônicos (DSM-IV-RT $\geq 2$ anos) (Teste Exato de Fisher, $\mathrm{p}=$ 0,20), frequência de número de episódios depressivos em vida (Teste Exato de Fisher, $\mathrm{p}=$ $0,90)$, idade de início do transtorno depressivo $\left(\mathrm{t}_{(1,40)}=1,30 ; \mathrm{p}=0,20\right)$, frequência de comorbidade psiquiátrica $\left(\chi^{2}=0,83 ; \mathrm{p}=0,36\right)$, frequência de comorbidade clínica $\left(\chi^{2}=\right.$ $0,087 ; \mathrm{p}=0,77)$ e frequência de história familiar de transtorno do humor e/ou psicótico (Teste Exato de Fisher, $\mathrm{p}=0,72)$ (v. TABELA 5).

O episódio atual de depressão dos pacientes foi avaliado quanto a características melancólicas e atípicas. Verificou-se maior frequência de características melancólicas segundo a escala de Hamilton e critérios do DSM-III-TR no grupo TDM-P, porém sem alcançar significância estatística $\left(\chi^{2}=3,43, p=0,6\right)$. A frequência de características atípicas segundo DSM-IV também não apresentou diferença entre os grupos $\left(\chi^{2}=2,96, p=0,8\right)$. Ambos os grupos apresentaram pacientes em que não havia predominância nem de características melancólicas nem de atípicas, sem diferença de frequência entre eles $\left(\chi^{2}=0,24\right.$, $\mathrm{p}=0,62)$. Considerando-se todas as características, não houve diferença da distribuição das mesmas entre os grupos (Teste Exato de Fisher, $p=0,13$ ) (v. TABELA 5).

A gravidade da depressão, segundo a pontuação da Hamilton, foi semelhante entre os grupos de pacientes. Esse dado foi encontrado tanto quando utilizada a escala com 31 itens, como visto acima (Tabela 4), como também não houve diferença quando comparadas categorias de gravidade (Teste Exato de Fisher, $p=0,1$ ) (v. TABELA 5). 
A média da pontuação geral da BPRS foi semelhante entre os dois grupos $\left(\mathrm{t}_{(1,40)}=\right.$ $1,04 ; \mathrm{p}=0,30)$, conforme já descrito acima e na Tabela 4. No entanto, quando analisamos as subescalas de sintomas, observamos que à pontuação da sub-escala "pensamento", o TDM-P apresentou média de pontuação maior $\left(\mathrm{t}_{(1,40)}=3,665 ; \mathrm{p}=0,001\right.$ com diferença média de 3,286 $\pm 0,897$ e IC 95\% de 1,479 a 5,094), enquanto em relação à sub-escala "ativação" da BPRS, apresentaram tendência à menor pontuação $\left(\mathrm{t}_{(1,40)}=-1,76 ; \mathrm{p}=0,09\right.$, com diferença média de $0,909 \pm 0,511$ e IC $95 \%$ de $-0,125$ a 1,943) (v. TABELA 5).

Tabela 5 - Características clínicas dos grupos TDM-P e TDM-NP (continua)

\begin{tabular}{|c|c|c|c|}
\hline Características & $T D M-P(n=20)$ & $T D M-N P(n=22)$ & $p$ \\
\hline \multicolumn{4}{|l|}{$\begin{array}{l}\text { Número de tentativas de suicídio na } \\
\qquad \text { vida, } \mathrm{n}(\%)^{1}\end{array}$} \\
\hline 1 & $5(27,8)$ & $11(57,9)$ & 0,09 \\
\hline 2 & $8(44,4)$ & $7(36,8)$ & \\
\hline 3 & $5(27,8)$ & $1(5,3)$ & \\
\hline Tentativa de suicídio atual, n (\%) & $14(70)$ & $10(45,45)$ & 0,11 \\
\hline $\begin{array}{l}\text { Duração do episódio depressivo } \\
\text { atual (em meses) (média } \pm \text { E.P.) }\end{array}$ & $25,66 \pm 9,82$ & $10,38 \pm 2,70$ & 0,15 \\
\hline ED atual crônico, n (\%) & $6(30)$ & $3(13,63)$ & 0,20 \\
\hline $\begin{array}{l}\text { Idade de início do TDM, em anos } \\
\text { (média } \pm \text { E.P.) }\end{array}$ & $35,65 \pm 2,49$ & $30,27 \pm 3,22$ & 0,20 \\
\hline \multicolumn{4}{|l|}{$\begin{array}{c}\text { Número de episódios depressivos na } \\
\text { vida, } \mathrm{n}(\%)^{2}\end{array}$} \\
\hline 1 & $13(65)$ & $13(59,09)$ & 0,90 \\
\hline 2 & $3(15)$ & $5(22,73)$ & \\
\hline$\geq 3$ & $2(10)$ & $3(13,63)$ & \\
\hline $\begin{array}{l}\text { TDM com critérios para melancolia, } \\
\qquad \mathrm{n}(\%)\end{array}$ & $13(65)$ & $8(36.37)$ & 0,13 \\
\hline $\begin{array}{l}\text { TDM com critérios para atipia, } \mathrm{n} \\
(\%)\end{array}$ & $2(10)$ & $7(31,82)$ & \\
\hline $\begin{array}{c}\text { TDM sem critérios para melancolia } \\
\text { ou atipia, } \mathrm{n}(\%)\end{array}$ & $5(25)$ & $6(27,27)$ & \\
\hline $\begin{array}{c}\text { Familiar } 1^{\circ} \text {. grau com T. Humor ou } \\
\text { T. Psicótico, n }(\%)\end{array}$ & $13(60)$ & $13(59,09)$ & 0,72 \\
\hline $\begin{array}{l}\text { Comorbidade psiquiátrica presente } \\
\text { (eixo I), n (\%) }\end{array}$ & $9(45)$ & $13(59,09)$ & 0,36 \\
\hline Comorbidade clínica presente, $\mathrm{n}(\%)$ & $10(50)$ & $12(54,54)$ & 0,77 \\
\hline
\end{tabular}


Tabela 5 - Características clínicas dos grupos TDM-P e TDM-NP (conclusão)

\begin{tabular}{|c|c|c|c|}
\hline Características & $T D M-P(n=20)$ & $T D M-N P(n=22)$ & $p$ \\
\hline $\begin{array}{l}\text { Em tratamento com AD no dia do } \\
\text { exame } n,(\%)\end{array}$ & $16(80)$ & $12(54,54)$ & 0,08 \\
\hline $\begin{array}{c}\text { Exposição à } \mathrm{AD} \text { (em dias) (mediana, } \\
\text { percentil } 25 \text { e } 75)\end{array}$ & $25(5-515)$ & $15(0-90)$ & 0,11 \\
\hline \multicolumn{4}{|l|}{ Gravidade da depressão (intervalos } \\
\hline \multicolumn{4}{|l|}{ de pontuação da Hamilton) } \\
\hline Leve $(8-14)(\%)$ & 0 & 0 & 0,10 \\
\hline Moderada (15-21) (\%) & $3(14,28)$ & 0 & \\
\hline Grave $(>21)(\%)$ & $17(85,71)$ & $22(100)$ & \\
\hline $\begin{array}{l}\text { BPRS Ansiedade/depressão } \\
\text { (média } \pm \text { E.P.) }\end{array}$ & $8,40 \pm 0,71$ & $9,00 \pm 0,58$ & 0,51 \\
\hline $\begin{array}{l}\text { BPRS Pensamento } \\
\text { (média } \pm \text { E.P.) }\end{array}$ & $7,15 \pm 0,67$ & $3,86 \pm 0,60$ & 0,001 \\
\hline BPRS Negativa (média \pm E.P.) & $5,75 \pm 0,86$ & $4,95 \pm 0,60$ & 0,45 \\
\hline BPRS Ativação (média \pm E.P.) & $1,50 \pm 0,32$ & $2,41 \pm 0,40$ & 0,09 \\
\hline
\end{tabular}

Teste "t" de Student; $\chi^{2}$ de Pearson; GAF: Escala de avaliação global analisado pelo teste de Mann-Whitney devido à não-normalidade dos dados; BPRS: Escala de Avaliação Psiquiátrica Breve; Hamilton: Escala de Hamilton para 21 e 31 itens; E.P.: Erro-padrão. ${ }^{1}$ pacientes não souberam precisar o número de tentativas de suicídio ( 2 do TDM-P e 3 do TDM-NP). ${ }^{2}$ não houve precisão do número de ED para 2 sujeitos TDM-P e 1 sujeito TDM-NP

Em relação aos sintomas psicóticos, delírios foram identificados em 19 pacientes (95\%) e alucinações em 14 (70\%) do grupo TDM-P. Cinco pacientes apresentaram apenas delírios (25\%), um paciente apresentou apenas alucinações $(5 \%)$ e $13(65 \%)$ a associação de delírios e alucinações. Dentre os delírios, o mais frequente foi o incongruente com o humor, apresentando-se em 17 pacientes (85\%), sendo o do tipo persecutório em 11 indivíduos (55\%), de referência em 5 indivíduos (25\%), místico-religioso em 3 indivíduos (15\%), um de ciúme $(5 \%)$ e bizarro em dois $(10 \%)$. Dentre os congruentes com o humor, obtiveram-se delírios de ruína (15\%), de culpa (15\%), hipocondríaco (15\%) e somático (10\%). Quanto aos tipos de alucinações, houve predomínio de alucinações auditivas (64,28\%), seguidas por visuais $(57,71 \%)$, táteis $(35,71 \%)$ e olfativas $(21,42 \%)$ (v. TABELA 6$)$.

Comorbidades psiquiátricas foram encontradas em 8 pacientes com TDM-P e em 14 dos TDM-NP, cuja diferença de frequência não alcançou significância estatística $\left(\chi^{2}=0,834\right.$; 
$p=0,361)$. Na tabela 6 estão descritas os tipos e as respectivas frequências de comorbidades psiquiátricas encontradas nos subgrupos de TDM.

Entre os pacientes com comorbidades psiquiátricas, 12 apresentavam mais de um tipo associado e 13 apenas um tipo de comorbidade. As associações encontradas foram: TEPT e Transtorno do Pânico (3 indivíduos); TEPT e Fobias (2 indivíduos); TOC e Transtorno do Pânico (1 indivíduo); TEPT e Transtorno Somatoforme do tipo doloroso (1 indivíduo) (v. TABELA 6).

Avaliou-se a presença de comorbidades clínicas no grupo de pacientes e controles. Verificou-se que 22 participantes apresentaram comorbidade clínica, sendo 10 de TDM-P, 12 de TDM-NP e nenhum do grupo controle. As comorbidades encontradas foram: hipertensão arterial sistêmica, cefaleia, gastrite, dor crônica, obesidade, osteoporose, diabetes mellitus, dislipidemia, asma e zumbido. 
Tabela 6 - Comorbidades psiquiátricas e sintomas psicóticos dos grupos TDM-P e TDM-NP.

\begin{tabular}{|c|c|c|}
\hline Caracteristicas & $T D M-P(n=20)$ & $T D M-N P(n=22)$ \\
\hline $\begin{array}{c}\text { Presença de comorbidades } \\
\text { psiquiátricas, } \mathrm{n}(\%)\end{array}$ & $8(40)$ & $14(63,63)$ \\
\hline Fobias, n (\%) & $1(5,0)$ & $4(18,2)$ \\
\hline Abuso ou dependência de álcool, n (\%) & $3(15,0)$ & $2(9,1)$ \\
\hline TAG, n (\%) & 0 & $2(9,1)$ \\
\hline TEPT, n (\%) & 0 & $1(4,5)$ \\
\hline TOC, n (\%) & 0 & $1(4,5)$ \\
\hline Bulimia & 0 & $1(4,5)$ \\
\hline TEPT + T. Pânico & $1(5,0)$ & $2(9,1)$ \\
\hline TEPT + Fobias & $1(5,0)$ & $1(4,5)$ \\
\hline TOC + Pânico & $1(5,0)$ & 0 \\
\hline TEPT + T. Somatoforme & $1(5,0)$ & 0 \\
\hline \multicolumn{3}{|l|}{ Sintomas psicóticos } \\
\hline Delírios, $\mathrm{n}$ total $(\%)$ & $19(95)$ & NA \\
\hline Delírio isolado, n (\%) & $5(25)$ & \\
\hline Associado à alucinação, n (\%) & $14(70)$ & \\
\hline Persecutório, n (\%) & $11(55)$ & \\
\hline Referência, n (\%) & $5(25)$ & \\
\hline Culpa, n (\%) & $3(15)$ & \\
\hline Somático, n (\%) & $3(15)$ & \\
\hline Hipocondríaco, n (\%) & $3(15)$ & \\
\hline Místico-religioso, n (\%) & $3(15)$ & \\
\hline Ruína, n (\%) & $2(10)$ & \\
\hline Bizarro, n (\%) & $2(10)$ & \\
\hline Ciúme, n (\%) & $1(5)$ & \\
\hline Alucinações, $\mathrm{n}$ total (\%) & $14(70)$ & NA \\
\hline Alucinação isolada, n (\%) & $1(5)$ & \\
\hline Associada a delírio, n (\%) & $13(65)$ & \\
\hline Auditivas, n (\%) & $9(45)$ & \\
\hline Visuais, $\mathrm{n}(\%)$ & $8(40)$ & \\
\hline Táteis, n (\%) & $5(25)$ & \\
\hline Olfativas, n (\%) & $3(15)$ & \\
\hline
\end{tabular}

TAG: Transtorno de ansiedade generalizada; TOC: Transtorno obsessivo-compulsivo; TEPT: Transtorno de estresse pós-traumático; T. Pânico: Transtorno do pânico 
Em relação ao tratamento, 32 pacientes estavam em uso de medicação no dia da ${ }^{1} \mathrm{H}$ ERM (76,19\%). As mais frequentemente utilizadas ao exame foram: ADs $(87,5 \%)$, BZD $(71,87 \%)$, AP $(31,25 \%)$ e outras classes de psicotrópicos $(3,12 \%)$. O uso de medicação nos subgrupos de pacientes está detalhado na Tabela 7.

O tratamento farmacológico utilizado pelos 42 pacientes era tanto monoterápico $(31,25 \%)$ quanto politerápico (68,75\%). A monoterapia foi encontrada em 5 dos 20 pacientes com TDM-P (25\%) e 5 dos 22 com TDM-NP (22,73\%), enquanto a politerapia em 14 dos TDM-P (70\%) e em 8 dos TDM-NP (36,36\%).

Em relação ao uso de $\mathrm{AD}, 16$ dos deprimidos psicóticos (80\%) e 12 dos não-psicóticos $(54,5 \%)$ encontravam-se nessa situação e assim se verificou uma tendência de maior frequência de uso dessa classe de medicação pelos pacientes com psicose $\left(\chi^{2}=3,05 ; p=0,08\right)$ (v. TABELA 7).

No dia da ${ }^{1} \mathrm{H}$-ERM, 11 dos pacientes com TDM-P estavam em uso de AP (55\%) e o tempo médio de uso era de 7,73 $\pm 6,72$ dias. Nenhum paciente com TDM-NP estava em uso de AP (v. TABELA 7).

À ${ }^{1}$ H-ERM, 14 dos TDM-P (70\%) e 10 dos TDM-NP (45,45\%) estavam em uso de benzodiazepínicos (BZD) (v. TABELA 7), o que não foi estatisticamente significativo $\left(\chi^{2}=\right.$ $2,58 ; \mathrm{p}=0,11)$. Quanto ao tempo de uso de BZD, também não se obteve diferença entre os grupos $\left(\mathrm{F}_{(1,22)}=0,978 ; \mathrm{p}=0,33\right)$.

O único paciente em uso de outras classes de psicotrópicos ao exame tinha diagnóstico de TDM-NP e estava em uso de carbamazepina há 60 dias (v. TABELA 7).

Tabela 7- Tratamento medicamentoso dos grupos TDM-P e TDM-NP

\begin{tabular}{lccc}
\hline \multicolumn{1}{c}{ Tratamento } & $T D M-P(n=20)$ & $T D M-N P(n=22)$ & $p$ \\
\hline AD, n (\%) & $16(80)$ & $12(54,5)$ & 0,08 \\
ISRS, n (\%) & $15(75)$ & $8(36,36)$ & \\
IRNS, n (\%) & $1(5)$ & $1(4,54)$ & \\
Tricíclicos, n (\%) & 0 & $1(4,54)$ & \\
ISRS + Tricíclico, n (\%) & 0 & $1(4,54)$ & - \\
Trazodona (antagonista 5HT $2 \mathrm{~A})$ & 0 & $1(4,54)$ & \\
AP, n (\%) & $11(55)$ & 0 & 0,11 \\
AP Típicos, n (\%) & $7(35)$ & 0 & - \\
AP Atípicos, n (\%) & $4(20)$ & 0 & \\
BZD, n (\%) & $14(70)$ & $10(45,45)$ & \\
Carbamazepina, n (\%) & 0 & $(4,54)$ & \\
\hline$\chi^{2}$ de Pearson. AD: Antidepressivo; AP: Antipsicótico; BZD: Benzodiazepínico; ISRS: Inibidor \\
seletivo da recaptura da serotonina; IRNS: Inibidore seletivo da recaptura da noradrenalina e da \\
serotonina; 5 HT ${ }_{2 \mathrm{~A}}$ : Receptor de serotonina tipo 2A.
\end{tabular}


5.4 RESULTADOS DAS ANÁLISES DE NÍVEIS DE METABÓLITOS DO CA POR ${ }^{1} \mathrm{H}-$ ERM

\subsubsection{Correlações entre metabólitos e idade entre si}

A maioria das variáveis metabólicas e a idade encontraram-se correlacionadas entre si com significância estatística (v. TABELA 8). Os níveis de PC+GPC e Cr correlacionaram-se moderadamente com a idade com sentido positivo (com ' $p$ ' respectivamente de 0,03 e 0,05 ). Os níveis de Glu se correlacionaram positivamente e com forte intensidade aos de Gln+Glu (conforme esperado) e moderadamente aos de NAA+NAAG de forma positiva (com $\mathrm{p}<$ 0,001 em ambas as estatísticas). Posteriormente, os níveis de Glu se correlacionaram com os de PC+GPC ( $\mathrm{p}=0,001)$ e de $\mathrm{Cr}(\mathrm{p}=0,05)$ ambas de forma positiva e fraca intensidade.

Os níveis de Gln+Glu também se correlacionaram positivamente e com intensidade moderada aos de NAA+NAAG $(\mathrm{p}=0,002)$ e fraca intensidade com os de PC+GPC $(\mathrm{p}=$ $0,025)$ e de $\mathrm{Cr}(\mathrm{p}=0,035)$. Os níveis de NAA+NAAG também se correlacionaram positivamente e com intensidade fraca aos de PC+GPC $(p=0,03)$ e de $\mathrm{Cr}(\mathrm{p}=0,005)$.

Por fim, os níveis de Cr apresentaram correlação positiva com os de $\mathrm{PC}+\mathrm{GPC}(\mathrm{p}=$ $0,008)$ e de Myo $(p=0,005)$ ambas com intensidade fraca.

Diante da presença de correlação significativa entre a maioria das variáveis metabólicas e dessas com a idade, procedeu-se a escolha da "Maior Raiz de Roy" da MANOVA para a obtenção da significância dos resultados a seguir. 
Tabela 8 - Correlações bivariadas das variáveis idade e metabólitos e de metabólitos entre si com significância estatística

\begin{tabular}{ccc}
\hline Variáveis & $r$ & $p$ \\
\hline Idade vs PC+GPC & 0,279 & 0,03 \\
Idade vs Cr & 0,255 & 0,05 \\
Glu vs Gln + Glu & 0,871 & $<0,001$ \\
Glu vs NAA+NAAG & 0,452 & $<0,001$ \\
Glu vs PC+GPC & 0,429 & 0,001 \\
Glu vs Cr & 0,359 & 0,005 \\
Gln+Glu vs NAA+NAAG & 0,402 & 0,002 \\
Gln + Glu vs PC+GPC & 0,292 & 0,02 \\
Gln + Glu vs Cr & 0,275 & 0,03 \\
NAA+NAAG vs Myo & 0,256 & 0,04 \\
NAA+NAAG vs PC+GPC & 0,276 & 0,03 \\
NAA+NAAG vs Cr & 0,352 & 0,005 \\
Cr vs PC+GPC & 0,334 & 0,01 \\
Cr vs Myo & 0,357 & 0,005
\end{tabular}

r: Correlação de Pearson; Glu: glutamato; Gln+Glu: glutamina+glutamato; NAA+NAAG: Nacetil-aspartato $+\mathrm{N}$-acetil-Aspartato- Glutamato; Myo: mio-inositol; PC+GPC: fosforilcolina + glicerol-fosforil colina + colina; Cr: creatina

\subsubsection{Efeito dos fatores grupo, sexo e interação grupo-sexo sobre os metabólitos}

Posteriormente, foi aplicada a MANOVA para avaliar se o fator diagnóstico e o sexo tiveram efeito significativo sobre a composição multivariada das variáveis neuroquímicas do CA, utilizando ainda a idade como covariável. A MANOVA revelou que o fator diagnóstico teve efeito significativo sobre o conjunto das variáveis neuroquímicas relacionadas ao $\mathrm{CA}$ (Maior Raiz de Roy $=0,394 ; \mathrm{F}_{(6 ; 48)}=3,149 ; \mathrm{p}=0,011$; efeito de elevada dimensão $\eta_{\mathrm{p}}{ }^{2}=0,282$; poder observado $=0,883$ ).

Com relação ao fator sexo, foi observado um efeito de média dimensão, porém sem significância estatística sobre a composição das variáveis metabólicas (Maior Raiz de Roy = 0,$268 ; \mathrm{F}_{(6 ; 47)}=2,101 ; \mathrm{p}=0,071 ; \eta_{\mathrm{p}}{ }^{2}=0,211 ;$ poder observado $\left.=0,696\right)$. 
Foi observado efeito de média dimensão e sem significância estatística para a interação entre diagnóstico e sexo (diferença de variação entre masculino e feminino para os grupos) (Maior Raiz de Roy $=0,228 ; \mathrm{F}_{(6 ; 48)}=1,822 ; \mathrm{p}=0,115 ; \eta_{\mathrm{p}}{ }^{2}=0,186$; poder observado $=0,624)$.

Observou-se ainda uma influência da idade nas variáveis neuroquímicas, mas não alcançou significância estatística (Maior Raiz de Roy $=0,224 ; F_{(6 ; 47)}=1,752 ; p=0,130$; com média dimensão de efeito $\eta_{\mathrm{p}}{ }^{2}=0,183$; poder observado $\left.=0,602\right)$.

A reduzida potência do teste e a dimensão da amostra podem ser fatores responsáveis pela falta de significância estatística na avaliação da influência do sexo, da interação gruposexo e da idade.

Observada significância multivariada no fator grupo, procedeu-se à ANOVA univariada para cada uma das variáveis dependentes do CA (v. TABELAS 9 e 10, GRÁFICOS 1, 2 e 3 e FIGURA 6).

As médias dos grupos diagnósticos diferiram entre si para o Glu $(\mathrm{p}=0,023$ com média dimensão do efeito $\eta_{\mathrm{p}}{ }^{2}=0,135$ e poder observado $\left.=0,699\right)$. O grupo TDM-P apresentou média de Glu inferior ao TDM-NP $(\mathrm{p}=0,012)$, sendo a diferença média entre eles de 1,762 $\pm 0,678$ e IC 95\% de 0,402 a 3,121. A média de Glu do TDM-P também diferiu do controle $(\mathrm{p}=0,021)$ com diferença média de 1,501 $\pm 0,628$ e IC 95\% de 0,240 a 2,762. Ainda, o TDM-NP não diferiu do controle quanto à média do Glu $(\mathrm{p}=0,680)(\mathrm{v}$. TABELA 9 e 10, GRÁFICO 1 e FIGURA 6).

Da mesma forma, a média de PC+GPC do CA diferiu entre os grupos $(\mathrm{p}=0,003 \mathrm{com}$ média dimensão do efeito $\eta_{\mathrm{p}}{ }^{2}=0,205$ e poder observado $\left.=0,901\right)$, onde o grupo TDM-P apresentou média inferior ao grupo TDM-NP $(\mathrm{p}=0,023)$ com diferença média de $0,171 \pm$ 0,073 e IC 95\% de 0,024 a 0,318. As médias de PC+GPC do TDM-P e do TDM-NP não diferiram do controle ( $p=0,111$ e $p=0,271$, respectivamente) (v. Tabelas 9 e 10, GRÁFICO 2 e FIGURA 6).

A média de NAA+NAAG diferiu entre os grupos, porém sem alcançar significância estatística (nível de tendência, com $\mathrm{p}=0,075$; com média dimensão do efeito $\eta_{\mathrm{p}}{ }^{2}=0,095$ e poder observado $=0,516)$. A média deste metabólito do grupo TDM-P apresentou média menor que o controle $(\mathrm{p}=0,029)$ com diferença média de $0,372 \pm 0,166$ e IC 95\% de 0,039 a 0,705, mas não diferiu do TDM-NP $(\mathrm{p}=0,085)$. Este último também não diferiu do controle $(\mathrm{p}=0,731)(\mathrm{v}$. Tabelas 9 e 10, GRÁFICO 3 e FIGURA 6). 
Tabela 9 - Distribuição das médias e E.P. dos metabólitos do CA entre os grupos TDM-P, TDM-NP e controle

\begin{tabular}{ccccccc}
\hline $\begin{array}{c}\text { Metabólitos } \\
\text { do } C A\end{array}$ & $\begin{array}{c}\text { TDM-P } \\
(n=20)\end{array}$ & $\begin{array}{c}\text { TDM-NP } \\
(n=22)\end{array}$ & $\begin{array}{c}\text { Controle } \\
(n=20)\end{array}$ & $p$ & $\eta_{p}{ }^{2}$ & Poder \\
\hline Glu & $6,911 \pm 0,460$ & $8,672 \pm 0,473$ & $8,411 \pm 0,421$ & $\mathbf{0 , 0 2 3}$ & $\mathbf{0 , 1 3 5}$ & $\mathbf{0 , 6 9 9}$ \\
Gln+Glu & $8,152 \pm 0,483$ & $9,492 \pm 0,497$ & $9,040 \pm 0,443$ & 0,168 & 0,066 & 0,368 \\
NAA+NAAG & $5,966 \pm 0,121$ & $6,281 \pm 0,125$ & $6,338 \pm 0,111$ & $\mathbf{0 , 0 7 5}$ & $\mathbf{0 , 0 9 5}$ & $\mathbf{0 , 5 1 6}$ \\
Myo & $6,471 \pm 0,413$ & $6,636 \pm 0,425$ & $6,577 \pm 0,378$ & 0,963 & 0,001 & 0,055 \\
PC+GPC & $1,497 \pm 0,050$ & $1,668 \pm 0,051$ & $1,744 \pm 0,045$ & $\mathbf{0 , 0 0 3}$ & $\mathbf{0 , 2 0 5}$ & $\mathbf{0 , 9 0 1}$ \\
Cr & $5,656 \pm 0,223$ & $5,581 \pm 0,229$ & $5,804 \pm 0,204$ & 0,752 & 0,011 & 0,093 \\
\hline
\end{tabular}

Média \pm E.P. (Erro Padrão) em mmol/Kg; Teste ANOVA; Médias ajustadas para a idade; $\eta_{p}{ }^{2}:$ Eta parcial; TDM-P: Transtorno depressivo maior com sintomas psicóticos; TDM-NP: Transtorno depressivo maior sem sintomas psicóticos; Glu: glutamato; Gln+Glu: glutamina+glutamato; NAA+NAAG: N-acetil-D-aspartato + N-acetil-D-Aspartato- Glutamato; Myo: mio-inositol; PC+GPC: fosforilcolina + glicerol-fosforil colina + colina; Cr: creatina

Tabela 10 - Distribuição das diferenças médias e E.P. dos metabólitos do CA entre os grupos TDM-P, TDM-NP e controle

\begin{tabular}{cccc}
\hline Metabólitos do $C A$ & Diferença média $\pm E P$ & $I C$ 95\% & $p$ \\
\hline Glu & & & \\
TDM-NP vs TDM-P & $1,762 \pm 0,678$ & 0,402 a 3,121 & 0,012 \\
Controle vs TDM-P & $1,501 \pm 0,628$ & 0,240 a 2,762 & 0,021 \\
NAA-NAAG & & & \\
TDM-NP vs TDM-P & $0,315 \pm 0,179$ & $-0,044$ a 0,674 & 0,085 \\
Controle vs TDM-P & $0,372 \pm 0,166$ & 0,039 a 0,705 & 0,029 \\
PC+GPC & & & \\
TDM-NP vs TDM-P & $0,171 \pm 0,073$ & $-0,01$ a 0,353 & 0,069 \\
Controle vs TDM-P & $0,247 \pm 0,068$ & 0,079 a 0,415 & 0,002
\end{tabular}

Diferença média \pm EP (Erro Padrão) em mmol/Kg; CA: Cíngulo anterior; IC: Intervalo de confiança. Teste ANOVA seguido de pós-teste de Tukey; TDM-P: Transtorno depressivo maior com sintomas psicóticos; TDM-NP: Transtorno depressivo maior sem sintomas psicóticos; Glu: glutamato; NAA+NAAG: N-acetil-aspartato $+\mathrm{N}$-acetil-Aspartato- Glutamato; $\mathrm{PC}+\mathrm{GPC}$ : fosforilcolina + glicerol-fosforil colina + colina 
No gráfico 1 a seguir ilustra-se a redução dos níveis de Glu do CA do TDM-P em relação aos demais grupos.

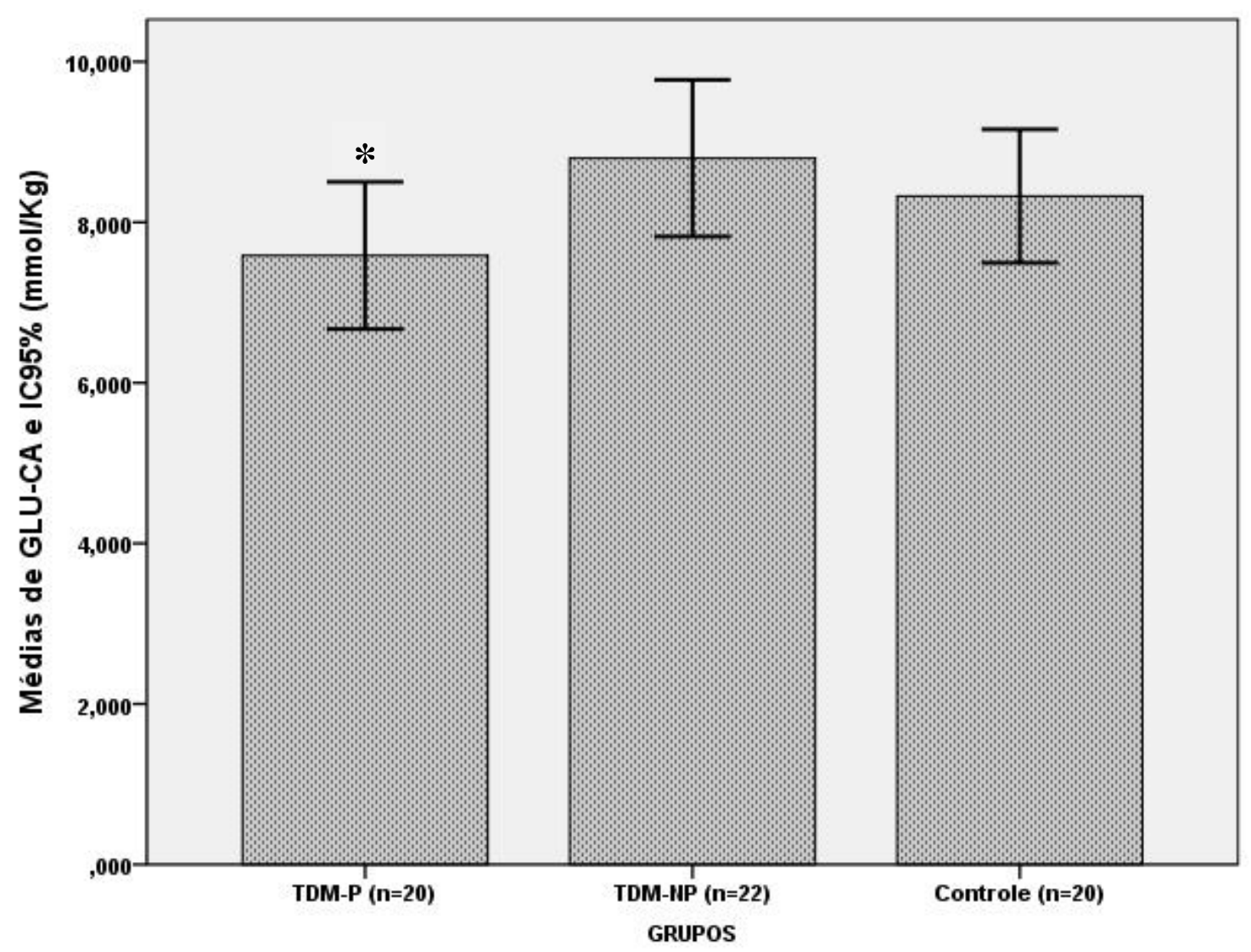

Gráfico 1: Distribuição das médias e EP dos metabólitos do CA entre os grupos TDM-P, TDM-NP e controle, evidenciando menores níveis de Glu para o TDM-P em relação aos demais grupos $(* p=0,023)$ TDM-P: Transtorno depressivo maior com sintomas psicóticos; TDM-NP: Transtorno depressivo maior sem sintomas psicóticos; Glu: glutamato 
No gráfico 2 a seguir ilustra-se os menores níveis de PC+GPC do CA do TDM-P em relação ao TDM-NP e ao controle (v. Gráfico 2).

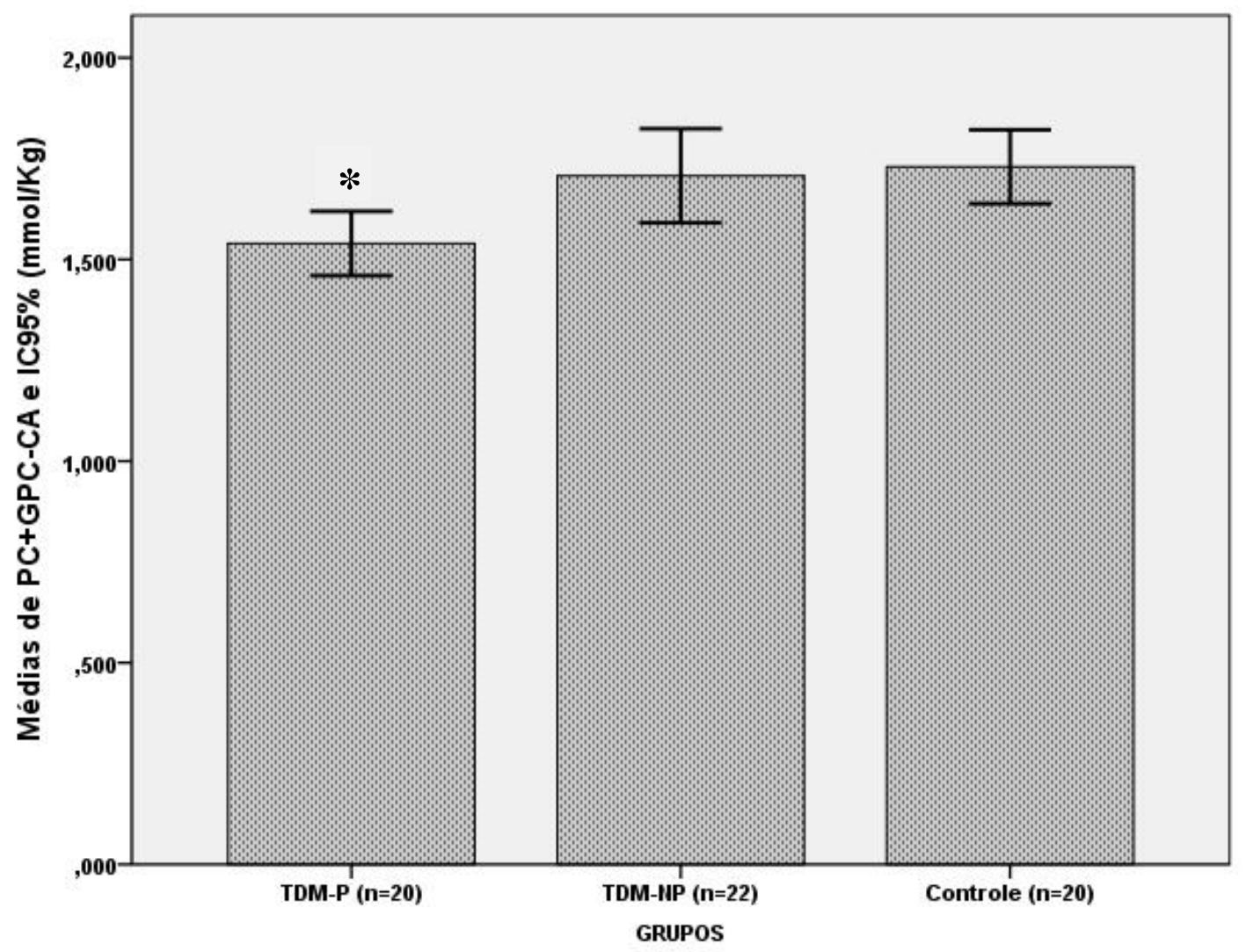

Gráfico 2: Distribuição das médias e EP dos metabólitos do CA entre os grupos TDM-P, TDM-NP e controle, evidenciando menores níveis de PC+GPC para o TDM-P em relação aos demais grupos $(* p=0,003)$. TDM-P: Transtorno depressivo maior com sintomas psicóticos; TDM-NP: Transtorno depressivo maior sem sintomas psicóticos; PC+GPC: fosforilcolina + glicerol-fosforil colina + colina 
No gráfico 3 a seguir ilustra-se os menores níveis de NAA+NAAG do CA do TDM-P em relação ao TDM-NP e ao controle, porém sem alcançar significância estatística (v. GRÁFICO 3).

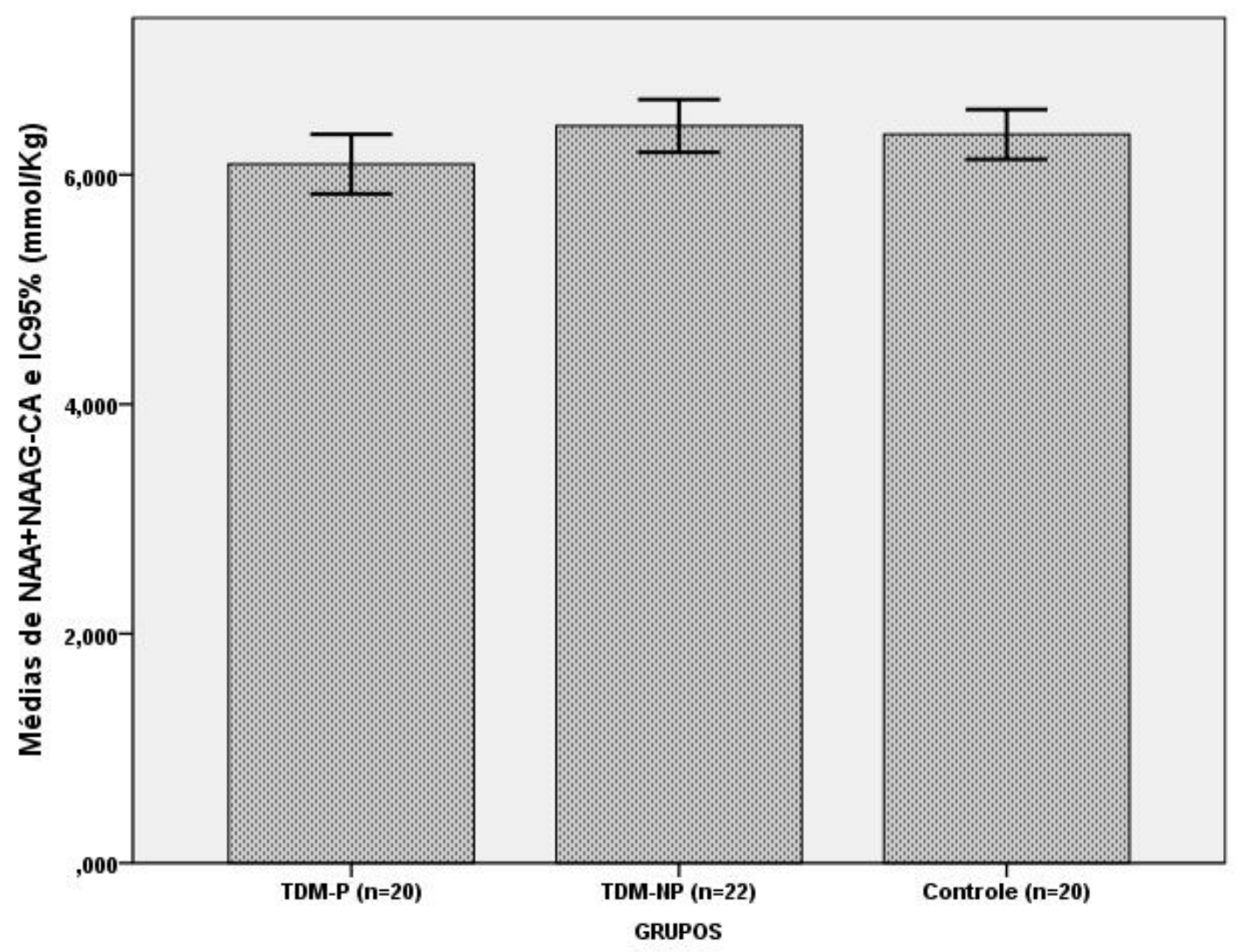

Gráfico 3: Distribuição das médias e EP dos metabólitos do CA entre os grupos TDM-P, TDM-NP e controle, evidenciando menores níveis de NAA+NAAG para o TDM-P em relação aos demais grupos sem significância estatística $(p=0,075)$. TDM-P: Transtorno depressivo maior com sintomas psicóticos; TDM-NP: Transtorno depressivo maior sem sintomas psicóticos; NAA+NAAG- N-acetil-aspartato+ N-acetil-aspartato+ glutamato. 
Na figura 6 a seguir é apresentado o espectro do CA de um paciente com TDM-P, em que pode ser observada redução de valores de picos de Glu, NAA+NAAG e PC+GPC (para fins de ilustração, apenas).

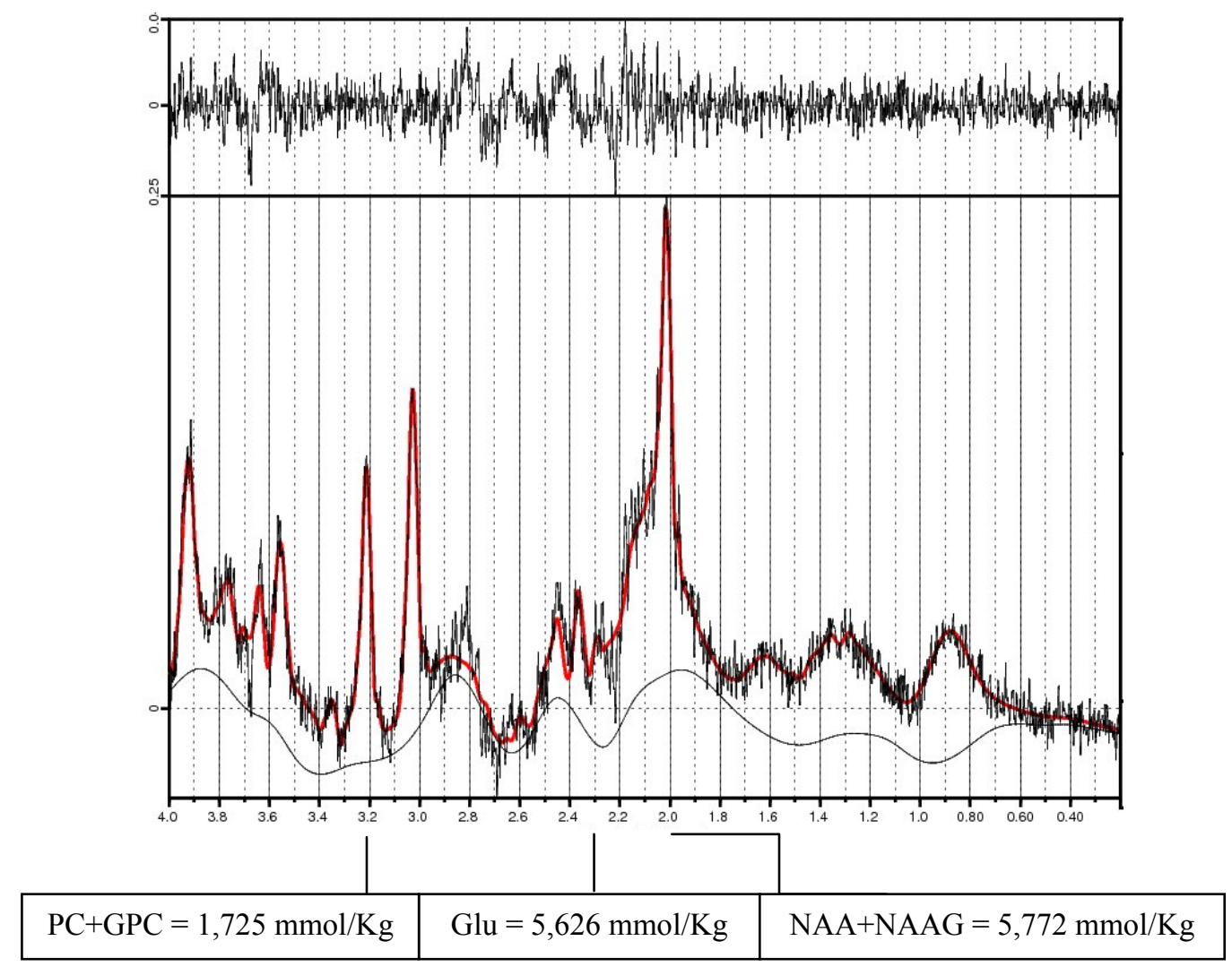

Figura 6: Espectro de paciente TDM-P com redução do pico de Glu, PC+GPC e NAA+NAAG.

As médias dos demais metabólitos do $\mathrm{CA}$ ( $\mathrm{Gln}+\mathrm{Glu}$, Myo e $\mathrm{Cr}$ ) não diferiram significativamente entre os grupos e apresentaram baixa dimensão de efeito e poder observado nas estatísticas relacionadas.

Considerando o efeito médio observado na análise multivariada para o fator sexo e o poder encontrado de 0,696 , optou-se por efetuar a ANOVA univariada para cada uma das variáveis dependentes do CA para esse fator, considerando-se todos os participantes (v. TABELAS 11 e 12 e FIGURA 7).

O sexo masculino apresentou média de Glu inferior ao feminino ( $\mathrm{p}=0,015$; com média dimensão do efeito $\eta_{\mathrm{p}}{ }^{2}=0,108$; poder observado $\left.=0,693\right)$, sendo a diferença média de $1,282 \pm 0,511$ e IC $95 \%$ de 0,257 a 2,307 (v. TABELA 11 e 12). 
De forma semelhante, a média do NAA + NAAG do sexo masculino foi inferior ao feminino ( $\mathrm{p}=0,014$, com média dimensão de efeito $\eta_{\mathrm{p}}{ }^{2}=0,111$; poder observado $=0,704$ ), sendo a diferença média de $0,343 \pm 0,135$ e IC 95\% de 0,072 a 0,614 (v. TABELA11 e 12).As médias de Gln+Glu, Myo, PC+GPC e Cr do sexo masculino foram inferiores em relação ao feminino, porém as diferenças não alcançaram significância estatística (v. Tabelas 11 e 12).

Tabela 11 - Distribuição das médias e E.P. dos metabólitos do CA entre os sexos

\begin{tabular}{cccccc}
\hline $\begin{array}{c}\text { Metabólitos do } \\
\text { CA }\end{array}$ & $\begin{array}{c}\text { Masculino } \\
(n=18)\end{array}$ & $\begin{array}{c}\text { Feminino } \\
(n=44)\end{array}$ & $p$ & $\eta_{p}{ }^{2}$ & Poder \\
\hline Glu & $7,583 \pm 0,436$ & $8,639 \pm 0,294$ & $\mathbf{0 , 0 1 5}$ & $\mathbf{0 , 1 0 8}$ & $\mathbf{0 , 6 9 3}$ \\
Gln +Glu & $8,718 \pm 0,455$ & $9,291 \pm 0,306$ & 0,145 & 0,040 & 0,306 \\
NAA+NAAG & $6,051 \pm 0,110$ & $6,367 \pm 0,074$ & $\mathbf{0 , 0 1 4}$ & $\mathbf{0 , 1 1 1}$ & $\mathbf{0 , 7 0 4}$ \\
Myo & $6,217 \pm 0,372$ & $6,950 \pm 0,250$ & $\mathbf{0 , 0 9 6}$ & $\mathbf{0 , 0 5 2}$ & $\mathbf{0 , 3 8 4}$ \\
PC+GPC & $1,627 \pm 0,046$ & $1,665 \pm 0,031$ & 0,307 & 0,020 & 0,173 \\
Cr & $5.510 \pm 0,200$ & $5,854 \pm 0,135$ & 0,167 & 0,036 & 0,280 \\
\hline
\end{tabular}

Média \pm E.P. (Erro Padrão) em mmol/Kg; Teste ANOVA; $\eta_{p}{ }^{2}$ : Eta parcial; CA: Cíngulo anterior; Glu: glutamato; Gln+Glu: glutamina+glutamato; NAA+NAAG: N-acetil-aspartato $+\mathrm{N}$-acetilAspartato- Glutamato; Myo: mio-inositol; PC+GPC: fosforilcolina + glicerol-fosforil colina + colina; Cr: creatina

Tabela 12 - Distribuição das diferenças médias e E.P. dos metabólitos do CA entre os sexos

\begin{tabular}{cccc}
\hline Metabólitos do $C A$ & Diferença média $\pm E P$ & IC 95\% & $p$ \\
\hline Glu & $1,282 \pm 0,511$ & 0,257 a 2,307 & 0,015 \\
Feminino vs Masculino & & & \\
NAA-NAAG & $0,343 \pm 0,135$ & 0,072 a 0,614 & 0,014 \\
$\begin{array}{c}\text { Feminino vs Masculino } \\
\text { Myo }\end{array}$ & $0,777 \pm 0,459$ & $-0,143$ a 1,698 & 0,096 \\
\hline
\end{tabular}

Diferença média \pm E.P. (Erro Padrão) em mmol/Kg; Teste ANOVA seguido de pós-teste de Tukey; CA: Cíngulo anterior; IC: Intervalo de Confiança; Glu: glutamato; NAA+NAAG: Nacetil-D-aspartato + N-acetil-D-Aspartato- Glutamato; Myo: mio-inositol 
A seguir, é apresentado o espectro de um paciente do sexo masculino em que pode ser observada redução de valores de picos de Glu e NAA+NAAG (para fins de ilustração, apenas).

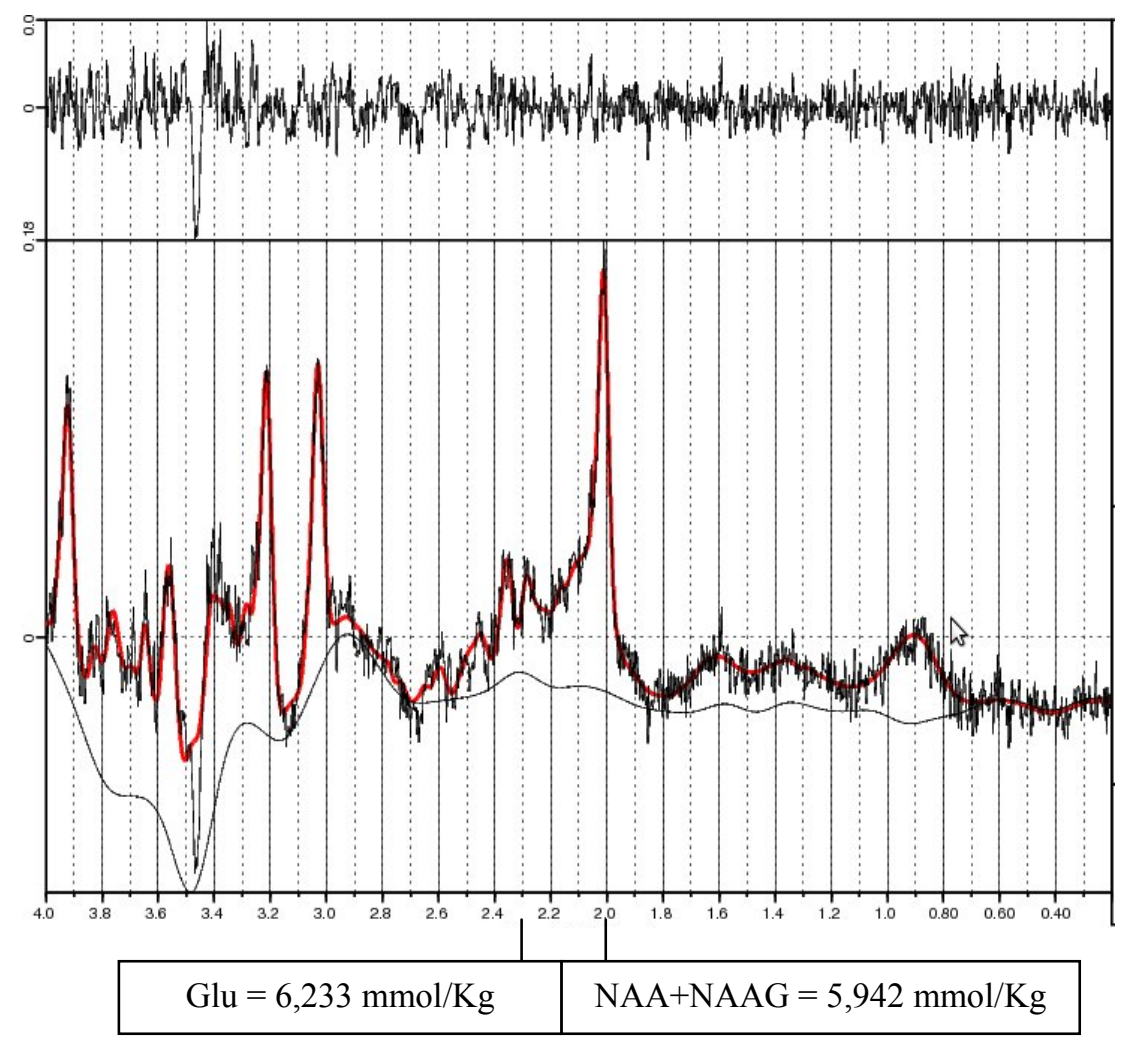

Figura 7: Espectro de paciente do sexo masculino com níveis reduzidos de Glu e NAA+NAAG

Ao se considerar o efeito médio e o poder de 0,626 observados na MANOVA para a interação diagnóstico-sexo, optou-se, ainda, por efetuar a ANOVA univariada para cada uma das variáveis dependentes do CA para esse fator.

A média de Glu foi diferente entre os sexos dentro dos grupos TDM-P, TDM-NP e controle $\left(\mathrm{p}=0,029\right.$; com média dimensão de efeito $\eta_{\mathrm{p}}{ }^{2}=0,127$; poder observado $\left.=0,664\right)(\mathrm{v}$. TABELA 13, GRÁFICO 4 e FIGURA 8). 
Tabela 13 - Distribuição das médias e E.P. de Glu do CA entre os sexos dentro dos grupos TDM-P, TDM-NP e controle

\begin{tabular}{cccc}
\hline $\begin{array}{c}\text { Metabólitos do } \\
\text { CA }\end{array}$ & Diagnóstico & Feminino (n=44) & Masculino (n= 18) \\
\hline \multirow{2}{*}{ Glu (média \pm EP) } & TDM-P & $8,396 \pm 0,498$ & $5,425 \pm 0,763$ \\
& TDM-NP & $9,337 \pm 0,466$ & $8,008 \pm 0,814$ \\
& Controle & $8,184 \pm 0,498$ & $8,639 \pm 0,681$ \\
\hline
\end{tabular}

Média \pm E.P. (Erro Padrão) em mmol/Kg; Teste ANOVA seguida de pós-teste de Tukey; CA: Cíngulo anterior; TDM-P: Transtorno depressivo maior com sintomas psicóticos; TDM-NP: Transtorno depressivo maior sem sintomas psicóticos; Glu: glutamato

O gráfico 4 ilustra a variação das médias de Glu dos sexos dentro dos grupos, onde há redução importante do sexo masculino em relação ao feminino para o TDM-P. Esta diferença entre os sexos se torna de menor monta para o TDM-NP que, por sua vez, assemelha-se à diferença entre os sexos para o controle (GRÁFICO 4).

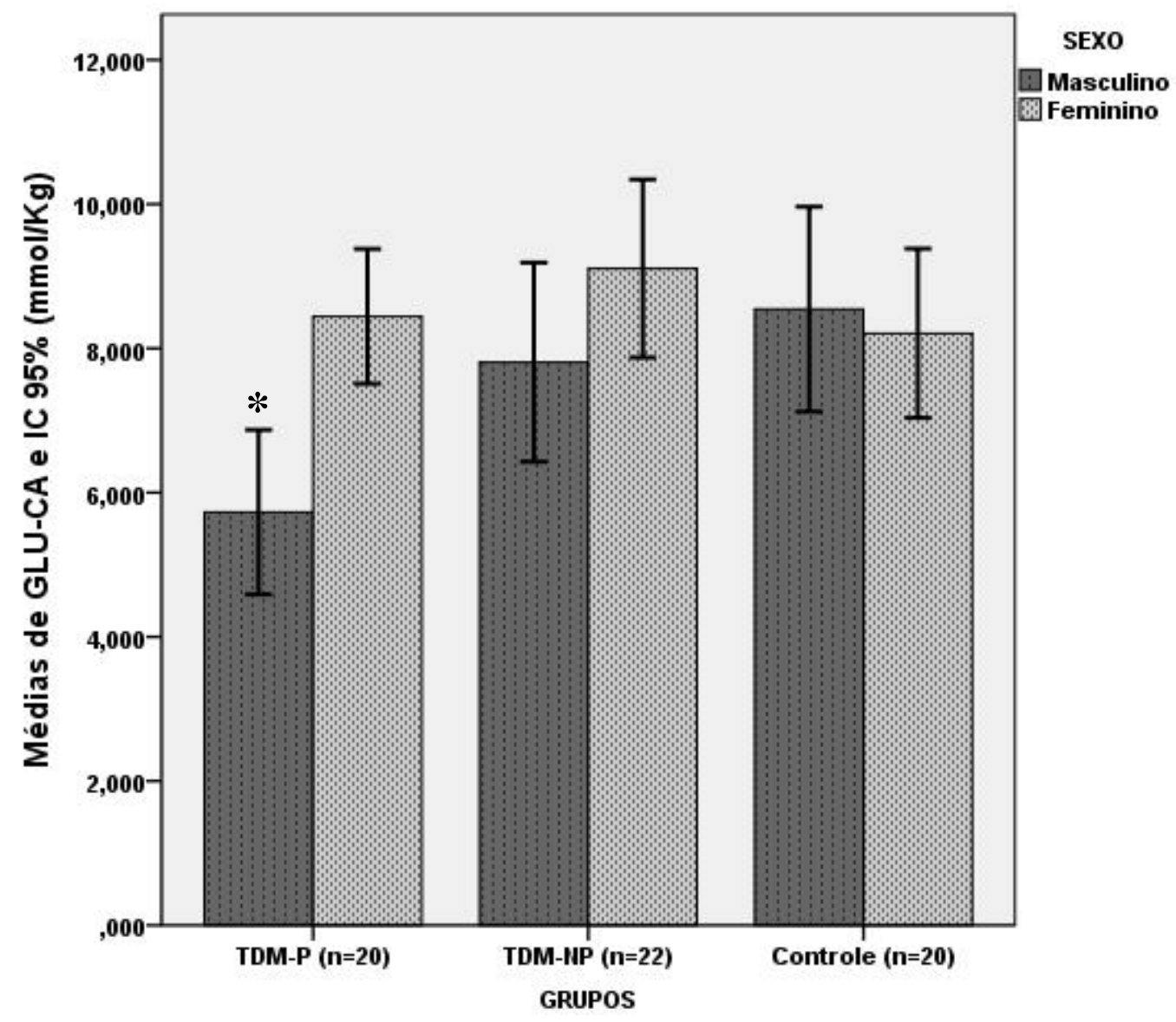

Gráfico 4: Médias de Glu do CA dos grupos masculino e feminino entre os diagnósticos TDM-P, TDM-NP e controle, em que o sexo masculino é inferior ao feminino para o TDM-P, o qu não é visto para os demais grupos $\left({ }^{*} p=0,029\right)$. TDM-P: Transtorno depressivo maior com sintomas psicóticos; TDM-NP: Transtorno depressivo maior sem sintomas psicóticos; Glu: glutamato. 
A média de Gln+Glu do CA diferiu de forma semelhante entre os sexos dentro dos grupos $\left(\mathrm{p}=0,034\right.$; com média dimensão de efeito $\eta_{\mathrm{p}}{ }^{2}=0,122$; poder observado $\left.=0,644\right)(\mathrm{v}$. TABELA 14, GRÁFICO 5 e FIGURA 8).

Tabela 14 - Distribuição das médias e E.P. de Gln + Glu do CA entre os sexos dentro dos grupos TDM-P, TDM-NP e controle

\begin{tabular}{cccc}
\hline $\begin{array}{c}\text { Metabólitos do } \\
\text { CA }\end{array}$ & Grupo & Feminino $(n=44)$ & Masculino $(n=18)$ \\
\hline \multirow{2}{*}{ Gln+Glu } & TDM-P & $9,476 \pm 0,524$ & $6,827 \pm 0,802$ \\
(média \pm E.P.) & TDM-NP & $9,800 \pm 0,490$ & $9,184 \pm 0,856$ \\
& Controle & $8,598 \pm 0,523$ & $9,493 \pm 0,716$
\end{tabular}

Média \pm E.P. (Erro Padrão) em mmol/Kg; Teste ANOVA seguida de pós-teste de Tukey; CA: Cíngulo anterior; TDM-P: Transtorno depressivo maior com sintomas psicóticos; TDM-NP:

Transtorno depressivo maior sem sintomas psicóticos; Gln+Glu: glutamina+glutamato

Observa-se no gráfico 5 comportamento semelhante da distribuição das médias do Gln+Glu entre os sexos para cada grupo ao encontrado para Glu em que há redução relevante dos níveis desses metabóitos no sexo masculino em relação ao feminino para o TDM-P e essa diferença entre os sexos encontra-se menor para o TDM-NP que é mais semelhante ao encontrado para o controle (v. GRÁFICO 5). 


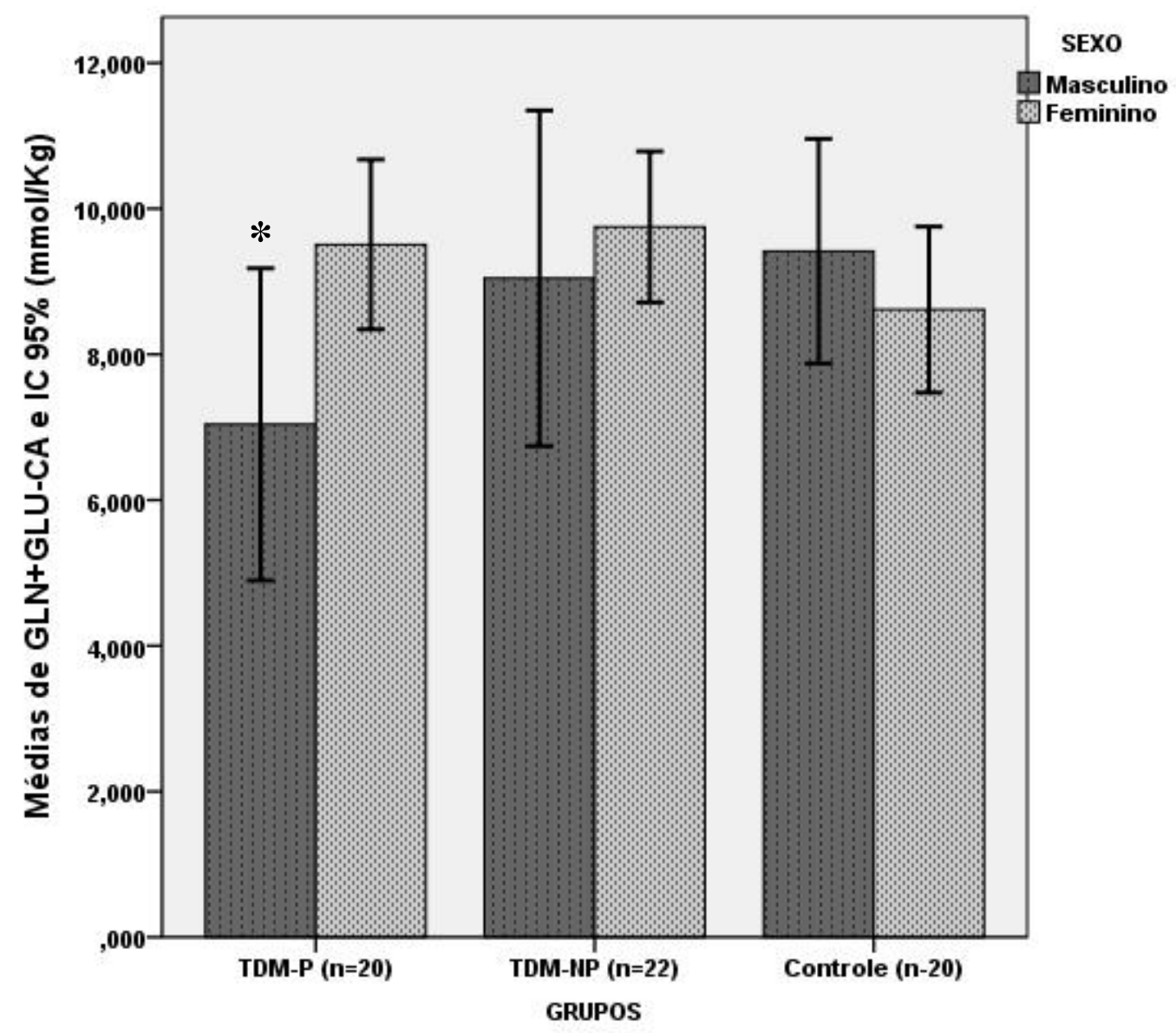

Gráfico 5: Médias de Gln+Glu do CA dos grupos masculino e feminino entre os diagnósticos TDM-P, TDM-NP e controle, com menores médias no sexo masculino em relação ao feminino dentro do TDM-P $(* p=0,034)$ o que não é encontrado dentro dos outros grupos. TDM-P: Transtorno depressivo maior com sintomas psicóticos; TDM-NP: Transtorno depressivo maior sem sintomas psicóticos; Gln+Glu: glutamina + glutamato

A seguir ilustra-se na figura 8 o Espectro de paciente do sexo masculino e TDM-P ilustando redução de picos de Glu e de Gln+Glu (apenas para fins de ilustração). 


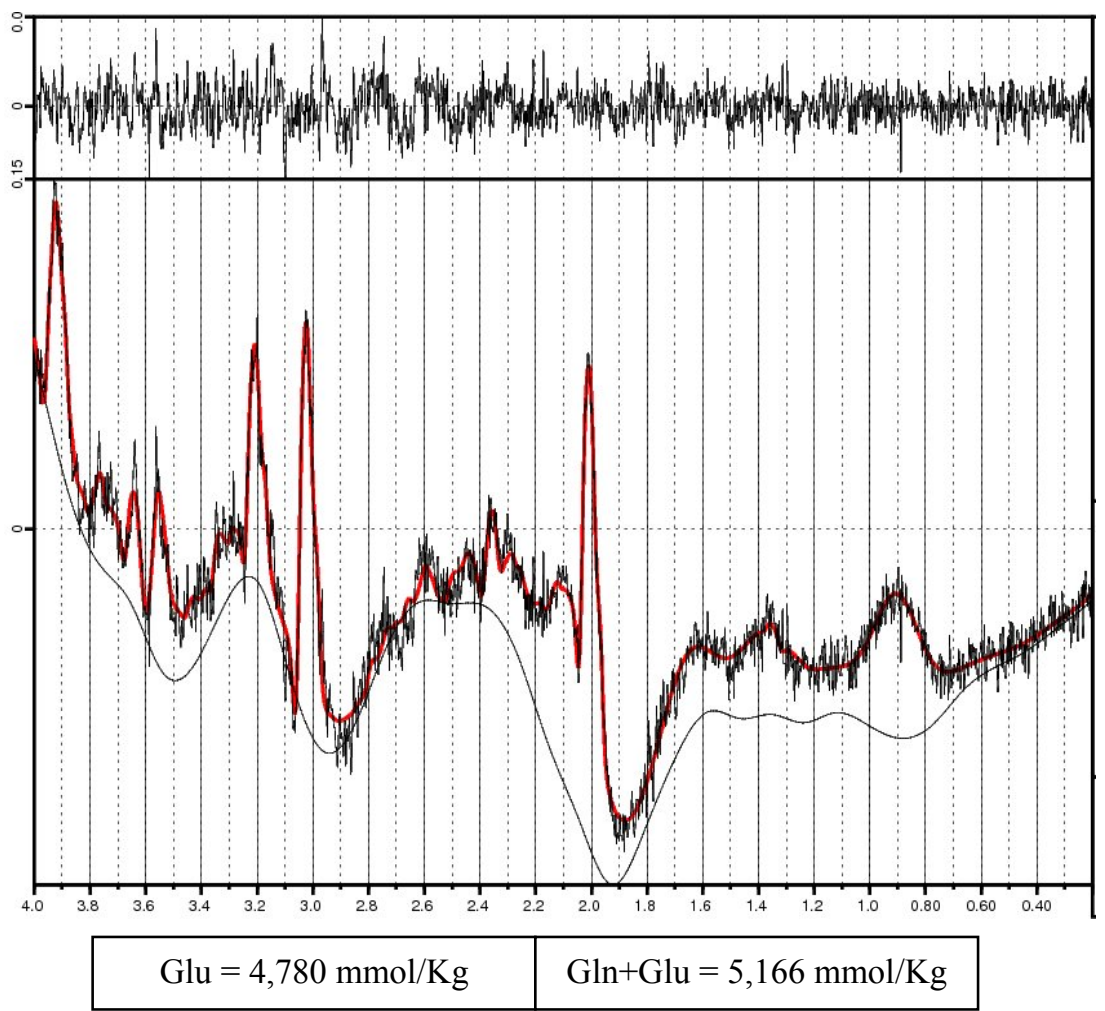

Figura 8: Espectro de paciente TDM-P do sexo masculino com níveis reduzidos de Glu e de Gln+Glu.

A média de Cr também diferiu entre os sexos dentro dos diagnósticos, porém de forma diferente à dos metabólitos anteriores $\left(\mathrm{p}=0,039\right.$; com média dimensão de efeito $\eta_{\mathrm{p}}{ }^{2}=0,117$; poder observado $=0,621)(\mathrm{v}$. TABELA 15, GRÀFICO 6)

Tabela 15 - Distribuição das médias e E.P. de Cr do CA entre os sexos dentro dos grupos TDM-P, TDM-NP e controle

\begin{tabular}{cccc}
\hline $\begin{array}{c}\text { Metabólitos do } \\
C A\end{array}$ & Diagnóstico & Feminino $(n=44)$ & Masculino $(n=18)$ \\
\hline \multirow{2}{*}{ Cr (média \pm E.P.) } & TDM-P & $5,683 \pm 0,370$ & $5,683 \pm 0,242$ \\
& TDM-NP & $6,213 \pm 0,226$ & $4,949 \pm 0,395$ \\
& Controle & $5,665 \pm 0,241$ & $5,942 \pm 0,330$
\end{tabular}

Média \pm EP (Erro Padrão) em mmol/Kg; Teste ANOVA seguido de pós-teste de Tukey; CA: Cíngulo anterior; TDM-P: Transtorno depressivo maior com sintomas psicóticos; TDM-NP: Transtorno depressivo maior sem sintomas psicóticos; Cr: creatina

Para a média de Cr, verifica-se no gráfico 6 a maior diferença entre os sexos no TDMNP, enquanto no TDM-P as médias dos sexos são semelhantes e mais próximas às do grupo controle (v. GRÁFICO 6). 


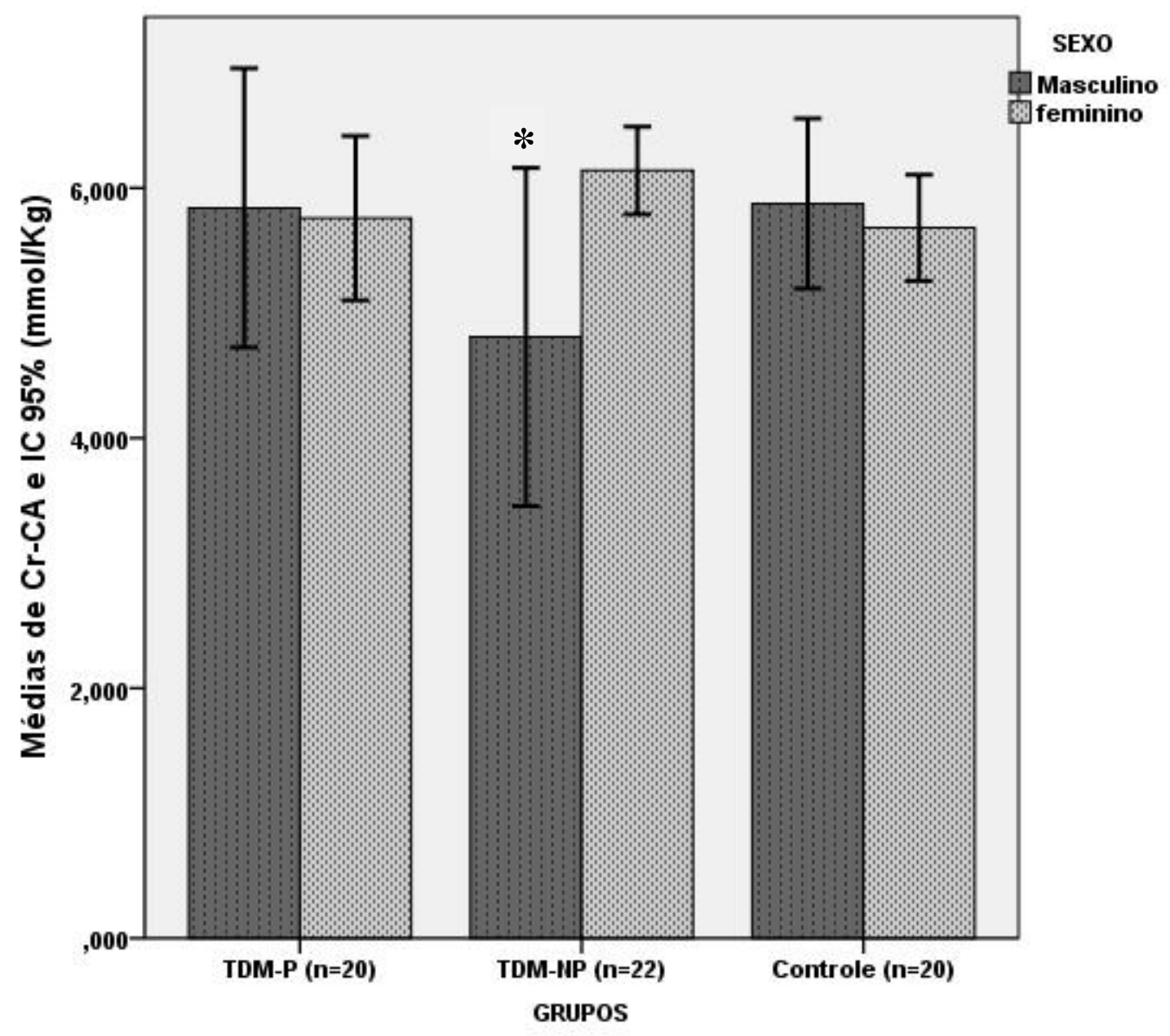

Gráfico 6: Médias de $\mathrm{Cr}$ do $\mathrm{CA}$ dos grupos masculino e feminino entre os diagnósticos TDM-P, TDM-NP e controle em que os níveis desse metabólito encontram-se inferiores ao do sexo feminino para o TDM-NP, o que não é visto para os demais grupos. TDM-P: Transtorno depressivo maior com sintomas psicóticos; TDM-NP: Transtorno depressivo maior sem sintomas psicóticos; Cr: creatina

A média de $\mathrm{PC}+\mathrm{GPC}$ diferiu entre os sexos dentro dos grupos, mas não alcançou significância estatística $\left(p=0,152\right.$ com média dimensão de efeito $\eta_{\mathrm{p}}{ }^{2}=0,070$; poder observado $=0,387)(\mathrm{v}$. TABELA 16 e GRÁFICO 7).

Tabela 16 - Distribuição das médias e E.P. de PC + GPC do CA entre os sexos dentro dos grupos TDM-P, TDM-NP e controle

\begin{tabular}{cccc}
\hline Metabólitos do CA & Diagnóstico & Feminino (n= 44) & Masculino (n= 18) \\
\hline \multirow{2}{*}{ PC+GPC (média \pm E.P.) } & TDM-P & $1,517 \pm 0,054$ & $1,477 \pm 0,082$ \\
& TDM-NP & $1,768 \pm 0,050$ & $1,569 \pm 0,088$ \\
& Controle & $1,710 \pm 0,054$ & $1,778 \pm 0,074$
\end{tabular}

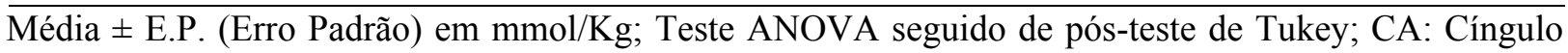
anterior; TDM-P: Transtorno depressivo maior com sintomas psicóticos; TDM-NP: Transtorno depressivo maior sem sintomas psicóticos; PC+GPC: fosforilcolina + glicerol-fosforil colina + colina 
Conforme ilustrado no gráfico 7, as médias de $\mathrm{PC}+\mathrm{GPC}$ foram semelhantes entre os sexos no TDM-P e apresentaram redução importante do masculino em relação ao feminino no TDM-NP. O sexo feminino do TDM-NP apresentou média de níveis de PC+GPC mais próximos ambas as médias dos sexos do controle. Essas diferenças entre os sexo para os grupos não alcançaram significância estatística (v. GRÁFICO 4).

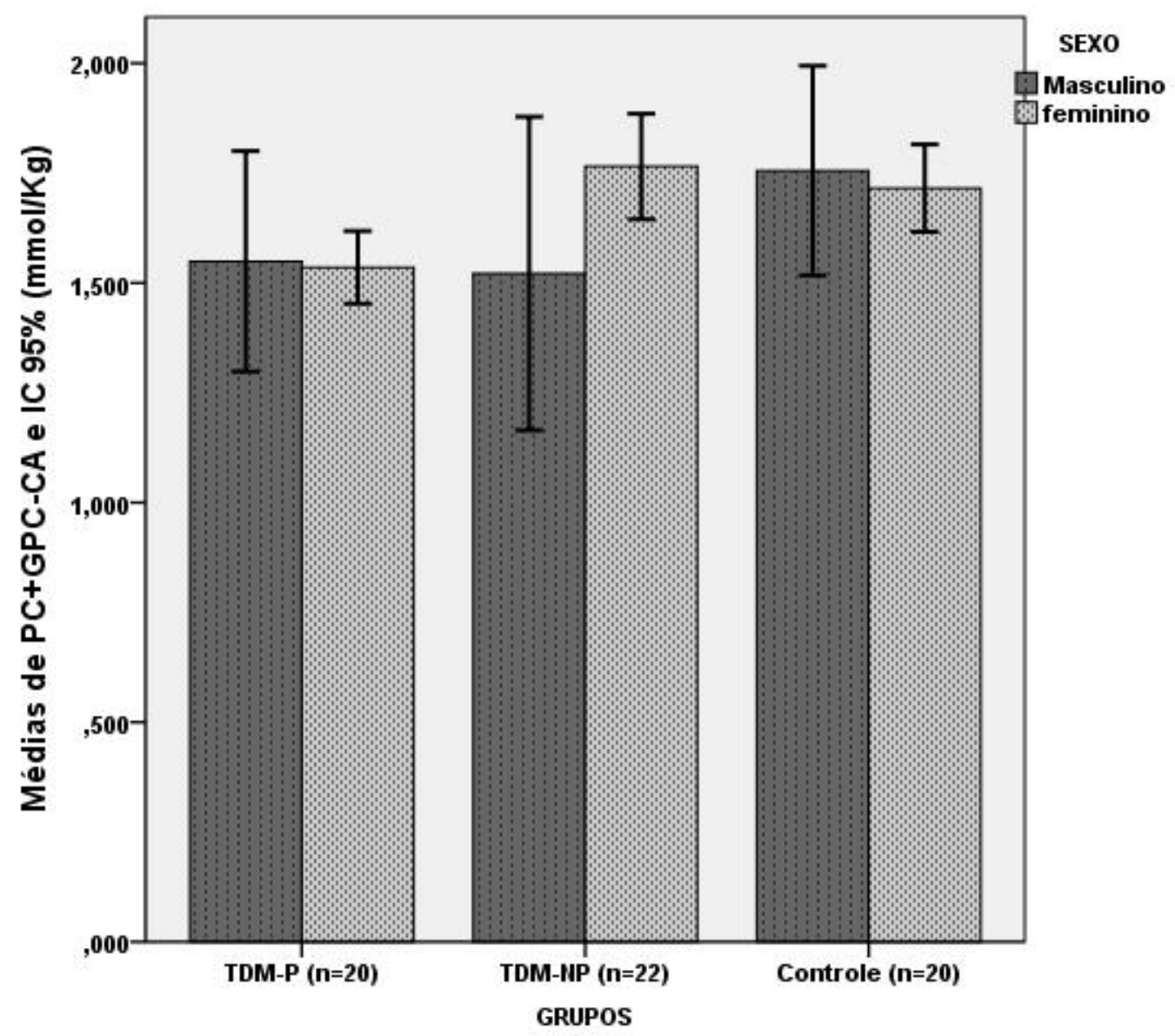

Gráfico 7: Médias de $\mathrm{PC}+\mathrm{GPC}$ do $\mathrm{CA}$ dos grupos masculino e feminino entre os diagnósticos TDM-P, TDM-NP e controle com níveis reduzidos de PG+GPC no sexo masculino e feminino do TDM-P e do sexo masculino do TDM-NP em relação aos demais grupos, porém sem alcançar significância estatística $(p=0,152)$. TDM-P: Transtorno depressivo maior com sintomas psicóticos; TDM-NP: Transtorno depressivo maior sem sintomas psicóticos; PC+GPC: fosforilcolina + glicerol-fosforil colina + colina

As médias do NAA+NAAG e myo-Ins não diferiram entre os sexos dentro dos diagnósticos estudados. 


\subsubsection{Sexo feminino e níveis de metabólitos}

A partir dos resultados observados a respeito de uma provável interação entre sexo e diagnóstico, conforme observado na MANOVA, optou-se por analisar os sexos separadamente. Inicialmente, serão apresentados os resultados referentes ao sexo feminino.

Foi usada a MANOVA para avaliar se o fator diagnóstico apresentou efeito significativo sobre a composição multivariada das variáveis neuroquímicas do $\mathrm{CA}$, utilizando a idade como covariável. A MANOVA revelou que o fator diagnóstico teve efeito significativo e de elevada dimensão sobre o conjunto das variáveis neuroquímicas relacionadas ao CA (Maior Raiz de Roy $=0,54 ; \mathrm{F}_{(6 ; 33)}=2,96 ; \mathrm{p}=0,020 ; \eta_{\mathrm{p}}{ }^{2}=0,350$; poder observado $=0,83)$.

Observou-se ainda uma influência com efeito de elevada dimensão para a covariável idade nas variáveis neuroquímicas do $\mathrm{CA}$ do sexo feminino, porém sem significância estatística (Maior Raiz de Roy $=0,349 ; \mathrm{F}_{(6 ; 32)}=1,859 ; \mathrm{p}=0,119 ; \eta_{\mathrm{p}}{ }^{2}=0,26$; poder observado $=0,603)$. A falta de significância estatística da idade pode ser explicada pelo reduzido poder do teste somado ao reduzido tamanho da amostra.

Diante da significância multivariada no fator diagnóstico, procedeu-se a ANOVA univariada para cada uma das variáveis dependentes do CA do sexo feminino. Observou-se uma diferença significativa entre as médias dos grupos diagnósticos para o NAA+NAAG (p = 0,04 com média dimensão do efeito $\eta_{\mathrm{p}}{ }^{2}=0,16$ e poder observado $=0,619$ ). Para este metabólito, o grupo TDM-NP apresentou média maior que o grupo TDM-P $(\mathrm{p}=0,035)$, sendo a diferença média de 0,510 $\pm 0,192$ com IC 95\% 0,027 a 0,993(v. TABELAS 17 e 18).

A média de PC+GPC do TDM-P também foi superior a do TDM-NP $(p=0,002)$, sendo a diferença média de 0,248 $\pm 0,065$ com IC 95\% 0,083 a 0,412. O grupo controle também apresentou média deste metabólito superior à do TDM-P $(\mathrm{p}=0,021)$, sendo a diferença média 0,192 $\pm 0,067$ com IC 95\% de 0,024 a 0,361 (v. TABELAS 17 e 18). 
Tabela 17 - Distribuição das médias e E.P. dos metabólitos do CA entre os grupos TDM-P, TDM-NP e controle do sexo feminino

\begin{tabular}{lcccccc}
\hline $\begin{array}{l}\text { Metabólitos } \\
\text { do CA }\end{array}$ & $\begin{array}{c}\text { TDM-P } \\
(n=14)\end{array}$ & $\begin{array}{c}\text { TDM-NP } \\
(n=17)\end{array}$ & $\begin{array}{c}\text { Controle } \\
(n=13)\end{array}$ & $p$ & $\eta_{p}{ }^{2}$ & Poder \\
\hline Glu & $8,362 \pm 0,535$ & $9,373 \pm 0,500$ & $8,163 \pm 0,534$ & 0,218 & 0,079 & 0,315 \\
Gln+Glu & $9,450 \pm 0,522$ & $9,829 \pm 0,488$ & $8,582 \pm 0,521$ & 0,221 & 0,078 & 0,312 \\
NAA-NAAG & $6,100 \pm 0,140$ & $6,610 \pm 0,131$ & $6,386 \pm 0,140$ & $\mathbf{0 , 0 4 0}$ & $\mathbf{0 , 1 6 0}$ & $\mathbf{0 , 6 1 9}$ \\
Myo & $6,649 \pm 0,486$ & $7,342 \pm 0,454$ & $6,854 \pm 0,485$ & 0,567 & 0,030 & 0,138 \\
PC+GPC & $1,528 \pm 0,048$ & $1,765 \pm 0,044$ & $1,710 \pm 0,047$ & $\mathbf{0 , 0 0 2}$ & $\mathbf{0 , 2 9 4}$ & $\mathbf{0 , 9 3 1}$ \\
Cr & $5,668 \pm 0,227$ & $6,227 \pm 0,212$ & $5,656 \pm 0,226$ & 0,121 & 0,108 & 0,427 \\
\hline
\end{tabular}

Média e EP (Erro Padrão) em mmol/Kg; Teste ANOVA seguido de pós-teste de Tukey; $\eta_{p}{ }^{2}$ : Eta parcial; CA: Cíngulo anterior; TDM-P: Transtorno depressivo maior com sintomas psicóticos; TDMNP: Transtorno depressivo maior sem sintomas psicóticos; Glu: glutamato; Gln+Glu: glutamina+glutamato; NAA+NAAG: N-acetil-aspartato + N-acetil-Aspartato- Glutamato; Myo: mioinositol; PC+GPC: fosforilcolina + glicerol-fosforil colina + colina; Cr: creatina

Tabela 18 - Distribuição das diferenças médias e EP dos metabólitos do CA entre os grupos TDM-P, TDM-NP e controle do sexo feminino

\begin{tabular}{cccc}
\hline Metabólitos do CA & Diferença média $\pm E P$ & $I C$ 95\% & $p$ \\
\hline NAA-NAAG & & & \\
TDM-NP vs TDM-P & $0,510 \pm 0,192$ & 0,027 a 0,993 & 0,035 \\
PC + GPC & & & \\
TDM-NP vs TDM-P & $0,248 \pm 0,065$ & 0,083 a 0,412 & 0,002 \\
Controle vs TDM-P & $0,192 \pm 0,067$ & 0,024 a 0,361 & 0,021
\end{tabular}

Diferença média e EP (Erro Padrão) expressos em mmol/Kg; Teste ANOVA seguido de pós-teste de Tukey; $\eta_{p}{ }^{2}$ : Eta parcial; CA: Cíngulo anterior; TDM-P: Transtorno depressivo maior com sintomas psicóticos; TDM-NP: Transtorno depressivo maior sem sintomas psicóticos; NAA+NAAG: N-acetil-D-aspartato + N-acetil-D-Aspartato-Glutamato; PC+GPC: fosforilcolina + glicerol-fosforil colina + colina

Não se observou diferença significativa entre a média de NAA+NAAG do grupo controle e a do TDM-P $(\mathrm{p}=0,469)$ e a do TDM-NP $(\mathrm{p}=0,747)$.

Da mesma forma, as médias de PC + GPC do TDM-NP e do controle foram semelhantes $(\mathrm{p}=1,0)$.

As médias do Glu, Gln + Glu, Myo e Cr também não diferiram significativamente entre os grupos diagnósticos para o sexo feminino. 


\subsubsection{Sexo masculino e níveis de metabólitos}

Diante de uma provável interação entre os fatores grupo e sexo, procedeu-se a análise no sexo masculino separadamente.

Em seguida, observou-se interferência do diagnóstico sobre a composição das variáveis metabólicas do $\mathrm{CA}$ do sexo masculino a partir da MANOVA multivariada, utilizando-se a idade como covariável (Maior Raiz de Roy $=2,385 ; \mathrm{F}_{(6,9)}=3,577 ; \mathrm{p}=0,043$; efeito de dimensão muito elevada $\eta_{\mathrm{p}}{ }^{2}=0,705$; poder $=0,713$ ).

A idade não mostrou influência significativa sobre as variáveis metabólicas na análise multivariada (Maior Raiz de Roy $=0,702 ; \mathrm{F}_{(6,8)}=0,936 ; \mathrm{p}=0,518$, com elevada dimensão de efeito $\eta_{\mathrm{p}}{ }^{2}=0,413$; poder $=0,203$ ). O reduzido poder do teste associado ao reduzido tamanho da amostra pode ter sido responsável pela falta de significância estatística deste resultado.

Diante da significância multivariada do fator diagnóstico, procedeu-se a ANOVA univariada para esse fator em relação a cada variável metabólica (v. Tabela 20). Obteve-se média de NAA+NAAG do CA com diferença entre os grupos diagnósticos ( $p=0,053$; com efeito de elevada dimensão $\eta_{\mathrm{p}}{ }^{2}=0,363$; poder $=0,573$ ). O grupo TDM-NP apresentou média do NAA+NAAG inferior ao controle, sem alcançar significância estatística $(\mathrm{p}=0,073)$ e apresentou semelhança ao TDM-P $(\mathrm{p}=1,0)$. O TDM-P e controle também não diferiram quanto à média de NAA+NAAG dessa região cerebral $(\mathrm{p}=0,265)(\mathrm{v}$. TABELAS 19 e 20).

Tabela 19 - Distribuição das médias e EP dos metabólitos do CA entre os grupos TDM-P, TDM-NP e controle do sexo masculino

\begin{tabular}{ccccccc}
\hline $\begin{array}{c}\text { Metabólitos do } \\
\text { CA }\end{array}$ & $\begin{array}{c}\text { TDM-P } \\
(\boldsymbol{n}=\mathbf{6})\end{array}$ & $\begin{array}{c}\text { TDM-NP } \\
(\boldsymbol{n}=5)\end{array}$ & $\begin{array}{c}\text { Controle } \\
(\boldsymbol{n}=7)\end{array}$ & $\boldsymbol{p}$ & $\eta_{\boldsymbol{p}}{ }^{2}$ & Poder \\
\hline Glu & $6,079 \pm 0,638$ & $7,603 \pm 0,621$ & $8,215 \pm 0,564$ & $\mathbf{0 , 1 0 5}$ & $\mathbf{0 , 2 9 3}$ & $\mathbf{0 , 4 4 0}$ \\
Glu+Gln & $7,255 \pm 0,961$ & $8,918 \pm 0,934$ & $9,302 \pm 0,849$ & 0,356 & 0,147 & 0,205 \\
NAA+NAAG & $5,957 \pm 0,143$ & $5,884 \pm 0,140$ & $6,339 \pm 0,127$ & $\mathbf{0 , 0 5 3}$ & $\mathbf{0 , 3 6 3}$ & $\mathbf{0 , 5 7 3}$ \\
Myo & $6,203 \pm 0,632$ & $5,996 \pm 0,614$ & $6,342 \pm 0,558$ & 0,892 & 0,017 & 0,064 \\
PC+GPC & $1,484 \pm 0,119$ & $1,560 \pm 0,115$ & $1,723 \pm 0,105$ & 0,340 & 0,153 & 0,213 \\
Cr & $5,888 \pm 0,495$ & $4,782 \pm 0,481$ & $5,781 \pm 0,437$ & 0,230 & 0,202 & 0,285
\end{tabular}

Média e EP (Erro Padrão) expressos em mmol/Kg; Teste ANOVA seguido de pós-teste de Tukey; $\eta_{p}{ }^{2}$ : Eta parcial; CA: Cíngulo anterior; TDM-P: Transtorno depressivo maior com sintomas psicóticos; TDM-NP: Transtorno depressivo maior sem sintomas psicóticos; Glu: glutamato; Gln+Glu: glutamina+glutamato; NAA+NAAG: N-acetil-aspartato + N-acetil-Aspartato- Glutamato; Myo: mioinositol; PC+GPC: fosforilcolina + glicerol-fosforil colina + colina; Cr: creatina 
Tabela 20 - Distribuição das diferenças médias e EP do NAA+NAAG do CA entre os grupos TDM-NP e controle do sexo masculino

\begin{tabular}{cccc}
\hline Metabólitos do $C A$ & Diferença média $\pm E P$ & IC 95\% & $p$ \\
\hline NAA+NAAG & $0,454 \pm 0,179$ & $-0,036$ a 0,945 & 0,073 \\
Controle $v$ s TDM-NP &
\end{tabular}

Diferença média e EP (Erro Padrão) expressos em mmol/Kg; Teste ANOVA seguido de pós-teste de Tukey; CA: Cíngulo anterior; IC: Intervalo de Confiança; TDM-NP: Transtorno depressivo maior sem sintomas psicóticos; NAA+NAAG: N-acetil-aspartato + N-acetil-Aspartato- Glutamato

Houve diferença para a média de Glu do CA, mas sem significância estatística entre os diagnósticos $\left(\mathrm{p}=0,105\right.$; com efeito de dimensão elevada $\eta_{\mathrm{p}}{ }^{2}=0,293$; poder $\left.=0,440\right)$. A média de Glu do TDM-P foi inferior ao controle, sem alcançar significância estatística $(p=0,112)$ e semelhante ao TDM-NP ( $\mathrm{p}=0,416)$, enquanto o controle e o TDM-NP também não diferiram estatisticamente $(\mathrm{p}=1,0)(\mathrm{v}$. TABELA 21).

Tabela 21 - Distribuição das diferenças médias e EP do Glu do CA entre os diagnósticos TDM-P e controle do sexo masculino

\begin{tabular}{cccc}
\hline Metabólitos do $C A$ & Diferença média $\pm E P$ & IC 95\% & $p$ \\
\hline Glu & & & \\
Controle vs TDM-P & $2,136 \pm 0,922$ & $-0,394$ a 4,667 & 0,112
\end{tabular}

Diferença média e EP (Erro Padrão) expressos em mmol/Kg; Teste ANOVA seguido de pós-teste de Tukey; CA: Cíngulo anterior; IC: Intervalo de Confiança; TDM-P: Transtorno depressivo maior com sintomas psicóticos; Glu: glutamato

Conforme demonstrado na tabela 20, não houve diferença entre os grupos para os demais metabólitos. O tamanho e poder dos testes reduzidos poderiam ser responsáveis pela falta de significância dos resultados obtidos.

\subsubsection{Correlações de níveis metabólitos do CA e pontuação de escala de sintomas depressivos}

Procederam-se correlações bivariadas entre pontuações em escala de sintomas depressivos (Hamilton 31) e os níveis de metabólitos, diante da impossibilidade de se 
proceder a análise da gravidade de sintomas como covariável na MANOVA em vista de reduzido tamanho da amostra.

Partindo-se da normalidade da pontuação da Hamilton de 31 itens, a correlação a gravidade dos sintomas depressivos aferidos por tal escala não apresentou correlação com significância estatística com nenhum dos níveis do metabóitos de CA dos grupos dos pacientes (TDM-P e TDM-NP) (v. TABELA 22).

Tabela 22: Correlações bivariadas entre pontuação da HAM 31 e as médias dos níveis dos metabólitos nos grupos TDM-P e TDM-NP.

\begin{tabular}{ccc}
\hline $\begin{array}{c}\text { HAM 31 vs média dos } \\
\text { metabólitos }\end{array}$ & $r$ & $p$ \\
\hline AD vs Glu & 0,047 & 0,773 \\
AD vs Gln+Glu & 0,118 & 0,474 \\
AD vs NAA+NAAG & 0,169 & 0,290 \\
AD vs PC+GPC & 0,058 & 0,718 \\
AD vs Myo & $-0,086$ & 0,595 \\
AD vs Cr & $-0,238$ & 0,134 \\
\hline
\end{tabular}

Legenda: r- Correlação de Pearson. HAM 31 - escala de Hamilton de 31 itens; Glu- Glutamato; Gln+Glu- glutamina mais glutamato; NAA+NAAG- N-acetil-aspartato + glutamato; PC+GPCfosforilcolina + glicerol-fosforil colina + colina. Myo- mio-inositol; Cr- creatina.

\subsubsection{Correlações entre níveis dos metabólitos do CA e dias de uso de medicação}

Procederam-se correlações bivariadas entre o tempo de uso das medicações utilizadas pelos pacientes e os níveis de metabólitos diante da impossibilidade da análise do efeito medicamentoso como covariável na MANOVA devido a insuficiência de tamanho da amostra.

Verificou-se que o tempo de uso de AD utilizados por ambos os grupos de pacientes (TDM-P e TDM-NP) não se correlacionou de forma estatisticamente significante como descrito na tabela 23. 
Tabela 23: Correlações bivariadas entre o tempo de uso de $\mathrm{AD}$ e as médias dos níveis dos metabólitos nos grupos TDM-P e TDM-NP

\begin{tabular}{ccc}
\hline $\begin{array}{c}\text { Uso de AD vs média dos } \\
\text { metabólitos }\end{array}$ & $\rho$ & $p$ \\
\hline AD vs Glu & $-0,256$ & 0,145 \\
AD vs Gln+Glu & $-0,043$ & 0,816 \\
AD vs NAA+NAAG & $-0,060$ & 0,735 \\
AD vs PC+GPC & $-0,027$ & 0,878 \\
AD vs Myo & $-0,014$ & 0,939 \\
AD vs Cr & $-0,062$ & 0,729 \\
\hline
\end{tabular}

$\rho$ - Correlação de Spearman. AD- antidepressivo; Glu- Glutamato; Gln+Glu- glutamina + glutamato; NAA+NAAG- N-acetil-aspartato + glutamato; $\mathrm{PC}+\mathrm{GPC}$ - fosforilcolina mais glicerofosforilcolina + colina. Myo- mio-inositol; Cr- creatina.

O mesmo ocorreu para a correlação entre os níveis d metabólitos de CA dos pacientes (TDM-P e TDM-NP) e o tempo de uso de BZD (v. TABELA 24).

Tabela 24: Correlações bivariadas entre o tempo de uso de BZD e as médias dos níveis dos metabólitos nos grupos TDM-P e TDM-NP

\begin{tabular}{ccc}
\hline $\begin{array}{c}\text { Uso de BZD vs média dos } \\
\text { metabólitos }\end{array}$ & $\rho$ & $p$ \\
\hline BZD vs Glu & $-0,081$ & 0,720 \\
BZD vs Gln+Glu & 0,056 & 0,810 \\
BZD vs NAA+NAAG & 0,063 & 0,774 \\
BZD vs PC+GPC & 0,271 & 0,211 \\
BZD vs Myo & 0,02 & 0,927 \\
BZD vs Cr & 0,146 & 0,506
\end{tabular}

$\rho$ - Correlação de Spearman; BZD- Benzodiazepínico; Glu- Glutamato; Gln+Glu- glutamina + glutamato; NAA+NAAG- N-acetil-aspartato + glutamato; PC+GPC- fosforilcolina + glicerolfosforil colina + colina. Myo- mio-inositol; Cr- creatina.

Quanto ao tempo de uso de AP pelos TDM-P e os níveis de metabólitos do CA desse grupo de pacientes, também não foram encontradas correlações com siginificância estatística (v. TABELA25). 
Tabela 25: Correlações bivariadas entre o tempo de uso de AP e as médias dos níveis dos metabólitos no grupo TDM-P

\begin{tabular}{ccc}
\hline $\begin{array}{c}\text { Uso de AP vs média dos } \\
\text { metabólitos }\end{array}$ & r & p \\
\hline AP vs Glu & $-0,137$ & 0,688 \\
AP vs Gln+Glu & $-0,341$ & 0,305 \\
AP vs NAA+NAAG & $-0,542$ & 0,085 \\
AP vs PC+GPC & 0,147 & 0,665 \\
AP vs Myo & $-0,403$ & 0,219 \\
AP vs Cr & 0,042 & 0,901 \\
\hline
\end{tabular}

r- Correlação de Pearson. AP- antipsicótico. Glu- Glutamato; Gln+Glu- glutamina + glutamato; NAA+NAAG- N-acetil-aspartato + glutamato; PC+GPC- fosforilcolina + glicerol-fosforil colina + colina. Myo- mio-inositol; Cr- creatina. 


\section{DISCUSSÃO}

Este trabalho avaliou pacientes adultos não idosos em episódio atual de Transtorno Depressivo Maior, permitindo a comparação direta de características sócio-demográficas, clínicas e neuroquímicas (em região de cíngulo anterior) entre pacientes com e sem sintomas psicóticos, bem como permitiu a comparação dos mesmos com um grupo controle. A seguir, serão discutidos os principais achados do estudo.

\subsection{CARACTERÍSTICAS DEMOGRÁFICAS E CLÍNICAS DA AMOSTRA}

Quando comparados os três grupos (TDM-P, TDM-NP e controle), houve diferença quanto à escolaridade, com o grupo TDM-P apresentando menor escolaridade do que o grupo controle. Estudo prévio evidenciou que TDM-P apresentou menor proporção de indivíduos com nível médio que os com TDM-NP, porém tal estudo não realizou a comparação com grupo controle (GAUDIANO et al., 2009).

A menor proporção de indivíduos com emprego dentre os casos, por sua vez, pode refletir o prejuízo funcional desse transtorno mental, o que foi evidenciado pelo pior resultado da avaliação pela GAF nesse estudo. Esse dado coincide com o relatório global de doenças da OMS na sua última edição (OMS, 2004) em que o TDM foi a principal causa de anos perdidos por incapacidade no mundo, na faixa etária de 15 a 59 anos, época de maior empregabilidade. O NCS-R também evidenciou maior associação do TDM a indivíduos inativos na população americana (KESSLER et al., 2003). Não se obteve dados equivalentes na literatura para comparação e análise do resultado de menor proporção de empregados no TDM-P em relação aos demais grupos do atual estudo. Porém, diante de sua pior pontuação da GAF e de dados da literatura indicativos de pior desempenho cognitivo desse grupo de pacientes (GAUDIANO et al., 2009), seria esperado que o TDM-P estivesse com menor proporção de empregados. Quanto ao maior número de filhos também do TDM-P, não se encontrou dado de literatura que ampliasse a compreensão desse resultado.

Apesar de semelhantes entre casos e controles no presente estudo, o sexo e a classe social diferiu entre pacientes com TDM e a população saudável americana no $N C S$ - $R$, onde pacientes portadores desse transtorno apresentaram maior associação ao sexo feminino e a 
indivíduos pobres ou próximos à faixa da pobreza (KESSLER et al., 2003). No entanto, o presente trabalho não é um estudo de base populacional e emprega uma amostra de pacientes graves que procuraram serviço de saúde pública especializado.

A avaliação dos controles pela BPRS serviu para os autores como ferramenta auxiliar para confirmação de ausência de psicopalotogia nos controles saudáveis. Diante de média da pontuação desta escala de 1,17 com D.P de 1,61 e de nenhum dos controles terem apresentado pontuação maior ou igual a sete, reforçou-se o achado da entrevista clínica (SCID) realizada pelos entrevistadores quanto à ausência de transtorno de humor ou psicótico ou de ansiedade grave atual nesses indivíduos.

Apesar de pacientes terem apresentado comorbidades clínicas sistêmicas, nenhum deles encontrava-se com grau de enfermidade de forma que esta pudesse comprometer o funcionamento mental. Onze pacientes (25\%) apresentavam condições que acometem o endotélio - HAS, dislipidemia, diabetes mellitus e obesidade - cujas alterações estão sob investigação como fator etiopatogênico para o TDM (BELMAKER et al., 2008).

A homogeneidade em relação à idade e ao sexo entre TDM-P e TDM-NP também foi verificada em estudos prévios. (GAUDIANO et al., 2009 ; FORTY et al., 2009; LEE et al., 2003; BELANOFF et al., 2001). O número de participantes do sexo feminino foi 2 a 3 vezes maior que o masculino o que de certa forma traduz a prevalência da população geral (KESSLER et al., 2003), mas não foram diferentes entre os grupos.

Dados a respeito de diferenças quanto à classe social entre esses grupos não foram encontrados, mas essa variável não diferiu entre os grupos de pacientes do presente estudo.

A diferença significativa das médias da GAF entre TDM-P, TDM-NP e controle aponta para maior prejuízo funcional do primeiro grupo. Os dois grupos de pacientes apresentaram pontuação abaixo de 70, mas o grupo com psicose teve menor média da GAF em relação aos não-psicóticos. Pior desempenho funcional pela GAF em deprimidos psicóticos também foi encontrado em estudo prévio com pacientes ambulatoriais em relação aos não psicóticos, mas sem comparação com grupo controle (GAUDIANO et al.,2009).

A média da pontuação da BPRS não diferiu entre os grupos de pacientes e todos eles pontuaram acima de 4, mas quando se analisou as subescalas, encontrou-se diferenças entre TDM-P e TDM-NP. O fato da pontuação do item "pensamento" do BPRS ter sido significativamente diferente entre os pacientes com TDM foi compatível com os diagnósticos atribuídos em vista de que esse item diz respeito à presença de sintomas psicóticos, como também foi compatível com dados prévios da literatura (KELLER et al., 2005). 
A pontuação do subitem "ativação" não diferiu entre os subgrupos de deprimidos, contrariando a literatura. Esse subitem do BPRS foi relacionado à psicomotricidade e o aumento ou diminuição deste sinal do exame clínico tem sido um dos aspectos mais comprometidos no TDM-P em relação ao TDM-NP na literatura (FORTY et al., 2009; LEE et al., 2003). Assim, a não diferença de média da pontuação do BPRS “ativação" não reforçou a possibilidade da alteração da psicomotricidade como um sinal específico do TDM-P.

Em relação à questão do suicídio, como já identificado em estudo prévio, houve maior frequência de tentativa de suicídio na vida no TDM-P, como o dado presente, porém, sem alcançar significância estatística (CORYELL, 1996; THAKUR et al., 1999; FORTY et al., 2009; GAUDIANO et al., 2009). A frequência de tentativa de suicídio no episódio atual, por sua vez, não diferiu entre os grupos. Nota-se que a frequencia foi alta em ambos os grupos, possivelmente refletindo o tipo de serviço médico em que os pacientes foram recrutados (hospital terciário, sendo que a maioria dos casos foi identificada a partir do serviço de emergência psiquiátrica).

A idade de início do TDM também discordou da literatura quando revelou semelhança entre os grupos. Início mais precoce foi descrito em estudos prévios em pacientes psicóticos em relação aos não psicóticos (FORTY et al., 2009; GAUDIANO et al., 2009).

O número de EDs na vida foi semelhante entre TDM-P e TDM-NP. Segundo revisão da literatura (CORYELL et al., 1996), o TDM-P apresenta recorrência dos delírios e alucinações, o que representa estabilidade diagnóstica ao longo do tempo desse subtipo clínico de TDM, o que ocorreu para 3 dos 5 sujeitos do TDM-P que apresentaram recorrência de ED. No entanto, como este foi um estudo transversal, não foi possível acessar a estabilidade diagnóstica dos casos de primeiro episódio.

A história cronológica foi semelhante entre TDM-P e TDM-NP. A duração do ED atual e a frequência de episódios crônicos não diferiram entre os grupos de pacientes, contrário à maior frequência de episódios crônicos no TDM-P segundo estudo prévio (GAUDIANO et al., 2009). A cronicidade do ED psicótico pode estar relacionado à má resposta ao uso de $\mathrm{AD}$ isoladamente e ao subdiagnóstico dos sintomas psicóticos (CORYELL, 1996; SCHATZBERG, 2003; KELLER et al. 2007) e, por isso, tratamento inadequado. O tempo de uso de $\mathrm{AD}$ atual não diferiu entre os grupos de pacientes no presente estudo, o que pode ter relação com a semelhanca de tempo de ED entre eles.

A história familiar dos pacientes desse estudo não diferiu entre os grupos, mas diferiu em um estudo prospectivo, em que pacientes com TDM-P possuiam familiares portadores de TAB tipo I com maior frequência que os com TDM-NP (MAJ et al., 2007). Porém outros 4 
estudos também não identificaram essa diferença (GAUDIANO et al., 2009, SIMPSOM et al., 1999; GAUDIANO et al., 2008; LEE et al., 2003). O tamanho da amostra deste estudo não permitiu a avaliação estatística de freqüência de história familiar de transtornos mentais específicos.

Observou-se comorbidade freqüente com outros transtornos mentais nos pacientes deprimidos, como já descrito na literatura. Dados prévios evidenciaram maior associação do TDM-P com o TEPT, TOC e transtorno somatoforme do que o TDM-NP (GAUDIANO et al., 2009) e o presente estudo encontrou pacientes com estes transtornos mentais, porém a média da pontuação do subitem "ansiedade/depressão" da escala BPRS não diferiu entre eles. O tamanho da amostra do presente estudo não permite a análise estatística dos tipos de comorbidades psiquiátricas entre os grupos, porém a freqüência de todas elas não diferiu entre TDM-P e TDM-NP.

Quando os pacientes desse estudo foram submetidos à escala de Hamilton para depressão, não se encontrou diferença entre os TDM-P e os TDM-NP, nem quando avaliada a pontuação de 21, nem a de 31 itens. Observou-se que a grande maioria dos pacientes psicóticos e todos os pacientes não psicóticos tiveram pontuação na escala de Hamilton indicativa de episódio grave, possivelmente refletindo o fato de terem sido recrutados em serviços clínicos especializados (serviço de emergência psiquiátrica na maioria dos casos).

Deve-se notar que 3 pacientes psicóticos tiveram pontuação na Hamilton indicativa de episódio moderado, o que está de acordo com a literatura que sugere que sintomas psicóticos não estão presentes apenas em episódios graves de depressão (KELLER et al., 2007; OHAYON \& SCHATZBERG, 2002; MAJ et al., 2007) e, por outro lado, opõe-se ao fato da psicose ser uma característica específica de TDM grave pelo DSM-IV.

Foi sugerido em artigo de revisão que se separasse a avaliação da psicose daquela relacionada à gravidade dos sintomas depressivos. Os autores sugeriram ainda que a psicose fosse avaliada em dimensões relacionadas a sintomas psicóticos e cognitivos cada um com sua classificação de gravidade e, dessa forma, proporcionar-se-ia o aprofundamento do significado clínico desses sintomas ainda pouco esclarecido (KELLER et al., 2007).

A presente amostra de pacientes com TDM-P apresentou delírios mais frequentemente do que alucinações, como se encontra em outros estudos da literatura (CORYELL et al., 1984; OHAYON et al., 2002). O conteúdo de delírio mais comumente encontrado nesse estudo foi o persecutório e de alucinações, a auditiva, ambos também mais comuns em estudo prévio com pacientes ambulatoriais (GAUDIANO et al., 2009). 
Vários aspectos a respeito dos sintomas psicóticos, como a predominância de alucinações ou de delírios e a congruência do humor do delírio, necessitam de aprofundamento para ampliar a compreensão da relevância clínica dos mesmos (KELLER et al. 2007) e, para isso, o segmento longitudinal dos pacientes seria de grande importância. Em estudo prospectivo foi encontrado prognóstico semelhante entre TDM-P com delírios congruentes com o humor e TDM-NP, diferente do grupo de TDM-P com delírios incongruentes com o humor que, por sua vez, também diferiu do grupo de pacientes com esquizofrenia (CORYELL \& TSUANG, 1985).

Os dados acima convergem para algumas conclusões semelhantes à da literatura a respeito das diferenças clínicas do TDM-P com o TDM-NP (SCHATZBERG \& ROTHSCHILD, 1992; KELLER et al., 2007). Estas diferenças seriam limitadas a aspectos específicos, alguns deles independentes da gravidade dos sintomas depressivos, como piores alterações cognitivas e psicomotoras e maior conteúdo de culpa do TDM-P (SCHATZBERG \& ROTHSCHILD, 1992). O presente estudo também encontrou diferenças pontuais como maior alteração psicomotora, segundo subescala do BPRS dos TDM-P, apesar dos subgrupos terem sido semelhantes quanto à maioria dos dados demográficos e clínicos, entre eles, como a gravidade dos sintomas a partir das pontuações da BPRS e Hamilton. Deve-se notar, entretanto, que apesar de semelhantes em termos de gravidade de sintomas depressivos, os pacientes com a forma psicótica da depressão apresentaram pior funcionamento global, compatível com a literatura prévia (GAUDIANO et al., 2009). Essa piora do funcionamento seria, então, independente da gravidade dos sintomas depressivos isoladamente.

Por fim, embora tradicionalmente na literatura a depressão psicótica seja associada à características melancólicas (PARKER et al., 1997) como piora matinal, perda de peso, insônia, humor não reativo, lentificação psicomotora, e não atípicas, como hiperfagia, hipersonia e reatividade a estímulos (JURUENA et al., 2011), os pacientes deste estudo não mostraram esta especificidade. Talvez uma amostra maior pudesse evidenciar esta diferença.

\subsection{ASPECTOS DE TRATAMENTO MEDICAMENTOSO}

O fato de a maioria dos pacientes da amostra estar em uso de tratamento politerápico pode ser indicativo de comprometimento do TDM na vida dos mesmos e da gravidade da depressão na amostra estudada. Como relatado anteriormente (OMS, 2004), esse transtorno 
mental apresenta uma morbidade elevada. Porém, a tendência de maior frequência de uso de AD pelo TDM-P não foi claramente relacionada a maior morbidade deste grupo, já que todos de ambos os grupos tinham indicação de uso deste medicamento e o padrão de uso de ADs foi heterogêneo, pois havia pacientes em tratamento regular, como também os que não haviam iniciado ou interrompido o tratamento, independente do grupo diagnóstico a que pertencia.

Deve-se notar que, à avaliação ao exame de RM, nem todos os pacientes estavam em tratamento medicamentoso. Em alguns casos, eles não haviam ainda iniciado nenhum tratamento para o episódio atual, em outros casos eles já haviam feito uso anterior, mas haviam suspendido o uso. Foi possível a aquisição da RM nestes pacientes quando a logística permitia que eles fossem convocados para o exame assim que admitidos no serviço. Por outro lado, alguns pacientes já vinham em uso regular de medicação, ou não foi possível realizar o exame de RM prontamente, de modo que a maioria dos pacientes estava em uso de alguma medicação psicotrópica.

Além disso, apenas pacientes com TDM-P estavam em uso de AP. Isso não foi visto em estudo prospectivo (MAJ et al., 2007), em que pacientes com TDM-NP também faziam uso dessa medicação, mas ambos os resultados evidenciaram que esse uso foi significativamente mais freqüente entre os com TDM-P. A melhor resposta do TDM-P à associação de AD + AP foi identificada em alguns estudos (SCHATZBERG, 2003), porém a maior eficácia desta combinação em relação ao uso do AD isoladamente ainda é controversa (WIJKSTRA et al., 2006).

\subsection{NEUROQUÍMICA DO CA POR ${ }^{1} \mathrm{H}-\mathrm{ERM}$}

\subsubsection{Correlações entre as variáveis idade e metabólitos entre si}

Os níveis de Glu do CA correlacionou-se positivamente com o NAA+NAAG, PC+GPC e Cr. A correlação positiva do Glu com o NAA+NAAG está em parte explicada pela própria composição deste segundo metabólito. O NAAG é composto por NAA conjugado ao Glu e o NAAG corresponde a $10 \%$ do pico de NAA+NAAG (BASLOW et al., 2003). Além disso, supõe-se que a redução dos níveis de ambos os picos estaria relacionada a processos semelhantes: prejuízo estrutural e funcional do CA. Conforme explanação prévia, 
ambos Glu e NAA são produzidos pelos neurônios e catabolizados pelos astrócitos (BASLOW et al., 2003) e no TDM, transtorno investigado pelo presente estudo, haveria redução da densidade de neurônios e do número da glia na região do $\mathrm{CA}$, segundo dados histopatológicos (ONGUR et al., 1998, RAJKOWSKA et al., 2000).

Os níveis de Gln+ Glu foram altamente correlacionados com os de Glu, conforme esperado, já que a primeira medida que resulta da soma de Glu com Gln, e assim também se correlacionou com NAA+NAAG, PC+GPC e Cr. Muitas vezes, porém, o sinal de Gln não foi captado e por isso o valor de Gln+Glu foi igual ao de Glu. A perda do valor de Gln impossibilitou a verificação da relação deste metabólito com o Glu, a qual tem demonstrado importância na diferenciação do estado do humor. Segundo dados de revisão recente, os valores de Gln apresentam-se inferiores aos de Glu no estado depressivo, independente do diagnóstico ser TDM ou THB e reforçaram-se os achados de revisões anteriores de que há redução do Gln+Glu no TDM (YÜKSEL e ONGÜR, 2010).

$\mathrm{O} \mathrm{PC}+\mathrm{GPC}$ encontra-se estreitamente relacionado ao metabolismo da membrana fosfolípide evidenciado em doenças onde há tanto aumento da sua renovação, quanto destruição da membrana (CHANG et al., 1996). Entre as condições de alteração de níveis de PC+GPC, há o envelhecimento na qual este metabólito encontra-se aumentado em controles saudáveis (CHANG et al., 1996; PFEFFERBAUM et al., 1999; JUNG et al., 2009). A presente amostra, por sua vez, evidenciou correlação positiva da idade com esse metabólito, independente do grupo de casos ou controles para a região do CA.

Este estudo também encontrou correlação positiva entre os níveis de $\mathrm{PC}+\mathrm{GPC}$ com os níveis de Glu, Gln+Glu, NAA+NAAG e Cr. O mesmo dano celular do CA no TDM possivelmente implicado com redução dos níveis de Glu e NAA+NAAG (ONGUR et al., 1998; RAJKOWSKA et al., 2000) também poderia explicar redução da renovação/destruição de membrana celular dessa região cerebral e assim estar relacionado com a diminuição dos níveis de $\mathrm{PC}+\mathrm{GPC}$ e com a correlação positiva entre esses três metabólitos para essa região cerebral (CHANG et al., 1996).

Os níveis de Cr, por sua vez, correlacionaram-se com os dos metabólitos explanados acima e com a idade. Com o envelhecimento, o cérebro perde água tanto intra quanto extracelular e o aumento da proporção $\mathrm{Cr} / \mathrm{H}_{2} \mathrm{O}$ poderia explicar o aumento da captação desse metabólito pela ${ }^{1}$ H-ERM como também do PC+ GPC e myo-Ins (CHANG et al., 1996).

As correlações positivas entre $\mathrm{Cr}$ e Glu, Gln+Glu e NAA+NAAG encontradas representariam vias metabólicas subjacentes que fogem ao alcance do nosso estudo visto que 
a redução encontrada de $\mathrm{Cr}$ foi no grupo masculino TDM-NP e de Glu, Gln+Glu e NAA+NAAG foi vista no TDM-P.

\subsubsection{Relação entre metabólitos, grupo e sexo}

Primeiramente, verificou-se a distribuição dos metabólitos do CA entre os grupos que mostrou diferença para o Glu, NAA+NAAG e PC+GPC.

\subsubsection{Distribuição dos metabólitos entre TDM-P, TDM-NP e controle}

Os três metabólitos acima apresentaram os menores valores no TDM-P e foram semelhantes entre o TDM-NP e o controle. Evidências histopatológicas apontam para a hipercortisolemia como um dos principais fatores relacionados ao dano do CA em TDM (ONGUR et al., 1998; RAJKOWSKI et al., 2000; BELMAKER et al., 2008). Há dados de maior hiperativação do eixo HPA no TDM-P do que no TDM-NP (GAUDIANO et al., 2009; CONTRERAS et al., 2007; GOMES et al., 2006; KELLER et al., 2006; BELANOFF et al., 2001), o que poderia levar a maior disfunção do CA no primeiro grupo de pacientes. Assim, o CA do grupo TDM-P poderia apresentar maior prejuízo tanto estrutural quanto funcional e, consequentemente, diminuição dos níveis de Glu, NAA+NAAG e PC+GPC, como encontrados no presente estudo.

Além disso, a presença de psicose na depressão maior já foi relacionada ao aumento de dopamina consequente à hipercortisolemia presente nesse transtorno mental (SCHATZBERG et al., 1995). O excesso de cortisol já foi relacionado à elevação de dopamina plasmática em humanos e em ratos e o CA é uma região rica em projeções dopaminérgicas oriundas da área tegumentar ventral (SCHATZBERG et al., 1995). Como o TDM-P apresentaria maior hiperativação do eixo HPA que o TDM-NP, poderia haver maior liberação de dopamina nessa região cerebral nos paciente com TDM-P e isso corresponder ao desenvolvimento dos sintomas psicóticos (SCHATZBERG et al., 1995).

$\mathrm{Na}$ esquizofrenia, que é o principal e mais estudado dentre os Transtornos Psicóticos também se encontra redução de Glu no CA em fase crônica (THEREBERGE et al., 2004; 
ABBOTT \& BUSTILLO, 2006). Essas alterações metabólicas seriam secundárias à hipofunção do receptor de Glu tipo NMDA, o que desencadearia aumento inicial de Glu (que é neurotóxico) e, por isso, haveria redução dos níveis de Glu e de NAA (Olney et al., 1999). A hipótese para processo fisiopatogênico descrito para a esquizofrenia crônica poderia em parte ocorrer no TDM, sendo subjacente à apresentação psicótica, com sintomas do tipo delírios e alucinações. A lesão do sistema glutamatérgico, por sua vez, seria desencadeada pela hipercortisolemia, já bem descrita nesses casos.

O estresse, por sua vez, também foi implicado na modulação do receptor NMDA (STEINER et al., 2011). A elevação do cortisol desencadeia a metabolização do triptofano pela via da kiurenina em diferentes produtos, sendo que no TDM predomina o ácido quinolínico (MYINT e KIM, 2003) e na Esquizofrenia o ácido kinurênico (ERHARDT et al., 2001; NILSSON et al., 2005). O primeiro foi associado ao o aumento de Glu por meio da ativação do receptor NMDA (TAVARES et al., 2005) e o segundo com redução desse metabólito por antagonismo do mesmo receptor (WU et al., 2009). Como o TDM-P do presente estudo evidenciou redução dos níveis de Glu em relação não só aos controles, mas também ao TDM-NP, supor-se-ia que nesse grupo de pacientes haveria o predomínio do ácido kinurênico, semelhante ao que ocorreria na Esquizofrenia.

Verificou-se ainda que essa modulação também difere de acordo com a região cerebral avaliada. O CA de ratos em modelo de depressão apresentou redução do ácido quinolínico, que estaria implicado com efeito anti-excitotóxico, enquanto a amígdala dos mesmos evidenciou aumento desse metabólito (LAUGERAY et al., 2010). Essa diferença regional foi descrita pelo modelo neuroanatômico de depressão citado acima e inclusive é compatível com o presente resultado de redução do Glu no CA no TDM-P, já que nesse modelo essa região cerebral estaria hipoativada (PHILLIPS et al., 2003a,b)

A diferença dos níveis de NAA+NAAG entre os três grupos não alcançou significância estatística, porém apresentou uma dimensão de efeito moderada, o que independe do tamanho da amostra. Talvez, caso se aumentasse o número de pacientes e controles, poder-se-ia evidenciar que o valor desse metabólito no TDM-P foi significativamente menor que nos demais grupos, corroborando os achados de literatura de psicose afetiva e de esquizofrenia onde há redução desse metabólito (BLASI et al., 2004, SHIMIZU et al., 2005), embora as regiões com redução de NAA nesses estudos tenham sido outras: na psicose afetiva a alteração foi encontrada em hipocampo (BLASI et al., 2004) e na Esquizofrenia foi em giro do cíngulo posterior (SHIMIZU et al., 2005). 
Assim como para os níveis de Glu, os de PC+GPC também se encontraram reduzidos no CA do TDM-P. Esse achado não foi compatível com o encontrado em metanálise prévia (YILDIZ-YESILOGLU e ANKERST, 2006) que encontrou aumento desse metabólito em gânglios da base. Por outro lado, a possibilidade de hipoatividade do CA no TDM sugerido pelo modelo neuroanatômico de perda glial por hipercortisolemia mais acentuada no TDM-P que no TDM-NP citados acima poderiam explicar uma redução da renovação celular no CA dos presentes pacientes.

A redução dos níveis de Glu, NAA+NAAG e PC+GPC no CA do TDM-P em relação ao TDM-NP e controles foram evidenciadas por resultados de mais de uma técnica de neuroimagem. Estudos prévios que compararam TDM-P e TDM-NP encontraram: menor volume do lobo frontal do grupo TDM-P em indivíduos idosos por RM estrutural (SIMPSON et al., 1999), menor FSC em CA subgenual (CAsg) do TDM-P por SPECT (SKAF et al., 2002) e aumento do metabolismo nesta região após remissão de sintomas depressivos por SPECT (MCCORMICK et al., 2007). Esses resultados são compatíveis com prejuízo tanto estrutural quanto funcional condizentes com a redução dos níveis de metabólitos nos psicóticos encontrada pelo presente estudo.

Deve-se notar que os pacientes com depressão não psicótica (TDM-NP) não apresentaram diferenças de metabólitos em relação aos controles. Apesar das evidências de atrofia do CA em TDM serem fortes, a redução do metabolismo não está bem esclarecida. Outros estudos funcionais evidenciaram aumento de atividade em CAsg que ocorreu após estímulo negativo em um trabalho e em outro, com pacientes com TDM que inicialmente haviam demonstrado redução do FSC, mas após correção do efeito de volume parcial dessa técnica de imagem, o resultado foi o oposto, de aumento de FSC nessa região cerebral (PHILLIPS et al., 2003a). Então, a condição de funcionamento dessa região cerebral no TDM ainda é controversa e ao mesmo tempo faz juz ao local de comunicação recíproca entre sistema ventral e dorsal cerebrais cujas ações são aparentemente opostas (PHILLIPS et al., 2003b) e que, provavelmente, não se apresenta em condições dentro dos limites do saudável durante um episódio depressivo maior. E de fato, a literatura de espectroscopia de CA em TDM não psicótico ainda não permitiram resultados consistentes (YILDZ-YESILOGLU e ANKERST, 2006; CAPIZZANO et al., 2007; YUKSSEL e ONGUR, 2010).

Por fim, cabe observar que apesar das diferenças neuroquímicas entre pacientes com depressão psicótica e não psicótica, as correlações dos metabólitos entre sintomas clínicos (por escalas de depressão e psicose) não foram significativas. No caso dos sintomas 
depressivos, isto é compatível com a ausência de diferenças entre TDM-NP e controles, já que não houve diferença nos níveis dos metabólitos entre esses grupos.

Por outro lado, relatos da literatura evidenciaram relação dos níveis de Glu em CA com a gravidade de sintomas de pacientes deprimidos (WALTER et al., 2009). Pacientes com maior grau de anedonia evidenciaram redução de Glu em CA enquanto os demais pacientes com TDM não apresentaram essa alteração metabólica (WALTER et al. 2009). Outro estudo evidenciou redução de Glu em CA em TDM grave segundo CID 10 diferentemente dos demais pacientes da amostra (AUER et al., 2000).

O subtipo clínico do TDM também foi relacionado a diferentes padrões metabólicos cerebrais nesse transtorno mental. O subtipo melancólico, por exemplo, foi relacionada a redução de GABA em lobo occipital em TDM enquanto o subtipo com características atípicas não apresentou essa alteração nessa região cerebral (SANACORA et al., 2004). O TDM melancólico, por sua vez, está mais associado a sintomas psicóticos que os demais grupos (PARKER et al., 1996) e atualmente já há várias evidência de diferenças fisiopatológicas entre os subtipos de depressão que poderiam explicar as diferenças dos níveis de metabólitos entre eles e não a gravidade dos sintomas depressivos em si (JURUENA et al., 2011).

\subsubsection{Distribuição dos metabólitos entre os sexos}

Apesar da interferência do sexo sobre a composição dos metabólitos ter apenas se aproximado da significância, esta evidenciou um efeito de dimensão moderado que independe do tamanho da amostra, apontando para o fato de que se aumentasse o mesmo a interferência do sexo sobre os metabólitos seria evidenciada. Além disso, sabe-se da relevância do estudo desse fator na epidemiologia, clínica e fisiopatologia tanto no TDM (KESSLER et al., 2003; FINK, et al., 1998; ACCORT et al., 2008) quanto nos transtornos psicóticos (FINK et al., 1998). Dessa forma, procedeu-se análise univariada para explicitar a diferença dos níveis dos metabólitos entre o sexo masculino e o feminino.

Os níveis de Glu e de NAA+NAAG foram inferiores no sexo masculino em relação ao sexo feminino. Estudos em animais evidenciam que o estrógeno aumenta a ramificação dendrítica, a formação sináptica (TANAPAT et al., 1999;) e a densidade do 5-HT2A (SUMNER et al., 1999) e o transportador de 5-HT no CPF (ACCORTT et al., 2008), além de evidências clínicas depressão pós-parto relacionado à redução brusca dos níveis desse 
hormônio (BLOCH et al., 2000). Supõe-se, assim, que os hormônios femininos exerceriam neuroproteção nas mulheres do presente estudo.

Além disso, o sexo masculino foi associado à maior taxa de suicídio (MANN et al., 2002), a maior frequência de TDM com características melancólicas (BREMMER et al., 2006) e a transtornos psicóticos que as mulheres (), O aumento de cortisol poderia estar implicado nessas diferenças clínicas entre os gêneros em vista de que não só o TDM-P, como citado anteriormente, mas também o tipo melancólico do TDM foram associados à maior hiperativação do eixo HPA que o TDM sem essas características ou do tipo atípico ().

Por fim, o TDM no sexo masculino também foi associado a hipercortisolemia enquanto o sexo feminino à hipocortisolemia (BREMMER et al., 2006).

No entanto, os níveis de $\mathrm{PC}+\mathrm{GPC}$ não diferiram entre os sexos. Há evidências por ${ }^{1} \mathrm{H}-$ ERM durante o ciclo menstrual de que os níveis deste metabólito não flutuam conforme os hormônios sexuais (RASGOM et al., 2001). Isso aponta para a não interferência dos hormônios sexuais sobre os níveis de $\mathrm{PC}+\mathrm{GPC}$ e consequentemente dos seus efeitos benéficos na renovação e destruição de membranas e explicaria a semelhança dos níveis desse metabólito entre os gêneros da presente amostra.

\subsubsection{Distribuição dos metabólitos entre os sexos dentro de cada diagnóstico}

Da mesma forma que o fator sexo, a interação grupo-sexo não interferiu sobre a composição dos níveis dos metabólitos de forma significativa, mas apresentou dimensão de efeito moderada que independe do tamanho da amostra e, por isso, supõe-se que se aumentasse tal tamanho, poder-se-ia encontrar efeito significativo da interferência desse fator.

Quando, então, realizamos uma análise univariada para verificar tal interferência sobre os metabólitos, encontramos que os níveis de Glu, o Gln+Glu e o Cr se comportaram diferente entre os sexos dentro de cada grupo de forma significativa.

Os homens apresentaram menores níveis de Glu e de Gln+Glu do que as mulheres no grupo TDM-P. Para esses metabólitos, os homens do TDM-P apresentaram valores discrepantes em relação aos homens do TDM-NP e das mulheres do TDM-P e do TDM-NP. Supor-se-ia então que essa redução de Glu e Gln+Glu preponderantemente mais importante nos homens do TDM-P seria resultante da possível maior ativação do eixo HPA desse grupo de pacientes somada a possível falta da neuroproteção dos hormônios femininos. 
Quanto ao $\mathrm{Cr}$ homens e mulheres apresentaram valores semelhantes dentro do grupo TDM-P, já no grupo não psicótico, os homens apresentaram valores menores do que as mulheres, A diferença de $\mathrm{Cr}$ entre os sexos foi encontrada em estudo prévio, em que os homens com TDM-NP também apresentaram menores níveis do que as mulheres (NERY et al., 2009), indicativo de pior reserva energética nesse subgrupo de pacientes. Porém, a redução de Cr também foi encontrada em pacientes com esquizofrenia (ÖNGÜR, et al., 2009), o que não ocorreu com os pacientes do TDM-P.

\subsubsection{Perfil neuroquímico do CA exclusivamente no sexo feminino}

Como a ausência de significância estatística pode ter sido devida à limitação do tamanho da amostra, optou-se por investigar os efeitos do sexo na análise dos metabólicos, ainda que de forma exploratória, e ainda que este não tenha sido o objetivo inicial do estudo.

Como citado anteriormente, os hormônios sexuais femininos apresentam função de neuroproteção (TANAPAT et al., 1999; SUMNER et al., 1999). Diante disso, faz-se crer que os níveis de Glu, de Gln+Glu próximos aos níveis do controle teriam relação com o papel protetor do estrógeno diante de alterações fisiopatológicas no TDM, pelo menos em termos deste metabólitos no CA. Possivelmente, a não hiperativação do eixo HPA e até hipoativação encontrada em pacientes com TDM do sexo feminino poderia estar subjacente à preservação do sistema glutamatérgico no CA da presente amostras, mas a ausência das medidas do eixo HPA impossibilitou que essa hipótese pudesse ser reforçada (BREMNER et al., 2006).

Ainda assim, as mulheres apresentaram redução dos níveis de NAA+NAAG e de $\mathrm{PC}+\mathrm{GPC}$ no grupo TDM-P. Esses resultados reforçam o achado para alterações nesses metabólitos em ambos os sexos, apontando para o prejuízo do ciclo do NAA e de renovação e destruição de membrana no CA desses pacientes

\subsubsection{Perfil neuroquímico do CA exclusivamente no sexo masculino}

Novamente, de forma exploratória analisamos o sexo masculino isoladamente, mesmo que esse não tenha sido objetivo de nosso estudo, diante da possibilidade de ausência de 
significância estatística para o fator sexo devido ao tamanho da amostra. Nessa análise acentuou-se a redução de Glu e de NAA+NAAG nesse grupo de pacientes.

Os níveis de Glu do sexo masculino foram inferiores no TDM-P, porém sem alcançar significância provavelmente devido ao tamanho da amostra já que a dimensão de efeito que independe do deste fato foi de elevada dimensão. Assim, sugere-se que há prejuízo do sistema glutamatérgico no CA dos homens da presente amostra devido à já comentada anteriormente maior ativação do eixo HPA no TDM-P que está associada à perda glial no CA, como também ao aumento da liberação de glutamato consequente neurotoxicidade. Além disso, no TDM-P há possibilidade haver predominância da produção do ácido kinurênico como na Esquizofrenia que está relacionada à hipofunção do receptor NMDA e consequente aumento e neurotoxicidade por excesso Glu (ERHARDT et al., 2001; NILSSON et al., 2005).

Já os níveis de NAA+NAAG foram reduzidos não apenas no TDM-P, mas principalmente no TDM-NP em relação ao controle. É possível que a ausência da diferença entre TDM-P e controle seja devido ao baixo poder da estatística e que se aumentasse o tamanho da amostra essa diferença poderia tornar-se significativa. Então, a redução dos níveis de NAA+NAAG em ambos os grupos de pacientes evidenciou comprometimento do ciclo do $\mathrm{NAA}+\mathrm{NAAG}$, mas não necessariamente implica em lesão irreversível dessa região cerebral, já que este metabólito também participa do funcionamento energético dos neurônios. Por outro lado, evidências mostraram menor evento estressante desencadeando o próximo ED em relação àquele que desencadeou o primeiro episódio sugerindo que o primeiro ED deixou alterações cerebrais que facilitaram o desencadeamento do ED seguinte (POST et al.,1992).

\subsubsection{Uso de medicação e níveis dos metabólitos CA}

Como já exposto anteriormente, não foi possível adquirir amostra exclusivamente composta por pacientes não medicados, uma vez que muitos pacientes já estavam em episódio depressivo há um tempo significativo e demandavam tratamento medicamentoso pelo quadro patológico. E pela heterogeneidade dos regimes terapêuticso a que estavam expostos, também não foi possível realizar análise estatística de diferenças de metabólitos de acordo com classes específicas de psicotrópicos. Assim, embora não tenha sido obejtivo inicial do estudo, fez-se necessário uma abordagem da possível interferência do uso de medicações pelos pacientes sobre os resultados encontrados e descritos até o momento, uma vez que nem todos os 
pacientes estavam em uso de AD e que apenas os pacientes com TDM-P faziam uso de AP, e este fato poderia ser responsável pelas diferenças de metabólitos entre os grupos.

Apesar de não ter sido possível a análise estatística da relação dos metabólitos com o uso de psicotrópicos na análise multivariada, devido ao tamanho limitado da amostra, as correlações bivariadas entre o tempo de uso dos medicamentos (AP, AD e BZD) e os níveis dos metabólitos. As três análises mostraram ausência de correlação significativa entre eles. Além disso, os dados da literatura quanto à interferência do uso de medicamentos no níveis do metabólitos são favoráveis aos resultados do presente estudo.

Segundo revisão de literatura (YÜKSEL e ÖNGÜR, 2010), os níveis de Glu não se correlacionaram com o uso de medicações psicotrópicas. Alguns relatos sugeriram, no entanto, que o uso de AP poderia estar associado ao aumento de NAA+NAAG em pacientes com esquizofrenia (BERTOLINO et al., 2001) e outros sugeriram a ausência da interferência do AP nos níveis de Glu, Gln e NAA (BUSTILLO e tal., 2005) . Os resultados aqui apresentados evidenciaram, pelo contrário, a redução dos níveis deste metabólito em pacientes deprimidos psicóticos, levando-nos a crer que realmente nossos achados não sofreram viés do uso de APs.

Quanto ao uso de benzodiazepínicos, houve relato de uso de lorazepam e os níveis de PC+GPC, Cr e Myo-Ins. Segundo relato da literatura, apontou-se para aumento desses metabólitos com o uso do lorazepam, no entanto, os níveis encontrados neste estudo foram de níveis reduzidos do primeiro metabólito em relação ao controle (DAVANZO et al., 1997).

$\mathrm{O}$ uso de $\mathrm{AD}$ também já foi relacionado à alteração dos níveis de metabólitos na literatura. Após tratamento com AD, há relatos de aumento de NAA+NAAG (GONUL et al., 2006) e Myo-Ins (KAYMAK et al., 2009), apesar disso, encontrou-se tendência à redução dos níveis de NAA nos pacientes psicóticos, e este grupo não diferiu dos não psicóticos em freqüência ou tempo de uso de AD. .

Este trabalho possui algumas limitações que devem ser reconhecidas e são listadas a seguir.

1. Trata-se de amostra coletada em serviço de referência especializado em tratamento de Transtornos Mentais, portanto, os achados do estudo não podem ser generalizados para todos os casos de transtornos depressivos.

2- O mesmo aplica-se à questão da faixa etária: avaliamos apenas adultos não idosos, ou seja, os resultados não podem ser generalizados para depressão na infância/adolescência ou depressão geriátrica. 
3. Foram avaliados apenas casos de TDM (ou seja, pacientes com forma unipolar de depressão). Os resultados, então, também não podem ser generalizados para as formas bipolares (como no caso de portadores de THB).

4 - A amostra foi coletada de acordo com o encaminhamento para o serviço de urgência ou ambulatorial do HC-FMRP, portanto, apresenta heterogeneidade clínica, em termos de aspectos cronológicos da depressão (casos de início recente e casos crônicos) e em termos de exposição a medicamentos. No entanto, a amostra foi homogênea em relação à gravidade, com a imensa maioria sendo constituída por pacientes graves. Este fato limitou a capacidade do estudo de avaliar formas leves de depressão.

5. Este estudo avaliou apenas uma região cerebral (Cíngulo anterior) e não foi possível avaliar o hipocampo, conforme planejado inicialmente, por motivos técnicos. Outra região de interesse, o córtex pré-frontal dorsolateral, não foi avaliado em todos os pacientes dessa amostra e será avaliado em estudo futuro.

6. Por fim, deve-se reconhecer que o tamanho da amostra pode ter sido insuficiente para permitir o encontro de algumas diferenças significativas, que no presente trabalho alcançaram níveis marginais de significância. Amostras maiores podem ser de grande valia para confirmar e expandir os achados do presente trabalho. 


\section{CONCLUSÕES}

Este estudo teve como objetivo investigar diferenças sócio-demográficas, clínicas e neuroquímicas (através de espectroscopia de cíngulo anterior, região cerebral implicada na fisiopatologia da dos Transtornos de Humor e Psicóticos) entre pacientes deprimidos com e sem sintomas psicóticos. Este é um tema muito pouco explorado na literatura dos Transtornos de Humor, e até o momento, apesar de algumas evidências sugerindo que a depressão psicótica deva ser considerada uma forma específica de Transtorno Depressivo, ainda não há consenso a respeito.

Os pacientes avaliados apresentaram depressão moderada/grave e eram usuários de serviço psiquiátrico especializado. Não se encontrou diferenças sócio-demográficas ou clínicas, com exceção de menor escolaridadde, proporção de indivíduos empregados e pior funcionamento global nos pacientes com sintomas psicóticos que foi independente da gravidade dos sintomas depressivos. Este achado pode ter relevância em termos de identificação e tratamento precoce destes pacientes, uma vez que os sintomas psicóticos em depressão costumam ser subdiagnosticados na prática clínica.

Em relação ao objetivo principal do estudo (avaliação neuroquímica de $\mathrm{CA}$ ), o resultado principal foi o de diferenças entre os grupos em relação ao glutamato e aos compostos de colina, sendo que pacientes com a forma psicótica da depressão apresentaram níveis reduzidos destes metabólitos, enquanto os não psicóticos não diferiram dos controles. Níveis menores de NAA também foram evidenciados nos psicóticos, embora a diferença entre os grupos não tenha atingido significância estatística. Esses resultados sugerem um comprometimento maior da região do CA quando da presença de sintomas psicóticos em TDM. As alterações destes metabólitos são compatíveis, respectivamente, com disfunções no sistema de neurotransmissão glutamatérgica (compatível com o descrito na literatura sobre fisiopatologia das psicoses), de metabolismo de membrana e de integridade neuronal.

Portanto, embora os achados sócio-demográficos e clínicos não corroborem a hipótese de que a depressão psicótica seja uma forma específica de Transtorno Depressivo (com exceção da maior disfunção global, que pode ser secundária à própria presença dos sintomas psicóticos), os achados da espectroscopia de CA apontam para diferenças fisiopatológicas entre as formas psicótica e não psicótica do TDM, corroborando outros achados biológicos, principalmente a ativação do eixo HPA.

Secundariamente, este estudo sugere que o perfil dos metabólitos no CA pode sofrer uma interação entre o diagnóstico e o sexo do paciente, visto que homens com depressão psicótica apresentam níveis de Glu e de Gln+ Glu inferiores ao das mulheres do mesmo grupo apontando para o papel neuroprotetor dos hormônios sexuais femininos. 


\section{REFERÊNCIAS BIBILIOGRÁFICAS}

ABBOTT C.; BUSTILLO J. What have we learned from proton magnetic resonance spectroscopy about schizophrenia? A critical update. Curr Opin Psychiatry. 2006. 19: 1359 .

ABEP. Associação Brasileira de Empresas de Pesquisa. Critério de Classificação Econômica Brasil, 2003.

ACCORTT E.E.; FREEMAN M.P.; ALLEN J.J.B. Women and Major Depressive Disorder: Clinical Perspectives on Causal Pathways. Journal of Women's Health. 2008; 17(10):158390.

APA. Diagnostic and Statistical Manual of Mental Disorders. 4. ed.; Text rev. (DSM-IVR). Washington: DC.American Psychiatry Association, 2000.

AZEVEDO-MARQUES PÉRICO C.; DURAN F.L.; ZANETTI M.V.; SANTOS L.C.; MURRAY R.M.; SCAZUFCA M.; MENEZES P.R.; BUSATTO G.F.; SCHAUFELBERGER M.S. A population-based morphometric MRI study in patients with first-episode psychotic bipolar disorder: comparison with geographically matched healthy controls and major depressive disorder subjects. Bipolar Disord. 2001; 13(1): 28-40.

BASLOW M.N. Acetylaspartate in the Vertebrate Brain: Metabolism and Function. Neurochemical Research, 2003; v. 28, n. 6, June, 941-953.

BELANOFF J.K.; KALEHZAN M.; SUND B.; FICEK S.K.F.; SCHATZBERG A.F. Cortisol activity and cognitive changes in psychotic major depression. Am J Psychiatry. 2001; 158:1612-1616.

BELMAKER R.H.; GALILA A. Major Depressive Disorder. N Engl J Med. 2008; 358: 5568.

BERTOLINO A.; CALLICOTT J.H.; ELMAN I.; MATTAY V.S.; TODESCHI G.; FRANK J.A.; BREIER A.; WEINBERGER D.R. The effect of treatment with antipsychotic drugs on brain N-acetylaspartate measures in patients with schizophrenia. Biological Psychiatry. 2001: 49: 39-46.

BIRD C.M.; BURGESS N. The hippocampus and memory: insights from spatial processing. Nat Rev Neurosci. 2008: 9: 182-94. 
BLASI G.; BERTOLINO A.; BRUDAGLIO F.; SCIOTA D.; ALTAMURA M.; ANTONUCCI N.; SCARABINO T.; WEINBERGER D.R.; NARDINI M. Hippocampal neurochemical pathology in patients at first episode of affective psychosis: a proton magnetic resonance spectroscopic imaging study. Psychiatry Res. 2004. 131: 95-105

BLOCH M.; SCHMIDT P.J.; DANACEAU M.; MURPHY J.; NIEMAN L.; RUBINOW D.R. Effects of gonadal steroids in women with a history of postpartum depression. Am $\mathbf{J}$ Psychiatry. 2000 Jun; 157(6):924-30.

BREMNER J.D.; VYTHILINGAM M.; VERMETTEN E.; VACCARINO V.; CHARNEY D.S. Deficits in hippocampal and anterior cingulate functioning during verbal declarative memory encoding in midlife major depression. Am J Psychiatry. 2004. 161: 637-45.

BROWN R.; FRANCES A.; KOCSIS J.; MANN J. Psychotic vs. nonpsychotic depression: comparison of treatment response. J Nerv Ment Dis. 1982; 170: 635-7.

CALABRESE J.R.; BOWDEN C.L.; SACHS G.S.; ASCHER J.A.; MONAGHAN E.; RUDD G.D. A doubleblind placebo-controlled study of lamotrigine monotherapy in outpatients with bipolar I depression: Lamictal 602 Study Group. J Clin Psychiatry. 1999;60:79-88.)

CAHILL L.; BABINSKY R.; MARKOWITSCH H.J.; MCGAUGH J.L. The amygdala and emotional memory. Nature. 1995: 377: 295-6.

CAMPBELL S.; MARRIOTT M.; NAHMIAS C.; MACQUEEN G.M. Lower hippocampal volume in patients suffering from depression: a meta-analysis. Am J Psychiatry. 2004: 161: 598-607.

CAPIZZANO A.A.; JORGE R.E.; ACION L.C.; ROBINSON R.G.In vivo proton magnetic resonance spectroscopy in patients with mood disorders: a technically oriented review. J Magn Reson Imaging. 2007: 26: 1378-89.

CARVALHO T.F.R.; CAETANO D.; LIMA M.G.; AZEVEDO R.C.S. Tradução do inglês para o português da escala do Questionário de Auto-avaliação da Escala de Hamilton para a depressão. J Bras Psiquiatr. 1993.42 (5): 255-60.

CASPI A.; SUGDEN K.; MOFFITT T.E.; TAYLOR A.; CRAIG I.W.; HARRINGTON H.; MCCLAY J.; MILL J.; MARTIN J.; BRAITHWAITE A.; POULTON R. Influence of life stress on depression: moderation by a polymorphism in the 5-HTT gene. Science. 2003; 301:386-389.

CHANG L.; ERNST T.; POLAND R.E.; JENDEN D.J. In vivo proton magnetic resonance spectroscopy of the normal aging human brain. Life Sci. 1996; 58:2049-2056. 
CONTRERAS F.; NAVARRO M.A.; MENCHON J.M.; ROSEL P.; SERRALONGA J.; PEREZ-ARNAU F.; URRETAVIZCAYA M.;.VALLEJO J. Growth hormone response to growth hormone releasing hormone in non-delusional and delusional depression and healthy controls. Psychological medicine. 1996; 26:301-7.

CORYELL W. Psychotic depression. J. Clin Psychiatry.1996; 57 (suppl 3):27-31.

CORYELL W.; TSUANG M.T. Major depression with mood-congruent or mood-incongruent psychotic features: outcome after 40 years. Am J Psychiatry. 1985; 142: 479-82.

CORYELL W.; NOPOULOS P.; DREVETS W.; WILSON T.; ANDREASEN N.C. Subgenual prefrontal cortex volumes in major depressive disorder and schizophrenia: diagnostic specificity and prognostic implications. Am J Psychiatry. 2005; 162: 1706-12.

CREBBIN K.; MITFORD E.; PAXTON R.; TURKINGTON D. First-episode psychosis: an epidemiological survey comparing psychotic depression with schizophrenia. J Affect Disord. 2008; 105: 117-24.

CULAV-SUMIĆ J.; JUKIĆ V. Minor physical anomalies in women with recurrent unipolar depression. Psychiatry Res. 2010 Mar 30;176(1):22-5. Epub 2010 Jan 13.

DANCEY C.P.; REIDY J. (trad. L. Viali). Estatística sem matemática para psicologia. In: Análise de correlação: o r de Pearson. 3. ed. Cap. 5. Porto Alegre: Artmed, 2006.

DAVANZO P.; OSHIRO T.; THOMAS M.A.; SHAH B.; BELIN T.; MCCRACKEN J. ${ }^{\mathbf{1}} \mathbf{H}-$ ERM spectroscopy in human brain with and without lorazepam. Poster presented at the annual meeting of the International Society for magnetic Resonance in Medicine, Vancouver, Canada, 1997.

DEAKIN J.F.W.; GRAEFF F.G. 5-HT and mechanisms of defense. Journal of Psychopharmacol. 1991;5:305-15.

DEL-BEN C.M.; VILELA J.A.A.; CRIPPA J.A.S.; HALLAK J.E.C.; LABATE C.M.; ZUARDI A.W. Confiabilidade da "Entrevista Clínica Estruturada para o DSM-IV - Versão Clínica" traduzida para o português. Rev Bras Psiquiatr. 2001; 23 (3): 156-9.

DREVETS W.C.; PRICE J.L.; SIMPSON J.R.; TODD R.D.; REICH T.; VANNIER M.; RAICHLE M.E. Subgenual prefrontal cortex abnormalities in mood disorders. Nature. 1997; 386: $824-7$

DREVETS W.C.; SAVITZ J.; TRIMBLE M. The subgenual anterior cingulate cortex in mood disorders. CNS Spectr. 2008; 13: 663-81. 
ERHARDT S.; BIENNOW K.; NORDIN C.; SKOGHE.; LINDSTROM L. H.; ENGBERG G.Kynurenic acid levels are elevated in the cerebrospinalfluid of patients with schizophrenia. Neurosci Lett. 2001; 313: 96-8.

FAVA G.A.; PARK S.K.; SONINO N. Treatment of recurrent depression. Expert Rev Neurother. 2006; 6: 1735-40.

FINK G.; SUMNER B.; MCQUEEN J.; WILSON H.; Rosie R. Sex steroid control of mood, mental state and memory. Clin Exp Pharmacol Physiol 1998;25:764-775.

FIRST M. B.; SPITZER R. L.; GIBBON M.; WILLIAMS J.B.W. Structured Clinical Interview for DSM-IV Axis I Disorders, Clinician Version (SCID-CV). Washington, D.C.: American Psychiatric Press, Inc., 1997.

FORTY L.; JONES L.; JONES I.; COOPER C.; RUSSEL E.; FARMER A.; MCGUFFIN P.; CRADDOCK N. Is depression severity the sole cause of psychotic symptoms during an episode of unipolar major depression? A study both between and within subjects. J Affect Disord. 2009; 114 (1-3): 103-9.

FRASURE-SMITH N.; LESPERANCE F.; TALAJIC M. Depression and 18-month prognosis after myocardial infarction. Circulation 1995; 91:999-1005.

GAUDIANO B.A.; DALRYMPLE K.L.; ZIMMERMAN M. Prevalence and clinical characteristics of psychotic versus nonpsychotic major depression in general psychiatric outpacients clinic. Depress Anxiety. 2009; 26(1):54-64.

GEORGE M.S.; KETTER T.A.; PAREKH P.I.; ROSINSKY N.; RING H.A.; PAZZAGLIA P.J.; MARANGELL L.B.; CALLAHAN A.M.; POST R.M. Blunted left cingulate activation in mood disorder subjects during a response interference task (the Stroop). J Neuropsychiatry Clin Neurosci. 1997; 9: 55-63.

GOLD P.W.; CHROUSOS G.P. Organization of the stress system and its dysregulation in melancholic and atypical depression: high vs low CRH/NE states. Mol Psychiatry. 2002;7(3):254-75.

GOMEZ R.G.; FLEMING S.H.; KELLER J.; FLORES B.; KENNA H.; DEBATTISTA C.; SOLVASON B.; SCHATZBERG A.F. The neuropsychological profile of psychotic major depression and its relation to cortisol. Biol Psychiatry. 2006; 60: 472-8.

GONUL A.S.; KULA M.; BILGIN A.G.; TUTUS A.; OGUZ A. The regional cerebral blood flow changes in major depressive disorder with and without psychotic features. Prog Neuropsychopharmacol Biol Psychiatry. 2004;28(6):1015-21. 
GONUL A.S.; KITIS O.; OZAN E.; AKDENIZ F.; EKER C.; EKER O.D.; VAHIP S. The effect of antidepressant treatment on $\mathrm{N}$-acetyl aspartate levels of medial frontal cortex in drug-free depressed patients. Progress in Neuro-Psychopharmacology \& Biological Psychiatry 2006; 30: $120-125$.

GROSS C.; SANTARELLI L.; BRUNNER D.; ZHUANG X.; HEN R. Altered fear circuits in5-HT1A receptor KO mice. Biol Psychiatry. 2000; Dec 15; 48 (12): 1157-63.

GUSNARD D.A.; AKBUDAK E; SHULMAN G.L.; RAICHLE M.E. Medial prefrontal cortex and self-referential mental activity: relation to a default mode of brain function. Proc Natl Acad Sci USA. 2001; 98: 4259-4264.

HAJEK T.; KOZENY J.; KOPECEK M.; ALDA M.; HOSCHL C. Reduced subgenual cingulate volumes in mood disorders: a meta-analysis. J Psychiatry Neurosci. 2008; 33: 919 .

HAMILTON J.P.; SIEMER M.; GOTLIB I.H. Amygdala volume in major depressive disorder: a meta-analysis of magnetic resonance imaging studies. Mol Psychiatry. 2008; 13: 993-1000.

HAMILTON M. A rating scale for depression. J Neurol Neurosurg Psychiatry. 1960; 23: 56-62.

HARRIS M.S.; REILLY J.L.; THASE M.E.; KESHAVAN M.S.; SWEENEY J.A. Response suppression deficits in treatment-naïve first-episode patients with schizophrenia, psychotic bipolar disorder and psychotic major depression. Psychiatry Res. 2009 Dec 30;170(2-3):1506. Epub 2009 Nov 10.

HOLTHOFF V.A.; BEUTHIEN-BAUMANN; ZÜNDORF G.; TRIEMER A.; LÜDECKE S.; WINIECKI P.; KOCH R.; FÜCHTNER F.; HERHOLZ K. Changes in brain metabolism associated with remission in unipolar major depression. Acta Psychiatr Scand. 2004; 110 (3): 184-94.

ITO H.; KAWASHIMA R.; AWATA S.; ONO S.; SATO K.; GOTO R.; KOYAMA M.; SATO M.; FUKUDA H. Hypoperfusion in the limbic system and prefrontal cortex in depression: SPECT with anatomic standardization technique. J Nucl Med. 1996; 37: 410-4.

JAGER M.; BOTTLENDER R.; STRAUSS A.; MOLLER H.J. Fifteen-year follow-up of diagnostic and statistical manual of mental disorders, fourth edition depressive disorders: the prognostic significance of psychotic features. Compr Psychiatry. 2005;46:322-327. 
JESTE D.V.; HEATON S.; PAULSEN J.; ERCOLI L.; HARRIS J.; HEATON R.K. Clinical and neuropsychological comparison of psychotic depression with nonpsychotic and depression and schizophrenia. American Journal of Psychiatry. 1996;153:490-6

JOHNSON J.; HORWATH E.; WEISSMAN M.M. The validity of major depression with psychotic features based on a community study. Arch Gen Psychiatry. 1991; 48: 1075-81.

JUNG R.E.; YEO R.A.; LOVE T.M.; PETROPOULOSH; SIBBITT W.L.; BROOKS W.M. Biochemical Markers of Mood: A Proton Magnetic Resonance Spectroscopy Study of Normal Human Brain. Biol Psychiatry. 2002;51:224-229.

JURUENA M.F.; CALIL H.M.; FLECK M.P.; DEL PORTO J.A. Melancholia in Latin American studies: a distinct mood disorder for the ICD-11. Rev Brasileira de Psiquiatria. 2001; vol 33 Supl I 48-58.

KARAASLAN F.; GONUL A.S.; OGUZ A.; ERDINC E.; ESEL E. P300 changes in major depressive disorders with and without psychotic features. J Affect Disord. 2003 Feb;73(3):283-7.

KAYMAK S.U.; DEMIR B.; OGUZ K.K.; SENTURK S.; ULUG B. Antidepressent effect detected on proton magnetic resonance spectroscopy in drug-naïve female patients with firstepisode major depression. Psychiatry and clinical neurosciences. 2009; 63: 350-356.

KELLER J.; GOMEZ R.G.; KENNA H.A.; et al. Detecting psychotic major depression using psychiatric rating scales. J Psychiatr Res. 2006a;40:22-29.

KELLER J.; FLORES B.; GOMEZ R.G.; SOLVASON H.B.; KENNA H.; WILLIAMS G.H.; SCHATZBERG A.F. Cortisol circadian rhythm alterations in psychotic major depression. Biol Psychiatry. 2006b; 60: 275-81.

KELLER J.; SCHATZBERG A.F.; MAJ M. Current issues in the classification of psychotic major depression. Schizophr Bull. 2007; 33: 877-85.

KELLER J.; SHEN L.; GOMEZ R.G.; GARRETT A.; SOLVASON H.B.; REISS A.; SCHATZBERG A.F. Hippocampal and amygdalar volumes in psychotic and nonpsychotic unipolar depression. Am J Psychiatry. 2008; 165: 872-80.

KESSLER R.C.; BERGLUND P.; DEMLER O.; JIN R.; KORETZ D.; MERIKANGAS K.R.; RUSH A.J.; WALTERS E.E.; WANG P.S. The epidemiology of major depressive disorder: results from the National Comorbidity Survey Replication (NCS-R). JAMA. 2003; 289: 3095-105. 
KIM D.K.; KIM B.L.; SOHN S.E.; LIM S.W.; NA D.G.; PAIK C.H.; KRISHNAN K.R.; CARROLL B.J. Candidate neuroanatomic substrates of psychosis in old-aged depression. Prog Neuropsychopharmacol Biol Psychiatry. 1999; 23: 793-807.

KIM H.; MCGRATH B.M.; SIVERSTONE P.H. A review of the possible relevance of inositol and the phosphatidyllinositol second messenger system (PI-cycle) to psychiatric disorders- focus on magnetic resonance spectroscopy (MRS) studies. Hum Psychopharmacol. 2005; 20:309-26.

KONARSKI J.Z.; MCINTYRE R.S.; KENNEDY S.H.; RAFI-TARI S.; SOCZYNSKA J.K.; KETTER T.A. Volumetric neuroimaging investigations in mood disorders: bipolar disorder versus major depressive disorder. Bipolar Disord. 2008; 10: 1-37

KUBICKI M.; SHENTON M.E.; SALISBURY D.F.; HIRAYASU Y.; KASAI K.; KIKINIS R.; JOLESZ F.A.; MCCARLEY R.W. Voxel-based morphometric analysis of gray matter in first episode schizophrenia. Neuroimage. 2002; 17: 1711-9.

KUMAR A.; THOMAS A.; LAVRETSKY H.; YUE K.; HUDA A.; CURRAN J.; VENKATRAMAN T.; ESTANOL L.; MINTZ J.; MEGA M.; TOGA A. Frontal White Matter Biochemical Abnormalities in Late-Life Major Depression Detected With Proton Magnetic Resonance Spectroscopy. Am J Psychiatry. 2002; 159:630-636.

LAUGERAY A.; LAUNAY J.M.; CALLEBERT J.; SURGET A.; BELZUNG C.; BARONE P.R. Peripheral and cerebral metabolic abnormalities of the tryotophan-kynureninepathway in a murine model of major depression. Behav Brain Res. 2010; 210: 84-91.

LAYER R.T.; POPIK P.; OLDS T.; SKOLNICK P. Antidepressant-like actions of the polyaminesite NMDA antagonist, eliprodil (SL-82.0715). Pharmacol Biochem Behav. 1995;52:621-627.

LEE T.W.; TSAI S.J.; YANG C.H.; HWANG J.P. Clinical and phenomenological comparisons of delusional and non-delusional major depression in the Chinese elderly. Int $\mathbf{J}$ Geriatr Psychiatry. 2003; Jun;18(6):486-90.

LEE B.H.; KIM H.; PARK S.H.; KIM Y.K. Decreased plasma BDNF level in depressive patients. J Affect Disord. 2007; Aug;101(1-3):239-44. Epub 2006 Dec 13.

LEE S.; JEONG J.; KWAK Y.; PARK S.K. Depression: where are we now? Molecular Brain; 2010, 3:8.

LOPEZ J.F.; AKIL H.; WATSON S.J. Role of biological and psychological factors in early development and their impact on adult life neural circuits mediating stress. Biol Psychiat. $1999 ; 46: 1461-71$. 
LYKOURAS L.; MARKIANOS M.; HATZIMANOLIS J.; OULIS P.; CHRISTODOULOU G.N. Prolactin secretion in response to haloperidol challenge in delusional (psychotic) and non-delusional depression. Eur Psychiatry. $2000 ; 15: 480-2$.

MAJ M.;PIROZZI R.; MAGLIANO L.; FIORILLO A.; BARTOLI L. Phenomenology and prognostic significance of delusions in major depressive disorder: a 10-year follow-up study. J Clin Psychiatry. 2007, Sep; 68: 1411-17.

MANN JJ. A current perspective of suicide and attempted suicide. Ann Intern Med 2002;136:302-311.

MAROCO, João. Análise estatística do SPSS. Lisboa: Sílabo, 2000.

MAYBERG H.S.; LEWIS P.J.; REGENOLD W.; WAGNER H.N. Paralimbic hypoperfusion in unipolar depression. J Nucl Med. 1994; 35: 929-34.

MAYBERG H.S; BRANNAN S.K.; MAHURIN R.K.; JERABEK P.A.; BRICKMAN J.; TEKELL J.L. Cingulate function in depression: a potential predictor of treatment response. Neuroreport. 1997; 8: 1057-61.

MAYBERG H.S.; BRANNAN S.K.; TEKELL J.L.; SILVA J.A.; MAHURIN R.K.; MCGINNIS S.; JERABEK P.A.Regional metabolic effects of fluoxetine in major depression: serial changes and relationship to clinical response. Biol Psychiatry. 2000; 48 (8): 830-43.

MCCORMICK L.M.; BOLES PONTO L.L.; PIERSON R.K.; JOHNSON H.J.; MAGNOTTA V.; BRUMM M.C. Metabolic correlates of antidepressant and antipsychotic response in patients with psychotic depression undergoing electroconvulsive therapy. J ECT. 2007; 23: 265-73.

MCKINNON M.C.; YUCEL K.; NAZAROV A.; MACQUEEN G.M.; A meta-analysis examining clinical predictors of hippocampal volume in patients with major depressive disorder. J Psychiatry Neurosci. 2009; 34: 41-54.

MACQUEEN G.M.; CAMPBELL S.; MCEWEN B.S. Course of illness, hipocampal function, and hippocampal volume in major depression. Proc Natl Acad Sci U S A. 2003; 100:1387-92.

MENEZES P.R.; SCAZUFCA M.; BUSATTO G.; COUTINHO L.M.; MCGUIRE P.K.; MURRAY R.M. Incidence of first-contact psychosis in Sao Paulo, Brazil. Br J Psychiatry, 2007; Suppl 51: s102-6 
MEYERS B.S.; ALEXOPOULOS G.S.; KAKUMA T.; TIRUMALASETTI F.; GABRIELE M.; ALPERT S.; BOWDEN C.; MELTZER H.Y. Decreased dopamine beta-hydroxylase activity in unipolar geriatric delusional depression. Biol psychiatry. 1999;45:448-452.

MORRIS J.S.; FRITH C.D.; PERRETT D.I.; ROWLAND D.; YOUNG A.W.; CALDER A.J.; DOLAN R.J. A differential neural response in the human amygdala to fearful and happy facial expressions. Nature. 1996; 383: 812-5.

MYINT A.M.; KIM Y.K. Cytocine-serotonin interaction through IDO: a neurodegenaration hypothesis of depression. Med Hypothesis. 2003; 61:519-25.

NELSON JC, DAVIS JM. DST studies in psychotic depression: a meta-analysis. Am J Psychiatry.1997; 154:1497-1503.

NELSON E.B.; SAX K.W.; STRAKOWSKI S.M. Attentional performance in patients with psychotic and nonpsychotic major depression and schizophrenia. Am J Psychiatry 1998; 155:137-139

NERY F.G.; STANLEY J.A.; CHENE H.H.; HATCH J.P.; NICOLETTIG M.A.; MONKUL E.S.; MATSUO K.; CAETANO S.C.; PELUSO M.A.; NAJTA P.; SOARES J.C. Normal metabolite levels in the left dorsolateral prefrontal cortex of unmedicated major depressive disorder patients: A single voxel ${ }^{1} \mathrm{H}$ spectroscopy study. Psychiatry Research: Neuroimaging. 2009; 174: 177-183.

NILSSON L.K.; LINDERHOLMK.R.; ENGBERG G.; PAULSON L.; BLENNOW K.; LINDSTROM L.H. Elevated levels of kynurenic acid in the cerebral fluid of male patients with schizophrenia. Schizophr Res. 2005; 80: 315-22.

NESTLER E.J.; BARROT M; DILEONE J.R.; EISCH A.J.; GOLD S.G.; MONTEGGIA L. M. Neurobiology of Depression Review. Neuron. 2002, March 28; 34: 13-25.

OGILVIE A.D.; BATTERSBY S.; BUBB V.J.; FINK G.; HARMAR A.J.; GOODWIM G.M.; SMITH C.A. Polymorphism in serotonin transporter gene associated with susceptibility to major depression. Lancet 1996; 347:731-733.

OHAYON M.M.; SCHATZBERG A.F. Prevalence of depressive episodes with psychotic features in the general population. Am J Psychiatry. 2002. 159: 1855-61.

OLDFIELD R.C. The assessment and analysis of handedness: the Edinburgh inventory. Neuropsychology. 1971; 9: 97-113. 
OMS - Organização Mundial da Saúde (WHO - World Health Organization). Classificação Internacional de Doenças. 10 ed., cap. V, 1992.

OMS. The global burden of disease report 2004. Publicado em <www.who.int/ global_burden_disease/2004_report_update/en/index.htlm>. Acesso em: 04/11/2010.

ÖNGÜR D.; DREVETS W.C.; PRICE J.L. Glial reduction in the subgenual prefrontal cortex in mood disorders. Neurobiology. 1998; 95: 13290-95.

ÖNGÜR D.; PRICE J.L. The organization of networks within the orbital and medial prefrontal cortex of rats monkeys and humans. Cereb Cortex. 2000;10: 206-219.

ÖNGÜR D.; FERRY A.T.; PRICE J.L. Architectonic subdivision of the human orbital and medial prefrontal cortex. J Comp Neurol 2003; 460: 425-449.

ÖNGÜR D.; PRESCOT A.P.; JENSEN J.E.; COHEN B.M.; RENSHAW P.F. Creatine abnormalities in schizophrenia and bipolar disorder. Psychiatry Res. 2009, 30; 172(1):44-8.

OVERALL JE.; GORHAM D.R. The Brief Psychiatry Rating Scale. Psychol Rep. 1962; 10: 799-812

PAPP M.; MORYL E. Antidepressant activity of non-competitive and competitive NMDA receptor antagonists in a chronic mild stress model of depression. Eur J Pharmacol. 1994;263:1-7.

PARKER G.; HADZI-PAVLOVIC D.; HICKIE I.; BOYCE P.; MITCHELL P.; WILHELM K.; BRODATY H. Distinguishing psychotic and non-psychotic melancholia. J Affect Disord. 1991; 22: 135-48

PARKER G.; HADZI-PAVLOVIC D.; AUSTIN M.P.; MITCHELL P.; WILHELM K.; HICKIE I.; BOYCE P.; EYERS K. Sub-typing depression, I. Is psychomotor disturbance necessary and sufficient to the definition of melancholia? Psychol Med. 1995; 25: 815-23.

PARKER G.; ROUSSSOS J.; MITCHELL P.; WILHELM K.; AUSTIN M-P.; HADZIPAVLOVICD. Distinguing psuchotic from melancholia. J Affect Disord 1997; 42:155-67.

PENNINX BW, BEEKMAN AT, HONIG A, DEEG DJ, SCHOEVERS RA, van EIJK JT, et al. (2001): Depression and cardiac mortality: Results from a communitybased longitudinal study. Arch Gen Psychiatry 58:221-227. 
PFEFFERBAUM A.; ADALSTEINSSON E.; SPIELMAN D.; SULLIVAN E.V.; LIM K.O. In Vivo Spectroscopic Quantification of the $N$-acetyl Moiety, Creatine, and Choline From Large Volumes of Brain Gray and White Matter: Effects of Normal Aging. Magnetic Resonance in Medicine. 1999; 41:276-284.

PHILLIPS M.L.; DREVETS W.C.; RAUCH S.L.; LANE R. Neurobiology of emotion perception I: the neural basis of normal emotion perception. Biol Psychiatry. 2003a; 54: 50414.

PHILLIPS M.L.; DREVETS W.C.; RAUCH S.L.; LANE R. Neurobiology of emotion perception II: Implications for major psychiatric disorders. Biol Psychiatry. 2003b; 54: 51528.

POST R.M. Transduction of psychosocial stress into the neurobiology of recurrent affective disorder. Am J Psychiatry. 1992 Aug; 149(8): 999-1010.

PRICE J.L.; DREVETS W.C.Neurocircuitry of Mood Disorders. Neuropsychopharmacology Reviews. 2010; 35: 192-216.

PROVENCHER S.W. Estimation of metabolite concentration from localized in vivo proton NMR spectra. Magn Reson Med. 1993. 30 (6): 672-9

RAJKOWSKA G. Dysfunction in neural circuits involved in the pathophysiology of mood disorders. Postmortem studies in mood disorders indicate altered numbers of neurons and glial cells. Biol Psychiatry. 2000; 48:766-777.

RASGON N.L.; THOMAS M.A.; GUZE B.H.; FAIRBANKS L.A.; YUE K.; CURRAN J.G. Menstrual cycle-related brain metabolite changes using $1 \mathrm{H}$ magnetic resonance spectroscopy in premenopausal women: a pilot study. Psychiatry Res 2001; 106:47-57.

ROTHMAN D,L.; BEHAR K.L.; HYDER F.; SHULMAN R.G. In vivo NMR studies of the glutamate neurotransmitter flux and neuroenergetics: Implications for brain function. Annu Rev Physiol. 2003; 65:401- 427.

ROTHSCHILD A.J. Challenges in the treatment of depression with psychotic features. Biol Psychiatry. 2003;53:680-690.

RUHÉ H.G.; MASON N.S.; SCHENE A.H. Mood is indirectly related to serotonin, norepinephrine and dopamine levels in humans: a meta-analysis of monoamine depletion studies. Mol Psychiatry. 2007. Apr; 12(4):331-59. 
SALEEM K.S.; KONDO H.; PRICE J.L. Complementary circuits connecting the orbital and medial prefrontal networks with the temporal insular and opercular cortex in the macaque monkey. J Comp Neurol. 2008; 506: 659-93.

SALIBI N.; BROWN M.A. Clinical MR spectroscopy. First Principles. John Wiley \& Sons, 1998.

SALOKANGAS R.K.; CANNON T.; VAN E.R.P.T.; ILONEN T.; TAIMINEN T.; KARLSSON H.; LAUERMA H.; LEINONEN K.M.; WALLENIUS E.; KALJONEN A.; SYVALAHTI E.; VILKMAN H.; ALANEN A.; HIETALA J. Structural magnetic resonance imaging in patients with first-episode schizophrenia, psychotic and severe non-psychotic depression and healthy controls. Results of the schizophrenia and affective psychoses (SAP) project. Br J Psychiatry. 2002. Suppl 43: s58-65

SANTA CLARA C.J.S. Melancolia: da antiguidade à modernidade - uma breve análise histórica. Mental. 2009; 7:13.

SAPOLSKY R.M.; ROMERO L.M.; MUNCK A.U. How do glucocorticoids influence stress responses? Integrating permissive, suppressive, stimulatory, and preparative actions. Endocr Rev. 2000;21(1):55-89.

SAPOLSKY R.M. The Possibility of Neurotoxicity in the Hippocampus in Major Depression: A Primer on Neuron Death. Biol Psychiatry. 2000; 48:755-765

SARRAMEA CRESPO F.; LUQUE R.; PRIETO D.; SAU P.; ALBERT C.; LEAL I.; DE LUXAN A.; OSUNA M.I.; RUIZ M.; GALAN R.; CABALEIRO F.; MOLINA V. Biochemical changes in the cingulum in patients with schizophrenia and chronic bipolar disorder. Eur Arch Psychiatry Clin Neurosci. 2008. 258: 394-401

SCHATZBERG A.F. New approaches to managing psychotic depression. J Clin Psychiatry. 2003. 64 Suppl 1: 19-23.

SCHATZBERG A.F.; POSENER J.A.; DEBATTISTA C.; KALEHZAN B.M.; ROTHSCHILD A.J.; SHEAR P.K. Neuropsychological deficits in psychotic versus nonpsychotic major depression and no mental illness. Am J Psychiatry. 2000; 157: 1095-100

SHATZBERG A.F.; POSENER J.A.; ROTHSCHILD A.J. The hole of dopamine in psychotic depression. Clin. Neuropharmachol. 1995;18(1): S66-S73.

SCHATZBERG A.F.; ROTHSCHILD J.R. Psychotic (delusional) Major Depression: should it be included as a distinct syndrome in DSM-IV? Am J Psychiatry. 1992;149(6): 733-45. 
SHELINE Y.I. Neuroimaging studies of mood disorder effects on the brain. Biol Psychiatry. $2003 ; 54: 338-352$.

SEGAL M.; AVITAL A.; DROBOT M.; LUKANIN A.; DEREVENSKI A.; SANDBANK S.; WEIZMAN A. Serum creatine kinase level in unmedicated nonpsychotic, psychotic, bipolar and schizoaffective depressed patients. Eur Neuropsychopharmacol. 2007 Feb;17(3):194-8. Epub 2006 Oct 16.

SIMPSON S.; BALDWIN R.C.; JACKSON A.; BURNS A. The differentiation of DSM-III-R psychotic depression in later life from nonpsychotic depression: comparisons of brain changes measured by multispectral analysis of magnetic resonance brain images, neuropsychological findings, and clinical features. Biol Psychiatry. 1999. Jan 15; 45(2):193204.

SKAF C.R.; YAMADA A.; GARRIDO G.E.; BUCHPIGUEL C.A.; AKAMINE S.; CASTRO C.C.; BUSATTO G.F. Psychotic symptoms in major depressive disorder are associated with reduced regional cerebral blood flow in the subgenual anterior cingulate cortex: a voxel-based single photon emission computed tomography (SPECT) study. J Affect Disord. 2002. 68: 295-305.

SOARES J.C.; MANN J.J. The functional neuroanatomy of mood disorders. J Psychiatr Res. 1997. 31: 393-432.

STANLEY J.A. In vivo magnetic resonance spectroscopy and its application to neuropsychiatric disorders. Can J Psychiatry. 2002. 47: 315-26

STEINER J.; BOGERTS B.; SARNYAI Z.; WALTER M.; GOS T.; BERNSTEIN H.G.; MYINT A.M. Bridging the gap between the immune and glutamate hypotheses of schizophrenia and major depression: Potential role of glial NMDA receptor modulators and impaired blood-brain barrier integrity. World J Biol Psychiatry. 2011 Jun 28.

SUMNER B.; GRANT K.; ROSIE R,; HEGELE-HARTUNG C.; FRITZEMEIER K.; FINK G. Effects of tamoxifen on serotonin transporter and5-hydroxytryptamine(2A) receptor binding sites and mRNA levels in the brain of ovariectomized rats with or without acute estradiol replacement. Brain Res Mol Braines 1999;73:119-128.

TANAPAT P.; HASTINGS N.B.; REEVES A.J.; GOULD E. Estrogen stimulates a transient increase in the number of new neurons in the dentate gyrus of the adult female rat. $\mathbf{J}$ Neurosci 1999;19:5792-5801.

TAVARES R.G.; SCHMIDT A.P.; ABUD J.; TASCA C.I.; SOUZA D.O. In vivo quinolinic acid increases synaptosomal glutamate release in rats: reversal by guanosine. Neurochem Res. 2005. Apr 30(4):439-44. 
THAKUR M.; HAYS J.; KRISHNAN K.R. Clinical, demographic and social characteristics of psychotic depression. Psychiatry Res. 1999. May 31; 86(2):99-106.

TOFTS P. Quantitative MRI of the Brain? Measuring changes caused by disease. West Sussex, England: John Wiley \& Sons Ltd., 2003.

VIDEBECH P.; RAVNKILDE B.Hippocampal volume and depression: a meta-analysis of MRI studies. Am J Psychiatry. 2004. 161: 1957-66.

YILDIZ-YESILOGLU A.; ANKERST D.P. (2006) Review of $1 \mathrm{H}$ magnetic resonance spectroscopy fin dings in major depressive disorder: a meta-analysis. Psychiatry Res. 2006. 147: $1-25$

YÜKSEL C; ÖNGÜR D. Magnetic Resonance Spectroscopy Studies of Glutamate Related Abnormalities in Mood Disorders. Biol Psychiatry. 2010; 68:785-794.

WAHLUND B.; PIAZZA P.; VON ROSEN D.; LIBERG B.; LILJENSTRÖM H. Seizure (Ictal)-EEG Characteristics in Subgroups of Depressive Disorder in Patients Receiving Electroconvulsive Therapy (ECT)-A Preliminary Study and Multivariate Approach. Comput Intell Neurosci. 2009;2009:965209. Epub 2009 Jun 15.

WAZIRI R.; BARUAH S.; ARNDT S.; BAUMERT K.; COONEY J.; CHRISTENSEN L. Psychosis and vulnerability to ECT-induced seizures. Psychiatry Res. 1996 May $17 ; 62(2): 191-201$.

WEDEKIND D.; PREISS B.; COHRS S.; RUETHER E.; HUETHER G.; ADLER L. Relationship between nocturnal urinary cortisol excretion and symptom severity in subgroups of patients with depressive episodes. Neuropsychobiology. 2007;56(2-3):119-22. Epub 2007 Jan 10.

WIJKSTRA J.; LIJMER J.; BALK F.J.; GEDDES J.R.; NOLEN W.A. Pharmacological treatment for unipolar psychotic depression: systematic review and meta-analysis. $\mathbf{B r} \mathbf{J}$ Psychiatry. 2006; 188: 410-415.

WU H.Q.; PEREIRA E.F.; BRUNO J.P.; PELLICCIARI R.; ALBUQUERQUE E.X.; SCHWARCZ R. The astrocyte-derived alpha7 nicotinic receptor antagonist kynurenic acid controls extracellular glutamate levels in the prefrontal cortex. J Mol Neurosci. 2010. Jan; 40 (1-2):204-10.

ZARATE CA JR, SINGH JB, CARLSON PJ. A randomized trial of an N-methyl-Daspartate antagonist in treatment-resistant major depression. Arch Gen Psychiatry. 2006; 63:856-64. 
ZHENG D.; MACERA C.A.; CROFT J.B.; GILES W.H.; DAVIS D.; SCOTT W.K. Major depression and all-cause mortality among white adults in the United States. Ann Epidemiol. 1997; 7(3): 213-8

ZUARDI A.W.; LOUREIRO S.R.; RODRIGUES C.R.C.; CORREA A.J.; GLOCK S.S. (1994). Estudo da estrutura fatorial, fidedignidade e validade da tradução e adaptação para o português da Escala de Avaliação Psiquiátrica Breve (BPRS) modificada. Rev. ABP-APAL 16: $63-8$ 


\section{ANEXOS}

\section{ANEXO A}

\section{TERMO DE CONSENTIMENTO LIVRE E ESCLARECIDO}

NOME DA PESQUISA: Transtorno Depressivo Maior com e sem sintomas psicóticos: avaliação de aspectos clínicos, genéticos, neuropsicológicos e de neuroimagem

\section{PESQUISADORES RESPONSÁVEIS:}

Maristela Schaufelberger Spanghero

CREMESP 94.146

Bolsista PRODOC-CAPES - psiquiatra

HCFMRPUSP

Profa. Dra. Cristina Marta Del-Ben

CREMESP 63.638

Orientadora - Docente do Depto. de Neurociências e

Ciências do Comportamento da FMRPUSP

Justificativa e objetivo da pesquisa: Depressão é um dos principais problemas de saúde mental e suas causas e características biológicas ainda não são totalmente esclarecidas. Muitas pesquisas vêm sendo feitas com o objetivo de se investigar possíveis diferenças entre pessoas que sofrem de depressão e pessoas não deprimidas. Essas pesquisas vêm mostrando que essas diferenças ocorrem no tamanho e nos níveis de algumas substâncias de algumas áreas do sistema nervoso central (cérebro). Também parecem existir diferenças no modo como as pessoas deprimidas reagem e se expressam afetivamente. Além disso, alguns fatores genéticos parecem ser responsáveis pela produção de substâncias cerebrais de modo diferente entre pessoas deprimidas e não deprimidas. $\mathrm{O}$ objetivo desta pesquisa é investigar, em pessoas deprimidas, as relações entre esses fatores: o tamanho de áreas cerebrais importantes para o funcionamento das emoções, os níveis de substâncias nessas áreas, as características psicológicas e os genes possivelmente relacionados à depressão. Serão avaliadas também pessoas que tenham depressão com alucinações, delírios e prejuízo do julgamento da realidade, chamados de sintomas psicóticos, para tentarmos descobrir quais as características biológicas que levam algumas pessoas deprimidas a ter esses sintomas.

Procedimentos que serão utilizados e seu propósito, bem como a identificação dos procedimentos que são experimentais: Convidamos o(a) $\operatorname{Sr}($ a) para participar deste projeto, no qual serão realizadas uma entrevista psiquiátrica e uma avaliação neuropsicológica. Além 
disso, serão realizados exame de Ressonância Magnética de crânio (que avalia o tamanho e níveis de algumas substâncias de partes do cérebro) e coleta de exame de sangue venoso para posterior avaliação genética.

A duração da entrevista psiquiátrica é estimada em $2 \mathrm{~h}$. A avaliação neuropsicológica e de personalidade é estimada em 2 horas, e será dividida em 2 sessões. $\mathrm{O}$ exame de Ressonância Magnética tem duração estimada de 50 minutos. A coleta de sangue venoso será feita por uma única punção, em membro superior (antebraço ou mão) e será realizada por profissional de enfermagem, qualificado para o procedimento.

Desconfortos e riscos esperados: Avalia-se que não haja riscos potenciais na realização das entrevistas e avaliação psicológica neste estudo: o único custo será o tempo em participar das entrevistas. $\mathrm{O}$ exame de Ressonância Magnética é indolor, seguro e não envolve radiação e não será usada anestesia ou contraste. $\mathrm{O}$ único cuidado a ser tomado diz respeito à presença de objetos metálicos e magnetizados, estejam eles presos em seu corpo (como implantes e próteses) ou eles sendo carregados por você (como jóias e relógios). Não podem fazer o exame pessoas com marcapasso cardíaco.

Será solicitado que você deixe os objetos metálicos e os magnetizados (como cartões de crédito) fora da sala de exame. Estes últimos podem ser danificados pelo campo magnético da máquina de Ressonância. Seus objetos ficarão sob os cuidados do pesquisador responsável que estiver lhe acompanhando. Algumas pessoas podem se sentirem desconfortáveis por ficarem deitadas em local estreito ou incomodadas com o barulho forte que a máquina de ressonância faz quando está funcionando. $\mathrm{O}$ exame será interrompido imediatamente e você poderá sair do aparelho, se desejar, podendo fazer o exame em outro momento. Algumas pessoas podem sentir dor no momento da coleta de sangue em que a veia será puncionada. $\mathrm{O}$ material utilizado será estéril e descartável e o procedimento será realizado por profissional de enfermagem.

Benefícios que se pode obter: Este estudo irá auxiliar no entendimento das bases biológicas da depressão e da relação entre alterações biológicas e a expressão dos afetos e emoções. Além disso, auxiliará a entendermos quais as diferenças biológicas ou psicológicas que fazem com que algumas pessoas deprimidas tenham sintomas psicóticos enquanto outras não os têm. O melhor entendimento do que ocorre na depressão poderá, no futuro, ajudar no desenvolvimento de novos tratamentos.

Endereço e telefone dos pesquisadores responsáveis:

Hospital das Clínicas da Faculdade de Medicina de Ribeirão Preto - USP

Divisão de Psiquiatria - Departamento de Neurociência e Ciências do Comportamento Avenida Bandeirantes, 3900 - (16) 3602-2607 
$\mathrm{Eu}$ , R.G.

abaixo assinado, tendo recebido as informações acima, e ciente dos meus direitos abaixo relacionados, concordo em participar.

A garantia de receber a resposta a qualquer pergunta ou esclarecimento de qualquer dúvida a respeito dos procedimentos, riscos, benefícios e de outras situações relacionadas com a pesquisa;

A liberdade de retirar o meu consentimento e deixar de participar do estudo, a qualquer momento, sem que isso me traga prejuízos;

A segurança de que não serei identificado e que será mantido o caráter confidencial da informação relacionada a minha privacidade;

O compromisso de que os dados coletados serão utilizados somente para esta pesquisa e devidamente divulgados na comunidade científica;

O compromisso de que me será prestada informação atualizada durante o estudo, ainda que esta possa afetar a minha vontade de continuar dele participando;

O ressarcimento de eventuais despesas decorrentes da minha participação no projeto, a ser promovido pelo orçamento da pesquisa.

Declaro, ainda, que concordo inteiramente com as condições que me foram apresentadas e que, livremente, manifesto a minha vontade em participar do referido projeto.

Ribeirão Preto, de de

ASSINATURA DO PARTICIPANTE NO ESTUDO

ASSINATURA DO RESPONSÁVEL PELO PARTICIPANTE DO ESTUDO

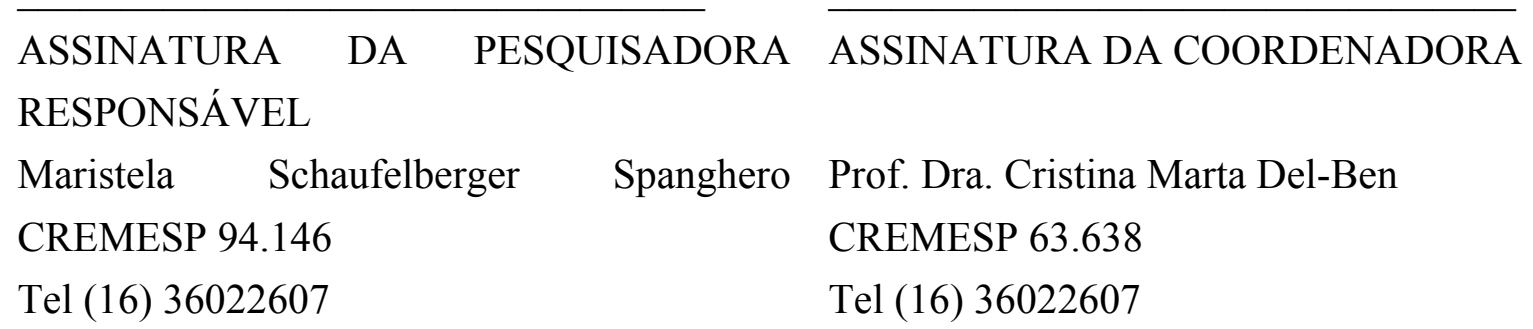




\section{ANEXO B}

\section{EIXO V DO DSM-IV: ESCALA DE AVALIAÇÃO GLOBAL DO FUNCIONAMENTO}

Considerar o funcionamento psicológico, social e ocupacional em um continuum hipotético de saúde-doença mental.

Não incluir prejuízo no funcionamento devido a limitações físicas (ou ambientais).

Código (Obs.: Usar códigos intermediários quando apropriado, por ex., 45, 68, 72)

100

|

91

Funcionamento superior em uma ampla faixa de atividades, problemas de vida jamais vistos fora de seu controle, é procurado por outros em vista de suas muitas qualidades positivas.

Não apresenta sintomas.

90

|

81

Sintomas ausentes ou mínimos (por ex., leve ansiedade antes de um exame), bom

funcionamento em todas as áreas, interessado e envolvido em uma ampla faixa de atividades, efetivo socialmente, em geral satisfeito com a vida, nada além de problemas ou preocupações cotidianas (por ex., uma discussão ocasional com membros da família).

80

|

71

Se sintomas estão presentes, eles são temporários e consistem de reações previsíveis a estressores

psicossociais (por ex., dificuldade para concentrar-se após discussão em família); não mais do que leve prejuízo no funcionamento social, ocupacional ou escolar (por ex., apresenta declínio temporário na escola). 70

|

61

Alguns sintomas leves (por ex., humor depressivo e insônia leve) OU alguma dificuldade no funcionamento social, ocupacional ou escolar (por ex., faltas injustificadas à escola ocasionalmente, ou furto dentro de casa), mas geralmente funcionando muito bem; possui alguns relacionamentos interpessoais significativos. 60

|

51

Sintomas moderados (por ex., afeto embotado e fala circunstancial, ataques de pânico ocasionais) OU dificuldade moderada no funcionamento social, ocupacional ou escolar (por ex., poucos amigos, conflitos com companheiros ou colegas de trabalho).

50

|

41

Sintomas sérios (por ex., ideação suicida, rituais obsessivos graves, freqüentes furtos em lojas) OU qualquer prejuízo sério no funcionamento social, ocupacional ou escolar (por ex., nenhum amigo, incapaz de manter um emprego).

40

|

(

31

Algum prejuízo no teste da realidade ou comunicação (por ex., fala às vezes ilógica, obscura ou irrelevante) OU prejuízo importante em diversas áreas, tais como emprego ou escola, relações familiares, julgamento, pensamento ou humor (por ex., homem deprimido evita amigos, negligencia a família e é incapaz de trabalhar; criança freqüentemente bate em crianças mais jovens, é desafiadora em casa e está indo mal na escola).

30

|

21 
Comportamento é consideravelmente influenciado por delírios ou alucinações OU sério prejuízo na comunicação ou julgamento (por ex., ocasionalmente incoerente, age de forma grosseiramente inapropriada, preocupação suicida) OU inabilidade para funcionar na maioria das áreas (por ex., permanece na cama o dia inteiro; sem emprego, casa ou amigos).

20

|

11

Algum perigo de ferir a si mesmo ou a outros (por ex., tentativas de suicídio sem clara expectativa de morte; freqüentemente violento; excitação maníaca) OU ocasionalmente falha ao manter a higiene pessoal mínima (por ex., suja-se de fezes) OU prejuízo grosseiro na comunicação (por ex., amplamente incoerente ou mudo).

10

1

Perigo persistente de ferir gravemente a si mesmo ou a outros (por ex., violência recorrente) OU inabilidade persistente para manter uma higiene pessoal mínima OU sério ato suicida com clara expectativa de morte.

0 Informações inadequadas.

Pontuação na Escala de Avaliação Global do Funcionamento:

Atual:

Mais alta no último ano: 


\section{ANEXO C}

\section{INVENTÁRIO DE DOMINÂNCIA LATERAL DE EDIMBURGO (Oldfield, 1971)}

- Por favor, indique sua preferência no uso das mãos nas seguintes atividades, colocando o sinal + na coluna apropriada. Quando a preferência é tão forte que você nunca usaria a outra mão, a não ser que fosse forçado a fazer, marque ++. Se em algum caso, o uso da mão é totalmente indiferente, coloque um + nas duas colunas.

\begin{tabular}{|l|l|l|}
\hline & Esquerda & Direita \\
\hline 1-Escrever & & \\
\hline 2- Desenhar & & \\
\hline 3- Arremessar & & \\
\hline 4- Usar a tesoura & & \\
\hline 5- Escovar os dentes & & \\
\hline 6- Uso da faca (sem garfo) & & \\
\hline 7- Uso de colher & & \\
\hline 8- Usar a vassoura (mão de cima) & & \\
\hline 9- Acender um fósforo (mão que risca o fósforo, e & & \\
não a mão que segura a caixa) & & \\
\hline 10- Abrir uma caixa (mão que abre a tampa) & & \\
\hline
\end{tabular}

\begin{tabular}{|l|l|l|}
\hline Total de + & Mão esquerda $=$ & Mão direita $=$ \\
\hline Total cumulativo & $\mathrm{TC}=$ mão esquerda + mão direita $=$ \\
\hline Diferença & $\mathrm{D}=$ mão direita - mão esquerda $=$ \\
\hline Resultado & $\mathrm{R}=(\mathrm{D} / \mathrm{TC}) \mathrm{x} 100=$ \\
\hline $\begin{array}{l}\text { Interpretação: } \\
(\text { Canhoto: } \mathrm{R}<-40) \\
(\text { Ambidestro: }-40 \geq \mathrm{R} \leq 40) \\
(\text { Destro: } \mathrm{R}>+40)\end{array}$ & \\
\hline
\end{tabular}




\section{ANEXO D}

\section{ESCALA DE HAMILTON PARA AVALIAÇÃO DE DEPRESSÃO - Hamilton Rating Scale for Depression (HAMILTON, 1960)}

1. Humor deprimido (tristeza, desesperança, desamparo, inutilidade):

0 - ausente

1- sentimentos relatados somente se perguntados

2- sentimentos relatados espontaneamente, com palavras

3- comunica os sentimentos não com palavras, mas com expressão facial, postura, voz e tendência ao choro

4- o paciente comunica quase que exclusivamente esses sentimentos, tanto em seu relato verbal como na comunicação não- verbal.

2. Sentimentos de culpa:

0 - ausente

1- auto-recriminação, acha que decepcionou outras pessoas

2- idéias de culpa ou ruminações de erros ou ações pecaminosas (más) no passado

3- paciente acha que a doença atual é uma punição (castigo). Delírio de culpa

4- ouve vozes que o acusam ou denunciam e/ou tem alucinações visuais ameaçadoras

3. Suicídio:

0 - ausente

1- acha que não vale a pena viver

2- deseja estar morto ou pensa em uma possível morte para si

3- idéias ou atitudes suicidas

4- tentativas de suicídio 


\section{Insônia inicial:}

0- sem dificuldades para iniciar o sono

1- queixa de dificuldade ocasional para iniciar o sono, ou seja, mais que meia hora

2- queixa de dificuldade para iniciar o sono todas as noites

5. Insônia intermediária:

0- sem dificuldade

1- queixa de agitação e perturbação durante a noite

2- acorda durante a noite - qualquer saída da cama (exceto por motivos de necessidade fisiológica)

6. Insônia terminal (madrugada):

0- sem dificuldade

1- acorda durante a madrugada, mas volta a dormir

2- não consegue voltar a dormir se levantar da cama durante a noite

7. Trabalho e atividades:

0 - sem dificuldades

1- pensamentos e sentimentos de incapacidade, fadiga ou fraqueza, relacionados a atividades, trabalho ou passatempos

2- perda de interesse em atividades, passatempos ou trabalho, quer relatado diretamente pelo paciente, quer indiretamente por desatenção, indecisão ou vacilação (sente que precisa se esforçar para o trabalho ou outras atividades)

3- diminuição no tempo gasto em atividades ou queda de produtividade. No hospital, o paciente ocupa-se por menos de três horas por dia em atividades (trabalho hospitalar ou passatempos) com exceção das tarefas rotineiras da enfermaria

4- parou de trabalhar devido à doença atual. No hospital, sem atividades, com exceção das tarefas rotineiras da enfermaria, ou se não consegue realizá-las sem ajuda 
8.Retardo (lentificação do pensamento e da fala, dificuldade de concentração, diminuição da atividade motora):

0 - pensamentos e fala normais

1 - lentificação discreta à entrevista

2 - lentificação óbvia durante a entrevista

3 - entrevista difícil

4 - estupor completo

9. Agitação: Avaliação baseada na observação durante a entrevista:

0 - nenhuma

1 - inquietação

2 - mexe as mãos, cabelos etc.

3 - movimenta-se bastante, não consegue permanecer sentado durante a entrevista

4 - retorce as mãos, rói as unhas, puxa os cabelos, morde os lábios

10. Ansiedade psíquica:

0 - sem dificuldade

1 - tensão e irritabilidade subjetivas

2 - preocupa-se com trivialidades

3 - atitude apreensiva aparente no rosto ou na fala

4 paciente expressa medo sem ser perguntado

\section{Ansiedade - somática:}

(boca seca, flatulência, indigestão, diarréias, cólicas, eructações, palpitação, cefaléias, hiperventilação, suspiros, vontade de urinar freqüentemente, sudorese)

0 - ausente

1 - duvidoso ou trivial: sintomas menores, relatados quando questionados

2 - leve: paciente descreve espontaneamente os sintomas, que não são acentuados ou incapacitantes

3 - moderado: mais do que 2 sintomas e com maior freqüência. São acompanhados de estresse subjetivo e prejudicam o funcionamento normal 
4 - grave: numerosos sintomas, persistentes e incapacitantes na maior parte do tempo, ou ataques de pânico quase diariamente

12. Sintomas Somáticos (apetite, digestivo):

0 - nenhuma alteração

1 - perda de apetite, mas come sem necessidade de insistência

2 dificuldade para comer se não insistirem

13. Sintomas somáticos (gerais):

0 - nenhuma alteração

1 - peso em membros, costas ou cabeça; dor nas costas, na cabeça ou nos músculos. Perda de energia e fatigabilidade

2 - qualquer sintoma bem caracterizado e nítido

14. Sintomas Genitais - ( perda de libido, distúrbios menstruais):

0 - ausentes

1 - leves ou infreqüentes: redução da libido ou desempenho sexual insatisfatório, tensão prémenstrual leve

2 - óbvio e graves: desinteresse ou impotência; tensão pré-menstrual grave

15. Hipocondria:

0 - ausente

1 - auto-observação aumentada (com relação ao corpo)

2 - preocupação com a saúde

3 - queixas freqüentes, pedidos de ajuda etc.

4 - delírios hipocondríacos 
16. Perda de Peso (desde o início da doença ou da última avaliação):

0 - sem perda de peso ou perda de peso NÃO causada pela doença atual

1 - perda de peso provavelmente causada pela doença atual. Perda de menos de meio quilo

2 - perda de peso definitivamente causada pela doença atual. Perda de meio quilo ou mais

\section{Crítica}

0 - reconhece estar deprimido e doente OU não estar deprimido no momento

1 - reconhece estar, mas atribui a causa à má alimentação, ao clima, ao excesso de trabalho, a um vírus, à necessidade de descanso etc.

2 - nega estar doente

18. Variação diurna:

A. Anote se os sintomas são piores de manhã ou à noite. SE NÃO HOUVER variação diurna, marque 'nenhuma':

- nenhuma ou não deprimido no momento

- pior pela manhã

- pior a tarde/à noite

B. Quando presente, anote a gravidade da variação:

0 - nenhuma

1 - leve

2 - grave

19. Despersonalização e Desrealização:

0 - ausentes

1 - leves

2 - moderadas

3 - graves

4 - incapacitantes 
20. Sintomas Paranóides:

0 - nenhum

1 - desconfiado

2 - idéias de referência

3 - delírios de referência e perseguição

21. Sintomas Obsessivos e Compulsivos:

0 - nenhum

1 - leves

2 - graves

22. Hipersônia - adormecer precoce:

0 - não

1 - leve, infreqüente - menos do que uma hora

2 - óbvia, definida - mais que 60 minutos mais cedo, todas as noites

23. Hipersônia - dormir mais que o habitual:

0 - não

1 - leve, infreqüente - menos do que uma hora

2 - óbvia/definida - dorme em excesso por mais do que uma hora, na maioria dos dias

24. Hipersônia - cochilos:

0 - ausentes

1 - leve, infreqüente - cochilos duram menos do que 30 minutos, ou relata sonolência diurna excessiva

2 - óbvia/ definida - sonecas duram mais do que 30 minutos na maioria dos dias 
25. Aumento de apetite (mudança no apetite caracterizada por aumento na quantidade de comida ingerida, ou fissura excessiva):

0 - ausente

1 - mínimo - aumento leve de apetite; fissura por comida

2 - definido - aumento acentuado de ingestão de comida, ou fissura

26. Ganho de peso:

0 - ausente

1 - duvidoso/mínimo - menos do que $0,5 \mathrm{~kg}$

2 - óbvio - ganho de peso de $0,5 \mathrm{~kg}$ ou mais

27. Retardo Psíquico: (Lentificação na fala e no processo de pensamento: descreve inibição da vontade ou sensação de que os processos de pensamento estão paralisados. Avalie com base na observação e na auto-descrição, mas diferencie de um real retardo motor.)

0 - ausente

1- leve; discreto retardo na fala e no processo de pensamento

2 - moderado - demora para responder às questões, descreve inibição de volição

3 - grave - retardo na fala e no processo de pensamento suficiente para prolongar significativamente a entrevista

4 - extremo (1/2)/ excessivo; quase em mutismo, minimamente responsivo

28. Retardo Motor:

0 - ausente

1 - leve - discreto achatamento do afeto, expressão fixa

2- moderado - voz monótona e diminuição de movimentos espontâneos

3 - grave - óbvio retardo de movimento, marcha; afeto embotado

4 - extremo - em estupor; retardo motor acentuado observado na marcha e na postura 
29. Desamparo:

0 - ausente

1 - sentimentos subjetivos extraídos apenas pela entrevista

2 - paciente relata espontaneamente sentimentos de desamparo

3 - necessita de insistência, orientação e reasseguramento para completar tarefas

4 - requer assistência para se vestir, comer, ou realizar higiene pessoal

30. Desesperança:

0 - ausente

1 - dúvida intermitentemente de que "as coisas irão melhorar", mas pode ser reassegurado

2 - consistentemente se sente desesperançado, mas aceita reasseguramentos

3 - expressa sentimentos de desencorajamento, desespero, pessimismo quanto ao futuro, que não podem ser desfeitos

4 - espontânea e inapropriadamente persevera "nunca vou melhorar" ou equivalente

31. Baixa auto-estima:

0 - ausente

1 - indica sentimentos de inutilidade (perda da auto-estima) apenas quando perguntado

2 - paciente indica espontaneamente sentimentos de inutilidade

3 - diferente de (2) acima por grau: paciente relata espontaneamente que é "ruim", "inferior"

4 - delírios de inutilidade 


\section{ANEXO E}

ESCALA DE AVALIAÇÃO PSIQUIÁTRICA BREVE (Brief Psychiatric Rating Scale BPRS)

01. Preocupações Somáticas

0. Atenção normal com a saúde física.

1. Grau mínimo ou duvidoso de preocupação excessiva com a saúde física.

2. O paciente expressa idéias de ter uma doença orgânica (p.ex. câncer ou doença cardíaca), mas sem interpretações delirantes.

3. As queixas são bizarras (p.ex. de estar apodrecendo por dentro), mas pode-se conseguir que o paciente, por breves períodos, admita que este não é o seu caso.

4. Está convencido, p.ex., de que seus órgãos estão podres ou desaparecendo, ou de que vermes estão devorando seu cérebro. Nem por breves períodos se pode fazê-lo admitir que este não é o seu caso.

\section{Ansiedade Psíquica}

0. O paciente não se encontra nem mais nem menos inseguro ou irritável do que o habitual.

1. É duvidoso se o paciente está mais inseguro ou irritável do que o habitual.

2. O paciente expressa mais claramente estar em um estado de ansiedade, apreensão ou irritabilidade que pode achar difícil de controlar. Isso ocorre sem influir no dia-a-dia do paciente, porque a preocupação ainda diz respeito a questões pouco importantes.

3. A ansiedade ou insegurança é, às vezes, mais difícil de controlar porque a preocupação diz respeito a perdas ou danos importantes, que podem ocorrer no futuro. P.ex., a ansiedade pode ser vivenciada como pânico, ou seja, como pavor subjugante. Ocasionalmente esta ansiedade já interferiu no dia-a-dia do paciente.

4. A sensação de pavor está tão freqüentemente presente que interfere acentuadamente no diaa-dia do paciente. 
03. Retraimento Emocional

0. Contato emocional normal.

1. Alguma (ou duvidosa) distância emocional

2. Reações emocionais reduzidas, como por exemplo, contato visual duvidoso.

3. Reações emocionais mais limitadas, como por exemplo, contato visual ocasionalmente inadequado.

4. Quando o contato emocional está fortemente reduzido ou quase ausente, como por exemplo, quando evita o contato visual.

\section{Desorganização Conceitual}

0 . Ausência de desorganização conceitual

1. pensamento é caracterizado por uma certa imprecisão, mas a fala não é gramaticalmente não usual.

2. Distúrbio moderado do pensamento. As palavras podem estar ligadas através de uma forma gramaticalmente não usual e particular ("pars pro toto") e a informação que comunica parece "vazia".

3. Acentuada desorganização conceitual. Ocasionalmente torna-se difícil entender o paciente, podendo surgir neologismos ou bloqueio

4. Desorganização conceitual extremamente grave. Apenas fragmentos da fala são compreensíveis.

05. Auto-depreciação e sentimentos de culpa

0. Ausência de auto-depreciação e sentimentos de culpa.

1. É duvidoso se sentimentos de culpa estão presentes, pois o paciente está apenas preocupado com o fato de que ele, durante a doença atual, seja um peso para a família ou colegas, devido à sua reduzida capacidade de trabalho.

2. Auto-depreciação ou sentimentos de culpa estão mais claramente presentes, pois o paciente está preocupado com incidentes do passado, anteriores ao episódio atual. Por exemplo, o paciente acusa-se de pequenas omissões ou falhas, de não ter cumprido com o seu dever ou de haver prejudicado outras pessoas. 
3. O paciente experimenta sentimentos de culpa mais graves. Ele pode afirmar que sente que o seu sofrimento atual é algum tipo de punição. Assinale 3 desde que o paciente possa perceber intelectualmente que sua opinião é infundada.

4. Os sentimentos de culpa são firmemente mantidos e resistem a qualquer argumentação, de modo que se converteram em idéias paranóides.

06. Ansiedade Somática.

0. Quando o paciente não está nem mais nem menos propenso que o habitual a experimentar concomitantes somáticos de estados de ansiedade.

1. Quando o paciente ocasionalmente apresenta leves manifestações, como sintomas abdominais, sudorese ou tremores. Entretanto, a descrição desses sintomas é vaga e questionável.

2. Quando o paciente ocasionalmente apresenta sintomas abdominais, sudorese, tremores, etc. Os sinais e sintomas são claramente descritos, porém não são acentuados e nem incapacitantes.

3. Os concomitantes emocionais dos estados subjetivos de ansiedade são acentuados e, às vezes, muito preocupantes.

4. Os concomitantes fisiológicos dos estados subjetivos de ansiedade são numerosos, persistentes e freqüentemente incapacitantes.

07. Distúrbios Motores Específicos

0 . Ausente.

1. Leve ou de presença duvidosa durante a entrevista.

2. Moderada. Presente durante a maior parte da entrevista.

3. Severa. Anormalidades motoras contínuas. Podem ser interrompidas.

4. Extremamente severa. Anormalidades motoras persistentes e incontroláveis. Entrevista difícil. 
08. Auto-estima exagerada

0. Auto-estima normal.

1. Auto-estima aumentada levemente ou de maneira duvidosa, como por exemplo: ocasionalmente superestima suas próprias capacidades habituais.

2. Auto-estima moderadamente aumentada. Por exemplo, superestima mais constantemente suas próprias capacidades habituais ou insinua possuir capacidades incomuns.

3. Idéias acentuadamente irreais, como por exemplo, de que tem habilidades, poderes ou conhecimentos (científicos, religiosos, etc.) extraordinários, mas pode, por breves períodos ser corrigido.

4. Idéias de grandeza que não podem ser corrigidas.

09. Humor Deprimido

0 . Humor neutro.

1. O paciente indica vagamente que está mais desanimado e deprimido que o habitual.

2. Quando o paciente está mais claramente preocupado com vivências desagradáveis, embora ainda não esteja se sentindo desamparado ou desesperançado.

3. O paciente exibe sinais não verbais claros de depressão e/ou às vezes sente-se dominado pelo desamparo ou desesperança.

4. As observações do paciente sobre desânimo e desamparo, ou as suas manifestações não verbais, dominam a entrevista, não sendo possível afastá-lo desta temática.

10. Hostilidade

0. Ausência de sinais de impaciência, irritabilidade, crítica ou hostilidade.

1. Esteve um pouco impaciente ou irritável, mas o controle foi mantido.

2. Esteve moderadamente impaciente ou irritável, mas tolerou as provocações.

3. Esteve verbalmente hostil, faz ameaças e quase chegou a ser fisicamente destrutivo, mas ainda pôde ser acalmado.

4. Extremamente hostil, com violência física manifesta. Fisicamente destrutivo. 
11. Desconfiança

0 . Ausente.

1. Vagas idéias de referência. Tende a suspeitar que as outras pessoas estão falando ou rindo de si. Sente que "alguma coisa está ocorrendo". Responde ao reasseguramento; portanto, fica duvidoso se existem idéias de referência ou delírios.

2. Idéias de referência com delírios vagos, não sistematizados, de perseguição. "Alguém pode ter más intenções". Isto é insinuado pela televisão ou pelos jornais. Ainda se trata de uma vivência do tipo "como se".

3. Delírios com alguma sistematização. Reasseguramento difícil.

4. Delírios paranóides sistematizados, floridos, de perseguição. Correção impossível.

\section{Alucinações}

0 . Ausente.

1. Em grau leve ou de presença duvidosa. Vivências alucinatórias hipnagógicas ou vivências alucinatórias elementares isoladas (ouvir sons, ver luzes).

2. Alucinações ocasionais, mas plenamente desenvolvidas (ouvir vozes, ver formas), que não afetam o comportamento.

3. Alucinações ocasionais que influenciam o comportamento.

4. Mais ou menos constantemente absorto em vivências alucinatórias.

\section{Retardo Psicomotor}

0 . Atividade verbal normal, atividade motora normal, com expressão facial adequada.

1. Velocidade de conversação duvidosa ou levemente reduzida e expressão facial duvidosa ou levemente diminuída.

2. Velocidade de conversação claramente reduzida, com pausas; gestos reduzidos e movimentação lenta.

3. A entrevista é claramente prolongada devido às longas latências e respostas curtas; todos os movimentos estão muito lentos.

4. A entrevista não pode ser completada; o retardo se aproxima de (e inclui) estupor. 
14. Falta de cooperação

0 . Atitude cooperativa natural.

1. Excessivamente formal e reservado na situação de entrevista. Responde um pouco resumidamente.

2. Resistência moderada. Responde evasivamente ou opõe-se a determinadas perguntas. Atitude acentuadamente hostil para com o entrevistador.

3. Resistência pronunciada. Responde inapropriadamente ou recusa-se a responder. Atitude abertamente hostil. Entrevista completa não é possível.

4. Entrevista impossível. O paciente recusa-se a permanecer na situação de entrevista.

15. Conteúdo do pensamento incomum.

0. Ausente.

1. Grau leve ou presença duvidosa (p.ex., idéias supervalorizadas).

2. Grau moderado (por exemplo, idéias com alguma qualidade delirante, mas ainda se constituindo em uma vivência do tipo "como se").

3. Os delírios delimitam a maior parte do conteúdo do pensamento e ocasionalmente influenciam o comportamento.

4. Delírios subjugantes delimitam o conteúdo do pensamento e o comportamento.

16. Afeto embotado ou inapropriado

0 . Reações e envolvimento emocionais apropriados.

1. Reações emocionais escassas ou questionavelmente inapropriadas. Por exemplo, menor desejo ou capacidade de estar em companhia de pessoas que conhece há mais ou menos tempo.

2. Afeto perceptivelmente embotado. Não apresenta necessidade ou capacidade de estabelecer contato mais íntimo com pessoas não pertencentes ao seu círculo familiar (companheiros de trabalho, outros pacientes, equipe terapêutica).

3. Emocionalmente indiferente e apático, mesmo em relação aos amigos íntimos e à família.

4. Emocionalmente ausente, ou então os afetos manifestados são grosseiramente inapropriados, sem qualquer motivação para o contato humano. 


\section{Agitação psicomotora}

0. Atividade motora normal. Expressão facial adequada e atividade verbal normal.

1. Atividade motora duvidosa ou levemente aumentada; por exemplo, expressão facial vívida ou certa loquacidade.

2. Atividade motora moderadamente aumentada; por exemplo, gestos vívidos ou grande loquacidade ou fala em voz alta e rapidamente.

3. Atividade motora claramente excessiva, movimentando-se durante a maior parte do tempo. Levanta-se uma ou várias vezes durante a entrevista. Fuga de idéias. Dificuldade para compreendê-lo.

4. Constante e incansavelmente ativo. Fala desintegrada. Comunicação significativa impossível.

18. Desorientação e confusão

0. O paciente está completamente orientado no tempo, no espaço, e quanto aos dados pessoais.

1. O paciente ocasionalmente tem algumas dificuldades, mas pode corrigir espontaneamente sua afirmação sobre a orientação no tempo, e/ou no espaço, e/ou quanto aos dados pessoais.

2. O paciente apresenta falhas que não são corrigidas espontaneamente. Por exemplo, não sabe o dia da semana ou do mês, embora saiba o mês e o ano corretamente, e/ou tem dificuldades espaciais, embora esteja orientado na enfermaria (ou em sua casa), e/ou tem dificuldades para recordar nomes, embora ainda saiba seu próprio nome.

3. O paciente está acentuadamente desorientado. Por exemplo, não sabe o mês e o ano corretamente, embora ainda se localize quanto a períodos significativos do ano (carnaval, festas juninas, natal)*, e/ou tem dificuldades para localizar o banheiro ou a sua cama sem auxílio, e/ou lembra seu próprio nome apenas através de alguma ajuda.

4. Está completamente desorientado no tempo e/ou no espaço, e/ou quanto aos dados pessoais.

* Adaptação à realidade brasileira. No original, "estações do ano". 


\section{ANEXO F}

CRITÉRIO DE CLASSIFICAÇÃO ECONÔMICA DO BRASIL - ABEP (Associação

Brasileira de Empresas de Pesquisa - 2008)

Nome:

Data:

Posse de itens

\begin{tabular}{|l|l|l|l|l|l|}
\hline \multirow{2}{*}{} & \multicolumn{6}{|l}{ Quantidade de itens } \\
\cline { 2 - 7 } & 0 & 1 & 2 & 3 & $4 \mathrm{ou}+$ \\
\hline Televisão & 0 & 1 & 2 & 3 & 4 \\
\hline Rádio & 0 & 1 & 2 & 3 & 4 \\
\hline Banheiro & 0 & 4 & 5 & 6 & 7 \\
\hline Automóvel & 0 & 4 & 7 & 9 & 9 \\
\hline Empregada mensalista & 0 & 3 & 4 & 4 & 4 \\
\hline Máquina de lavar & 0 & 2 & 2 & 2 & 2 \\
\hline Videocassete e ou DVD & 0 & 2 & 2 & 2 & 2 \\
\hline Geladeira & 0 & 4 & 4 & 4 & 4 \\
\hline $\begin{array}{l}\text { Freezer (aparelho independente } \\
\text { ou parte de geladeira duplex) }\end{array}$ & 0 & 2 & 2 & 2 & 2 \\
\hline
\end{tabular}

Grau de instrução do chefe da família

\begin{tabular}{|l|l|l|}
\hline Analfabeto / primário incompleto & $\begin{array}{l}\text { Analfabeto / até } \\
\text { Fundamental }\end{array}$ & 0 \\
\hline Primário completo / ginasial incompleto & Até 4 . Série Fundamental & 1 \\
\hline Ginasial completo / colegial incompleto & Fundamental completo & 2 \\
\hline Colegial completo/ superior incompleto & Médio completo & 4 \\
\hline Superior completo & Superior completo & 8 \\
\hline
\end{tabular}

Soma de pontos:

Classe:

Cortes do critério Brasil:

\begin{tabular}{|l|l|}
\hline Classe & Pontos \\
\hline A1 & $42-46$ \\
\hline A2 & $35-41$ \\
\hline B1 & $29-34$ \\
\hline B2 & $23-28$ \\
\hline C1 & $18-22$ \\
\hline C2 & $14-17$ \\
\hline D & $8-13$ \\
\hline E & $0-7$ \\
\hline
\end{tabular}

